\title{
SECLUSION MANAGEMENT \\ IN AN ACUTE IN-PATIENT UNIT
}

by

Barbara Joy Mosley

\author{
A thesis submitted to the Victoria University of Wellington \\ in partial fulfilment of the \\ requirements for the degree of \\ Master of Nursing (Clinical)
}

Victoria University of Wellington

2005 


\section{Abstract}

Trends in modern day mental health facilities have been towards the least restrictive environment with emphasis on patients' rights, but these rights have to be balanced against the safety of both the patients themselves and anyone else in the immediate environment. One way of restricting a person's movement is through the use of seclusion, a means of isolating a person in a locked room with minimal stimulus and from where that person cannot freely exit.

This study was developed to explore the use of seclusion in an acute in-patient unit for people with mental illnesses. Investigation into this issue was considered important due to an identified large increase in seclusion use over the previous two years.

The study used a qualitative research methodology with a descriptive and interpretive approach. Data collection included a retrospective file audit of patients who had been secluded over the past seven years, and one-to-one staff interviews. I also included some personal reflections of seclusion events.

The principle reason for using seclusion was violence and aggression in the context of mental illness. It was also used for people who were at risk of, or who had previously absconded from the unit. A recovery approach and the use of the strengths model was fundamental to nurses' way of working with patients in the unit. Nurses believed that the strengths process should be adapted to the person's level of acuity and to their ability to engage in this approach in a real and tangible way.

Seclusion continues to be a clinical management option in the unit that is the subject of this study. It is used when a person is so unwell that they cannot be managed in any other identified way. However, in many circumstances there are other options that could be explored so that the utmost consideration is given to the dignity, privacy and safety of that person. 


\section{ACKNOWLEDGEMENTS}

Chris Walsh was an outstanding guide in her role as supervisor, and she was ably assisted by Thelma Puckey. They have both provided much support and critical comment over the past months. My sincere and grateful thanks to them for their encouragement and assistance throughout this study and during the preparation of this report. I have benefited greatly from their presence and contributions. Chris and Thelma - thank you.

To my colleagues from the mental health service in which this study was carried out, and in particular to those who participated freely in the interviews, my thanks and warmest appreciation for your support and for your interest in this study. Thank you too for the discussions we have had, your valuable comments, and your patience when I had files stacked and piled on desks and on the floor. My sincere appreciation to the manager and clinical leaders of the mental health service who provided the support and assistance that enabled me to carry out and complete this study.

This study is, first and foremost, about those people who are users of mental health services. My admiration and respect goes to them for their endurance and determination in their work towards recovery. Although they will remain unknown and unrecognised to those who read this research, I carry with me the memories of their courage and tenacity as they fought to regain their strength. I especially remember those people who found the fight too much and sought another way to find their peace.

Pam has supported, encouraged and remained alongside me throughout the length of this study. She has made the journey a much smoother one by taking responsibility for organising and maintaining all the daily activities that are essential to live well, provided endless cups of coffee while I spent hours at the computer, has listened to my complaints and cajoled me into carrying on when enthusiasm began to wane. Pam, with my loving thanks - you have a special place in my heart. 


\section{CONTENTS}

$\begin{array}{lr}\text { CHAPTER 1: INTRODUCTION } & 1\end{array}$

$\begin{array}{ll}\text { Background } & 1\end{array}$

The Unit 3

Recovery 4

Strengths Model 5

$\begin{array}{lr}\text { Seclusion } & 6\end{array}$

Quality Project $\quad 8$

$\begin{array}{ll}\text { The Study } & 10\end{array}$

$\begin{array}{ll}\text { Aims of the Study } & 10\end{array}$

Literature Review $\quad 11$

$\begin{array}{ll}\text { Methodological Matters } & 12\end{array}$

Data Collection 12

Rigour 13

$\begin{array}{ll}\text { The Research Process } & 14\end{array}$

Ethical Issues $\quad 14$

$\begin{array}{ll}\text { Methods of Analysis } & 14\end{array}$

Key Findings $\quad 15$

$\begin{array}{ll}\text { Significance of the Study } & 16\end{array}$

CHAPTER 2: LITERATURE REVIEW 18

$\begin{array}{ll}\text { Introduction } & 18\end{array}$

$\begin{array}{ll}\text { Seclusion Defined } & 19\end{array}$

$\begin{array}{ll}\text { A Brief History } & 20\end{array}$

Reasons for Using Seclusion $\quad 22$

$\begin{array}{lr}\text { Nurse Perspectives } & 24\end{array}$

$\begin{array}{ll}\text { Predictors for Seclusion } & 26\end{array}$

$\begin{array}{ll}\text { Staffing Issues } & 27\end{array}$

The New Zealand Scene $\quad 29$

$\begin{array}{ll}\text { Conclusion } & 31\end{array}$ 
Introduction 33

Nurses and Research 33

The Qualitative Method 34

A Descriptive Approach 35

An Interpretive Approach 36

Pragmatism and Evaluation Research 36

$\begin{array}{ll}\text { Data Collection } & 37\end{array}$

$\begin{array}{ll}\text { Interviews } & 37\end{array}$

Audit 38

Reflection $\quad 39$

$\begin{array}{ll}\text { Rigour } & 40\end{array}$

$\begin{array}{ll}\text { Conclusion } & 42\end{array}$

CHAPTER 4: THE RESEARCH PROCESS 44

Introduction $\quad 44$

Ethical Considerations $\quad 44$

File Audit $\quad 45$

Staff Interviews 45

Confidentiality of Files $\quad 46$

Treaty of Waitangi 46

Consumer Participation $\quad 47$

The File Audit $\quad 47$

Patient Information 48

$\begin{array}{ll}\text { Patient Files } & 49\end{array}$

Data Analysis $\quad 51$

Staff Interviews

Data Analysis 53

Personal Journal 54

Process Reflections $\quad 56$

$\begin{array}{ll}\text { Conclusion } & 57\end{array}$ 
CHAPTER 5: RESULTS - FILE AUDIT

Introduction $\quad 58$

File Exclusions $\quad 58$

Overview of Seclusion Use $\quad 59$

Person Analysis $\quad 62$

Demographic Data 66

Gender $\quad 66$

Age $\quad 66$

$\begin{array}{ll}\text { Ethnicity } & 67\end{array}$

$\begin{array}{ll}\text { Clinical Information } & 68\end{array}$

Diagnoses $\quad 68$

Emergency Medication $\quad 69$

The Mental Health (CAT) Act 1992

$\begin{array}{ll}\text { Admissions and Seclusion } & 72\end{array}$

$\begin{array}{ll}\text { Seclusion Event Analysis } & 73\end{array}$

Day of the Week 73

Time of Day $\quad 74$

$\begin{array}{ll}\text { Conclusion } & 75\end{array}$

CHAPTER 6: RESULTS - RATIONALE FOR SECLUSION 76

$\begin{array}{ll}\text { Introduction } & 76\end{array}$

$\begin{array}{ll}\text { Reasons for Seclusion } & 77\end{array}$

1: Violence and the Threat of Violence (Aggression) 78

2: Agitation, Frustration and Coping Skills (Anxiety) 79

3: Cognitive Processes and Functioning (Cognition) 80

4: Mood and Affective Functioning (Mood) 82

5: Comprehension, Understanding and Feelings 83

(Perceptions) 83

6: Compliance and Conformity 84

7: External Variables $\quad 85$

Conclusion $\quad 86$ 
$\begin{array}{ll}\text { CHAPTER 7: THE INTERVIEWS } & 87\end{array}$

$\begin{array}{ll}\text { Introduction } & 87\end{array}$

$\begin{array}{lc}\text { The Seclusion Process } & 88\end{array}$

A Seclusion Event $\quad 88$

Indicators for Seclusion Use $\quad 89$

Decision Points in the Seclusion Process $\quad 90$

The Seclusion Decision $\quad 91$

Admission into Seclusion $\quad 92$

Inappropriate use $\quad 92$

$\begin{array}{ll}\text { De-escalation } & 93\end{array}$

$\begin{array}{ll}\text { Specialling } & 94\end{array}$

Nursing Issues $\quad 95$

Staff Experience $\quad 96$

$\begin{array}{ll}\text { Practice Decisions } & 99\end{array}$

$\begin{array}{ll}\text { Debriefing } & 100\end{array}$

$\begin{array}{ll}\text { Documentation } & 101\end{array}$

The Unit Environment 102

An Open Unit 102

The Acute Area 104

$\begin{array}{ll}\text { Privacy } & 105\end{array}$

$\begin{array}{ll}\text { A Recovery Approach } & 107\end{array}$

$\begin{array}{ll}\text { Conclusion } & 110\end{array}$

CHAPTER 8: DISCUSSION 112

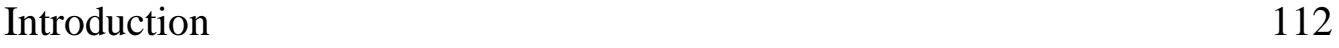

Profile of Seclusion 112

The People 114

Predictors for Seclusion 115

The Mental Health (CAT) Act 1992

Admissions into Seclusion 117

Timing of Events 117

$\begin{array}{ll}\text { Reasons for Seclusion } & 119\end{array}$

Absconding and Self Harm 119

The Open Unit 120

$\begin{array}{ll}\text { Nursing Issues } & 121\end{array}$ 
Preferred Interventions

A Suitable Acute Environment

Recovery

Significance of this Study

Limitations of this Study

CHAPTER 9: CONCLUSIONS

CHAPTER 10: RECOMMENDATIONS

Education and Training

Management of Seclusion Events

Seclusion Monitoring

Seclusion Facilities

Minimisation of Seclusion

Future Research

A Service Provision Framework Documents

B Quality Project: Continuous Reduction in the Use of Seclusion

C Quality Project: Continuous Reduction in the Use of Seclusion (stage two)

D Ethics Committee Letter of Approval

E Information Sheet

F $\quad$ Consent Form

G Letter of Support: Maori Adviser

$\mathrm{H} \quad$ Letter of Support: Consumer Adviser

I Audit Form

J Seclusion Recording Form

K Seclusion Observation Forms

L Themes for Seclusion Use (Johnson, 1997)

M Request for Volunteers: Notice

$\mathrm{N} \quad$ Interview Format

O Demographic and Clinical Data Tables 


\section{TABLES}

$1 \quad$ Seclusion Events Per Year $\quad 59$

2 Audit Data Compared with Survey Data 60

3 Inaccurate versus Accurate Time Reporting 61

4 Events Not Recorded in the Seclusion Register 61

$5 \quad$ Number of Years Each Person Involved in Seclusion Events 62

$6 \quad$ Number of Seclusion Events per Person per Year 63

$7 \quad$ Seclusion Use per Person per Year 64

8 Time Spent in Seclusion in Minutes 65

9 Seclusion Event Occurring at Admission $\quad 72$

10 Reasons for Seclusion 78

\section{FIGURES}

$1 \quad$ Seclusion use 1997-2003: Original data (minutes) 9

2 Comparison survey and audit data (in minutes) 60

$3 \quad$ Number of persons secluded per year 63

4 Average time spent in seclusion each year 65

$5 \quad$ Gender distribution per year 66

$6 \quad$ Age distribution for total seclusion events 67

$\begin{array}{lll}7 & \text { Ethnicity distribution each year } & 68\end{array}$

8 Diagnosis at discharge $\quad 69$

$9 \quad$ Emergency medication administered $\quad 70$

10 Mental Health (CAT) Act 1992 status at time of seclusion 71

11 Seclusion events by day of the week 73

12 Time of day for seclusion events 74 


\section{CHAPTER 1: INTRODUCTION}

Seclusion continues to be widely used in mental health in-patient units throughout New Zealand. It is a means of isolating a person from the open environment of a unit by containing them in a locked room from which they cannot freely exit.

The use of seclusion in mental health in-patient units raises issues of patient rights and patient safety. Its use has increasingly become the subject of debate in recent years. Human rights issues and ethical questions about patients' rights to least restrictive treatment and the least possible use of coercion and restraint, are now required to be balanced against the safety needs and therapeutic considerations of both the individual and others in the immediate environment (Lakeman, 2000; MuirCochrane \& Holmes, 2001; O’Hagan, 2003; Standards New Zealand, 2001).

With the emergence of the patients' code of rights, privacy legislation, consumers' rights groups, and mental health legislation contained in the Mental Health (Compulsory Assessment and Treatment) Act 1992 MHA), emphasis was placed on a person's right to treatment and interventions within the least restrictive environment. Mental health services began, therefore, coming under increasing pressure to review seclusion practices and decisions with the aim of reducing seclusion use.

\section{BACKGROUND}

I first became interested in seclusion issues in 1999 when, as a nursing student, I encountered its use in my first mental health placement in an acute in-patient unit. At that time I reflected on power and control issues and how failing to de-escalate unacceptable behaviour in its early stages could lead to patients becoming more and more volatile resulting inevitably in a seclusion event. At this time I wrote the 


\title{
following exemplar about this issue relating it to the New Zealand Nurses Organisation Standards for nursing practice (1993):
}

\begin{abstract}
As I write this exemplar I have been on the ward for seven days. Over this time I have seen four instances where a person has been taken into seclusion following a violent outburst. What strikes me most about this is that in each of these cases the scenario has been the same. The person involved each time began shouting and using bad language towards staff after restrictions had been placed on him or her (on two occasions staff had refused to give the person a cigarette that they had in safekeeping). The patient would be told to stop using this language and directed either to her room or a quiet place to calm down. When the abusive language and swearing continued the patient would then be restrained, taken to the ICU area and either left in the open area there or placed in seclusion.
\end{abstract}

Today I was sitting in the office behind the nurses' station with several nursing and medical staff. A patient, Fiona*, walked to the door of the office and said that she wanted to go out on leave. She was told that this was to be discussed with the doctor tomorrow and that nothing would be done until then. At this, Fiona became quite angry and demanded to go out. She was told that if she didn't calm down then it wouldn't be considered tomorrow either, a statement that I felt was very confrontational. At this Fiona became very abusive and began swearing. She continued this behaviour and began backing out of the office as several nurses began to walk towards her. She was directed to the ICU lounge so she could calm down, she refused, continued loudly abusing everyone present (including another patient) and so was restrained and taken into seclusion. Once in there, Fiona wailed, screamed and cried continuously for 45 minutes before calming down and sitting, unmoving.

I don't pretend that I'm going to come up with any answers here. Perhaps all I can do is put my thoughts down on paper and apply them as best I can to the NZNO Standards of Practice (1993) and Code of Ethics (1995). From what I have read, the use of seclusion is a continuing dilemma in mental health services. As Craig, Ray \& Hix (1989) said "The right to least restrictive treatment must be balanced against safety needs and considerations for the individual and the unit milieu; achieving this balance is a complex undertaking" (p.16).

I think this exemplar is a specific example (and the most extreme of the ones I have observed) of a situation that occurs regularly on this ward. The fact that I have seen so many incidents of people placed in seclusion for the same behaviour raises the question of why isn't something done to intervene at an earlier stage. I think the handling of verbal aggression is not managed well.

I have observed two things during these incidents which I am sure must increase the volitility of the situation. The first is the level of confrontation by staff. When faced with a verbally abusive patient they demand that person stop swearing which, in each case, causes the problem to escalate. My second concern is that when a patient then becomes verbally out of control, a group of three or four staff advances on him or her, a situation which must be exceedingly frightening for the person on the receiving end. The patient's behaviour then, of course, continues.

This confrontational behaviour on the part of the staff is at odds with literature I have read on this subject. Turnbull, Aitken, Black and Patterson (1990) discuss de-escalation responses which I consider make good sense. They suggest such things as removing the patient to another area, encouraging the patient to think through what is going on for them by asking appropriate questions, suggesting options, allowing greater body space and approaching the person from an angle rather than front on. Above all, they recommend being flexible and applying various de-escalation skills, according to the cues from the patient.

If a patient displays signs of aggression, I believe it is important to start working with them as early as possible to defuse a situation before it gets out of hand. Fiona had been showing signs of anger and frustration from 7.30 in the morning until the incident which occurred after lunch. I did not see staff interacting with her in any meaningful way during all of that morning.

Standard Two of the NZNO Standards for Nursing Practice (1993) states that: "Within their scope of practice, nurses are responsible for the safety and well-being of their client group”. Outcomes include 
"Nursing practice is appropriate and acceptable to identified client needs", and "Nursing practice enhances the spiritual and emotional well-being of clients". I think nursing practice as described in the above exemplar falls short of this standard. Allowing the situation to escalate for a whole morning without attempting to intervene does not seem to be appropriate. I also feel that the style of dealing with verbal aggression does not enhance the well-being of patients.

I believe that the use of seclusion does have a place within the psychiatric setting in extreme cases where there is a real threat of violence to patients and/or staff. What I have witnessed in the last few days almost seems like a routine and I don't think it can be justified within the standards of nursing in the least restrictive setting.

Barbara Mosley

June 1999

* Not her real name

These events had such a marked impact on me that I wished to continue investigating this topic. I therefore applied for and was granted a summer student scholarship to conduct a literature search and write a literature review (Mosley, 2000). I updated this review and explored current issues related to seclusion use in 2002 in partial fulfilment of the requirements of a post-graduate paper in mental health (Mosley, 2002a). My continued interest in the management of seclusion and issues related to its use led me to undertake this study in the mental health in-patient unit in which I was working as a registered nurse.

\section{THE UNIT}

The unit in which this study was carried out was a 15 bed acute and sub-acute unit that catered for a wide range of mental disability and illness of varying degrees of severity. The catchment population was approximately 60,000 and came from both urban and rural areas.

The unit was staffed by a complement of 14 registered nurses and four enrolled nurses (two each of whom worked permanent night duty). Morning and afternoon duties were staffed by 3-4 nurses each and there were two nurses rostered for each night duty. There was also a part-time social worker and a full time occupational therapist. The clinical leader had overall responsibility for the unit. When this person 
was not working, responsibility rested with the lead nurse of the duty. The lead nurse role was allocated on a rotational basis among all registered nursing staff. There was one full-time psychiatrist whose duties were divided 50/50 between the unit and the community team. Another psychiatrist travelled from the closest city for two days a week. Out of town psychiatrists also acted in an on-call capacity for those weekends and holidays when the full-time psychiatrist was not on duty.

The in-patient unit was based on the same site as the community mental health team, the triage, assessment and crisis treatment team (TACT), the Maori mental health team, and the alcohol and other drugs service. The Maori mental health team was available for advice and assistance with patients in the unit who identified as Maori. A consumer adviser was also available on site to provide advice and assistance to any patients who requested this service.

The unit had adopted a recovery approach to treatment. Recovery had become the accepted focus of mental health services since the implementation of the New Zealand Government's national mental health strategy (Ministry of Health, 1997). The unit had adopted the strengths model (Rapp, 1998) as its mode of working with patients within this recovery approach.

\section{RECOVERY}

Recovery is supported and upheld as the most appropriate means of working with people in mental health services in New Zealand by the Mental Health Commission. The Mental Health Commission was established in New Zealand as a ministerial committee under Section 46 of the Health and Disability Services Act, 1993 and began work in September 1996. Its main roles were to monitor and report on the performance of key agencies, to promote recovery approaches, and to ensure that meeting the needs of service users and families was a priority in mental health services (Mental Health Commission, 2004a). Recovery as an important concept in both understanding and treating people with mental illness was viewed as a process rather than an end in itself: 
Recovery does not always mean that people will return to full health or retrieve all their losses, but it does mean that people can live well in spite of them (Mental Health Commission, 1998, p.1)

The spotlight on recovery has occurred within the context of a treatment focus based on community care. Present models of care now see the community as being the most appropriate place for people with mental illness. Recovery includes enhancing mental wellbeing by improving the social, economic, cultural, political and physical environments in which we all live (Ministry of Health, 2001). The recovery policy of the Ministry of Health advocates putting energy and resources into keeping people well and creating environments for them to reach their potential.

\section{STRENGTHS MODEL}

The emphasis on a national recovery oriented, community based system rather than the use of a deficits model has been the precursor to the use of a strengths model approach. The strengths model was first developed by Charles Rapp in the early 1980s and was promoted as a positive method of working with people with mental health problems in the community. The focus of the model was to identify and enrich a person's strengths and to secure the resources needed for that person to integrate into the community with the express purpose of improving the quality of his or her life. The objective was to identify the capacities and strengths of individuals and their community by using a strengths assessment, then working with these people to set goals and plan how to achieve them (Rapp, 1998). At the time of its introduction to the in-patient setting in October 2001 it was believed (following a literature search and discussion with its proponents) that the strengths model had not previously been used in a similar setting anywhere else in the world.

\section{SECLUSION}

Seclusion is used as a patient management option when a person is unable to remain within the open unit environment due to actual or potential harm to themselves or to 
others. Seclusion is the use of a room where a person is isolated from the general milieu and cannot freely exit. Its use is designed to ensure a safe environment for both the person who is being contained and others in the immediate area. This option should only ever be used when all other possible means of de-escalation or defusing a situation have been exhausted. De-escalation has been defined as:

A complex interactive process in which (a person) is redirected from an unsafe course of action towards a supported and calmer emotional state ... through timely, appropriate and effective interventions (Standards New Zealand, 2001, p. 42)

De-escalation techniques should be an integrated part of the treatment plan and should include such interventions as boundary or limit setting, provision of a low stimulus environment, one to one nursing care, involvement of family/whanau or support persons and/or the use of 'as required' medications. In most instances seclusion should be the least desirable outcome and it should never be considered as a first option (Standards New Zealand, 2001).

The unit had two seclusion rooms which were situated in what is referred to as the 'acute wing'. This area also contained three bedrooms and a shower and toilet area. Access to this area was through the main entrance, and it could not be closed off from the rest of the unit.

Seclusion use is governed by the Mental Health (CAT) Act 1992:

\section{Section 71:}

“Right to company, and seclusion -

(1) Every patient is entitled to the company of others, except as provided in subsection (2) of this section.

(2) A patient may be placed in seclusion in accordance with the following provisions:

(a) Seclusion shall be used only where, and for as long as, it is necessary for the care or treatment of the patient, or the protection of other patients;

(b) A patient shall be placed in seclusion only in a room or other area that is designated for the purposes by or with the approval of the Director of Area Mental Health Services;

(c) Except as provided in paragraph (d) of this subsection, seclusion shall be used only with the authority of the responsible clinician;

(d) In an emergency, a nurse or other health professional having immediate responsibility for a patient may place the patient in seclusion, but shall forthwith bring the case to the attention of the responsible clinician;

(e) The duration and circumstances of each episode of seclusion shall be recorded in the register kept in accordance with section 129(1)(b) of this Act." 
In 2001 the Restraint Minimisation and Safe Practice standard was published (Standards New Zealand, 2001) and included the use of seclusion as a subset of restraint. Seclusion was defined in the Standard (p. 43) as “... the placing of a person at any time, and for any duration, alone in an area where he or she cannot freely exit”, under the conditions as specified in section 71 of the MHA. The Standard further stated that, "The use of ... seclusion within mental health services must be in accordance with this Standard", and detailed the clinical indicators and contraindications for the use of seclusion:

The following are situations where seclusion may be appropriate:

(a) The control of violent behaviour occurring during the course of a psychiatric illness which cannot be adequately controlled with psychosocial techniques and/or medication;

(b) Disturbance of behaviour as a result of marked agitation, thought disorder, severe confusion, hyperactivity or grossly impaired judgement;

(c) To reduce the disruptive effects of external stimuli in a person who is highly aroused due to their illness;

(d) To prevent violent or destructive behaviour, using specific indicators of impending disturbance which may be identified by either the individual or the staff, and which should wherever possible be part of an agreed management plan.

Seclusion should not be used in the following circumstances:

(a) Where the consumer has had escalating requirements for medication and there is:

(i) Evidence of serious recent side effects

(ii) Likelihood of serious side effects

(b) Physical deterioration;

(c) Where the consumer is in need of intensive assessment and/or observation, especially where there is a history suggestive of significant trauma, ingestion of unknown drugs/substances or organic diagnosis.

Seclusion should be used with extreme caution in the following circumstances:

(a) Presence of physical illness or injury requiring specific physical treatment;

(b) Presence of self-injurious behaviour;

(c) Likelihood of escalation of anxiety, aggression or distress or a previous adverse response;

(d) No demonstrable psychiatric diagnosis;

(e) Intoxication with alcohol, or possibility of other drug ingestion;

(f) Where the consumer is a child or young person. 
In addition, the mental health service in which this research took place had developed a policy and standards for the use of seclusion within the in-patient unit. These were documented in the local District Health Board's Service Provision Framework (2002) (see Appendix A). These were largely based on the provisions set out in the MHA and the Standards described above.

\section{QuAlity Project}

In 2003 a quality project Continuous reduction in the use of seclusion (District Health Board, 2003) (Appendix B) involving the Clinical Leader and in-patient staff of the mental health in-patient unit was developed. The aim was to measure the annual use of seclusion from 1997 as a baseline for improvement. Stage one of this project involved gathering information related to the number of seclusion events, the amount of time in seclusion per event, the number of individuals secluded, the number of times each individual was secluded and the amount of time in total each year. This information was gathered exclusively from the seclusion register which was a record of each seclusion event and was required to be kept under the provisions of section 129 of the MHA. I assisted in gathering this data then summarised the information and updated it to the end of 2003. Figure 1 shows the results of this survey: 


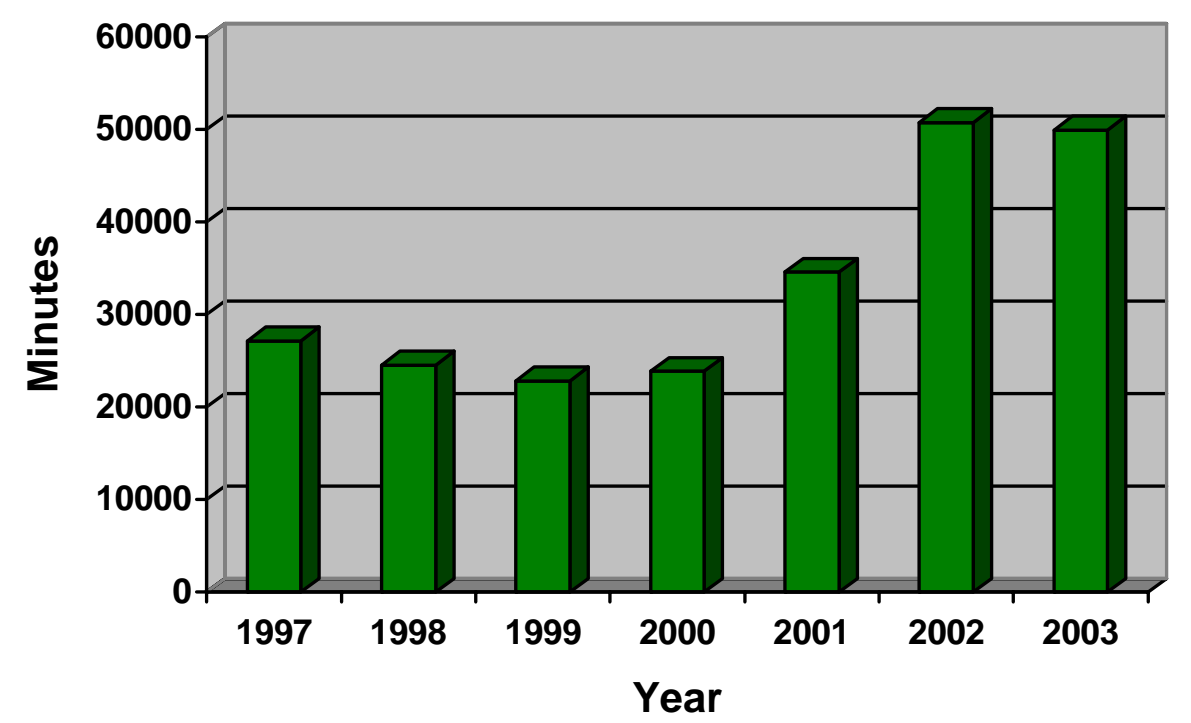

Figure 2: Seclusion use 1997-2003: Original data (minutes)

Of note there was an increase in seclusion events in the year 2001 compared with the previous three years followed by an even more dramatic rise in the amount of seclusion use in the years 2002-2003.

In June 2003 an accreditation assessment of the local District Health Board was carried out (Clark et al., 2003). At this time the accreditation team noted the occasional inappropriate use of seclusion. Specific instances referred to in the report included holding a person in seclusion for several hours as that person had continually attempted to leave the unit, and another seclusion event only ending once a person had agreed to staff requests not to leave the unit. The committee also commented that the unit was investigating ways of reducing seclusion use whilst ensuring that the safety of people in the unit (both patients and staff) was maintained.

In January 2004 I began developing stage two of the quality project (District Health Board, 2004a) (Appendix C). At this time, through a perusal of the seclusion register and through working with patient files, it became apparent that the original figures produced were not necessarily an accurate reflection of the amount of seclusion use over the period surveyed. Stage two of the quality project was closely aligned to this research study. 


\section{THE STUDY}

The decision to develop this study arose out of the identified increase in seclusion use in the in-patient unit during the years 2001-2003 and the need to work towards minimisation of seclusion use whilst ensuring that the safety of everyone in the environment was maintained. Only through identifying the reasons for the increase in seclusion use could an informed decision be made about the type of interventions needed to bring about a reduction in seclusion use. This study was designed, therefore, to investigate these reasons by focusing on the extent of seclusion use, the factors involved in making the decision to initiate seclusion and by investigating how this could be reconciled with the values of recovery and strengths that were being promoted in the unit.

\section{AIMs OF THE STUDY}

The aim of this study was to investigate seclusion by obtaining data that more accurately reflected the amount of seclusion use, by exploring the precipitants for seclusion, and by evaluating the processes nursing staff went through when they made the decision to use seclusion. It was proposed to conduct an audit of patient files, and to interview nursing staff involved in the use of seclusion in order to gather information related to personal, professional and environmental issues, and to examine the current policies and protocols in use.

From this broad aim, the following research question was formed:

- What is the extent of seclusion practice used as a management strategy for mental illness in one acute mental health in-patient unit, and what influences the decision to use seclusion, having regard to the requirements of current legislation, standards, policies and protocols, and the desire to work from a recovery and strengths based perspective?

Specific objectives of this study were: 
- $\quad$ To identify from recent literature factors recognised as being associated with the decision to initiate seclusion

- To establish the extent to which seclusion was used in the in-patient unit

- $\quad$ To identify the clinical basis for nurses making the decision to use seclusion

- To explore other practice issues that influenced nurses deciding to use seclusion

- To explore how nurses reconciled the use of seclusion with the recovery and strengths model approach which was practised in the in-patient unit.

\section{LITERATURE REVIEW}

The subject of this study was the use of seclusion in an acute in-patient mental health unit and Chapter Two discusses the literature on this topic. Seclusion, as a means of managing aggressive and disturbed behaviour in people with psychiatric disorders, has a long history and it is only in recent times that its practice has come under scrutiny.

Definitions of seclusion are provided with most describing the use of seclusion in terms of its elements of containment, isolation and sensory deprivation. Later definitions also considered the purpose of seclusion in terms of protection from harm and the opportunity for closer observation.

A historical overview of seclusion is then given followed by discussion on the reasons for using seclusion. This was most often for the control of disruptive and aggressive behaviour, when all other options had been tried and when less restrictive measures had failed or were inappropriate.

Some literature dealt with nurses' perspectives on the use of seclusion and how they felt about their involvement in its use. Generally, nurses deemed seclusion as a necessary adjunct to their work. However, it presented a dilemma for them between developing and sustaining therapeutic relationships with patients and having to act as enforcers of treatment and containment. 
Staffing issues discussed in this review included nurses' experience and attitudes, the ratio of staff on duty to patients, the patient mix and the timing of seclusion events.

In the final section of Chapter Two, the literature review describes the use of seclusion in New Zealand from published research and discussion. It was only in the four years prior to this study that seclusion literature began to appear in New Zealand. Investigations and reviews into seclusion practice have since increased, culminating in a recent publication of a review into seclusion practice by the Mental Health Commission (2004b).

\section{Methodological MatTers}

The philosophical framework and assumptions of a qualitative research perspective are discussed in Chapter Three. Firstly, the position of nurses in research is considered followed by discussion on the qualitative method with its descriptive and interpretive approaches which form the basis of this study. While description seeks to explain and understand the experience, interpretation is about perceptions and the implications people put on events. From this it was possible to identify patterns and relationships between concepts and create theoretical explanations.

There is another way of interpreting research and this is from a pragmatic and practice perspective. This often takes the form of generating useful and practical knowledge for action or evaluating programmes and events. It is this pragmatic approach I have taken in this research, using a qualitative methodology that is descriptive and interpretive.

\section{Data Collection}

There is a range of data collection methods that can be used for qualitative studies. Researchers choose one or a combination of methods. In this study I have chosen to combine three different approaches: one-to-one interviews, an audit of patient files 
and personal reflection. Using a combination of methods assists in overcoming the possibility of bias that can develop from using a single method (Patton, 2002).

The patient file audit investigated the use of seclusion over seven years. Audit is a process that is often used within the health sector to review care provided to patients. Written documents and records are a large part of present day society and can provide a rich source of information about systems and processes (National Advisory Committee on Health and Disability Support Services Ethics, 2003).

One-to-one interviews were carried out with six nursing staff who were familiar with seclusion processes in the unit. This type of data collection usually provides much more in depth information than can be obtained otherwise and can give a unique and individual view of events that is not accessible otherwise.

My own experience of seclusion events formed the third approach to this research. Using personal reflection can raise conflict between demonstrating a self-awareness and unique understanding of the events being studied and introducing subjectivity into the research process. However, this subjectivity can be similar to that injected by participants in an interview process who also place their own interpretations on events. According to Walkerdine, Lucey and Melody (2002), the addition of a researcher's reflections can provide a more complete picture of events.

\section{RIGOUR}

The applicability of the concepts of reliability and validity to qualitative research have been debated extensively and Emden and Sandelowski $(1998,1999)$ provided a detailed history of this debate. Both descriptive and interpretive validity were considered in this study and I aimed to present both an accurate description of the facts and a clear, concise and honest evaluation of the data. 


\section{The Research Process}

In Chapter Four, I have focused on the actual processes leading up to and including data collection, and the analysis of the data.

\section{ETHICAL ISSUES}

In obtaining approval from the local ethics committee to conduct this research, I considered several important matters around individual privacy and anonymity in accessing patient files. I ensured that information that could identify individuals was protected at all times and ensured that the anonymity of patients was preserved in all reported data.

Conducting interviews with colleagues raised questions of conflict between my role as a staff member and as a colleague. To overcome this, the study was designed to ensure that participation in the study was completely voluntary.

I considered Treaty of Waitangi issues and discussed this study with the local Maori Adviser of the Maori mental health team who gave their support.

I also discussed this study with the local Consumer Adviser who was fully supportive of the study going ahead.

\section{METHODS OF ANALYSIS}

Data from the file audit is presented in Chapter Five and was analysed to provide a demographic and clinical profile of people placed in seclusion over the seven year study period. Information about the documented reasons for seclusion was coded according to the method established by Johnson (1997) and the results of this analysis are presented in Chapter Six. 
Interviews were audio-taped and transcribed by myself. Transcripts were thematically coded into five main areas, four of which contained several sub-themes. The results from these interviews are contained in Chapter Seven. I have also incorporated several personal experiences into the interview analysis where my experiences were relevant to the material being discussed.

\section{KEY FindingS}

This study provided more accurate data of seclusion use through a file audit of patients who had been placed in seclusion during admission to the in-patient unit. However, the accuracy of the data was compromised due to missing information in the seclusion register which was the main source of referral to patient files. This meant that the final count could only be considered a conservative estimate of actual seclusion use.

The main predictors for seclusion were that people were younger and had diagnoses of schizophrenia, mania or substance abuse. There was no correlation between gender and seclusion use.

Many people went immediately to seclusion when they were admitted to the unit. In these instances in-patient staff performance or unit environmental reasons could not be claimed as a precipitant for seclusion use.

Day of the week and time of the day were two other predictors of seclusion use. Sunday was the busiest day for seclusion events, while events tended to occur more in late afternoons and evenings than at other times of the day.

Seclusion was generally a response to threatened or actual violence, aggression and/or threatening behaviour. Other factors noted in this study were people at risk of absconding and self harm. This raised issues about the operation of the unit as an unlocked or open environment. 
Nurses' roles in seclusion events often raised issues related to their desire to establish a therapeutic relationship and the need also for them to be enforcers of compulsory detainment. De-escalation skills played a large part in nurses' work, but concern was expressed that one-to-one nursing or specialling of at risk patients did not seem to play as large a part as it might.

Several environmental issues were raised, especially related to the layout of the unit and access to the acute area. Issues of privacy and dignity were important considerations for nurses, and the inadequacies of the present setup were apparent in their descriptions of the environment.

Recovery was formally recognised through the strengths model approach where selfresponsibility and active participation in a person's own recovery was encouraged. However, nurses did not believe it to be in a person's best interests for a full strengths model approach to be used when they were acutely unwell. While the principles of recovery should be used and role-modelled by nurses during the acute phase of a person's illness, full use of the strengths model could have a negative effect (Mosley, 2002b). Nurses considered that it should only be used once the active symptoms of a person's mental disorder were abating, and when they were more able to readily and actively participate in the process of strengths assessment and goal setting.

\section{SIGNIFICANCE OF THE STUDY}

Seclusion can have long lasting and detrimental effects on some patients. If its use can be restricted to those situations deemed most urgent and as a last resort after consideration of all other alternative interventions, then this should have a positive effect on the health care of patients in acute in-patient areas.

The study also has potential significance for advancement of knowledge by clarifying clinical practice in the use of seclusion. It identifies processes that would allow seclusion to be used only when absolutely necessary and in keeping with 
standards, policies and guidelines. This includes consideration of safety and ethical issues, and compatibility with current accepted practice.

In the following chapter, the literature review addresses the first objective of this study which was to identify those factors associated with decision-making when initiating seclusion. 


\section{CHAPTER 2: LITERATURE REVIEW}

\section{INTRODUCTION}

Humane treatment and legal protection for the rights of persons with mental illness was not a priority until well into the $20^{\text {th }}$ century. Until this time seclusion, as a method for managing aggressive and disturbed behaviour in psychiatric patients, could be used at will and people could be detained indefinitely. Seclusion currently continues to be used worldwide (El-Badri \& Mellsop, 2002).

The placing of people in seclusion and the use of other forms of restraint is controversial and literature debating its appropriate implementation is increasing (Vittengl, 2002). While many people claim there is no longer a need for such "nontherapeutic” interventions, others say they are a necessary adjunct to therapeutic practices (Belkin, 2002). As seclusion has come under increasing scrutiny there has been a proliferation of journal articles, books, policy statements and legal frameworks, particularly from the 1980s onwards. I have therefore limited this review to those publications that are directly related to the focus of this study. This focus includes the extent of seclusion use in an acute in-patient unit, the reasons for initiating seclusion in this unit, and the clinical basis and practice issues that influence nurses in using seclusion. I have also discussed how this fits with a recovery approach to the care and management of people with mental disorders.

This review will define seclusion and provide a brief history following which the reasons for using seclusion, predictors for seclusion, and staffing issues will be discussed. I have then included a short description of seclusion in a New Zealand context. 


\section{SECLUSION DEFINED}

Seclusion is the term most often used to describe the involuntary confinement of patients in a locked room specifically designed for the purpose and from where the person is physically prevented from leaving (Keltner, Schwecke \& Bostrom, 1999; Lendemeijer \& Shortridge-Baggett, 1997).

In defining the process of seclusion, Yee and Bateman (2003) stated that any definition of seclusion has three important elements: containment, isolation and sensory deprivation. El-Badri and Mellsop (2002, p. 399) extended this and provided a more detailed definition with elements regarding supervision, time and reason for seclusion: "the supervised confinement of a patient specifically placed alone in a locked room for a period at any time of the day or night for the protection of the patient, staff or others from serious harm”.

There are many other definitions for seclusion, all of which contain similar concepts. Older definitions included Angold (1989, p. 437) who stated that seclusion: "is the containment of a patient alone in a room or other enclosed area from which that patient has no means of egress". Gutheil (1978, p. 325) described seclusion as "the process whereby a psychiatric inpatient voluntarily or involuntarily is placed for a specific time in a seclusion room which is generally a securely built, small room ... (and) has a lockable door with an observation window.”

Latterly definitions have become more succinct and refer to the purpose of seclusion. McDonnell \& Reeves (1996, p. 43) stated that seclusion was "the supervised confinement of a patient alone in a room which may be locked for the protection of others from significant harm”, while Keltner et al. (1999, p. 158) stated it was the "process of placing a patient alone in a specially designed room for protection and closer observation”. Wynn (2002, p. 287), equally concise, also conveyed the element of sensory deprivation: "seclusion is containing an emergency situation by placing and keeping the patient in a bare room”. 
Alty and Mason (1994) outlined six fundamental components for a definition of seclusion. These were: place (a designated area for seclusion), social isolation, egress (being locked in), compulsion (moving, against the will of the patient, to another area), time (duration of seclusion), and rationale (reasons for seclusion). They found that no definition incorporated all of these components. A further component, the requirement for observation, was suggested by Lendemeijer and Shortridge-Baggett (1997).

\section{A BRIEF History}

Seclusion has been used to contain patients for thousands of years and was largely ignored as an intervention until recent times:

Historically, seclusion is an area steeped in myth and folklore, with relatively little research undertaken into current practices to establish empirical evidence resulting in entrenched views and in polarized arguments for and against its use and efficacy as a therapeutic tool (Mason, 1993, p. 95)

Some of the earliest writings about seclusion date back to the $2^{\text {nd }}$ century AD when Soranus described a method of calming a mentally ill patient by placing him (sic) in a room especially designated for that purpose. Alty and Mason (1994, p. 17-18) quoted from his writings:

Have the patient lie in a moderately light and warm room. The room should be perfectly quiet, unadorned by paintings ... and the bed should be firmly fastened down. It should face away from the entrance to the room so that the patient will not see those who enter. In this way the danger of exciting and aggravating his madness by letting him see many different faces will be avoided 
By the $18^{\text {th }}$ century patients who proved difficult to control were often isolated for long periods (sometimes many years) and were frequently also maintained in physical restraints. Seclusion was implemented as a punishment, to intimidate and exclude (Farrell \& Dares, 1996). Conolly, in his 1856 book: Treatment of the insane without mechanical restraints, advocated strongly for the use of the padded seclusion room for violent or extremely excited patients, regarding it as an enlightened means of providing disturbed patients with calm and security, while avoiding the use of restraints and pharmacological over-sedation (Angold, 1989).

Phillipe Pinel in France and William Tuke in England are best known for their humane efforts to ensure the insane were no longer treated as less than human. In the 1790s Pinel "unchained the shackled, clothed the naked, fed the hungry, and abolished the whips and other instruments of cruel treatment”. In the meantime, Tuke was reported to be "planning a private facility that would ensure moral treatment for the mentally ill after he had witnessed the deplorable conditions in public facilities" and opened the York Retreat in 1796. He provided "a place in which the unhappy might obtain refuge - a quiet haven in which the shattered mind might find a means of reparation or safety” (Keltner et al., 1999, p. 4-5).

By the beginning of the $20^{\text {th }}$ century seclusion was still considered essential, if more moderately used than previously, but persons with mental illness (and sometimes those who were sane) could still be confined indefinitely and against their will. It was not until the rapid advances in psychotropic medication in the middle of the $20^{\text {th }}$ century that the care and treatment of patients with psychiatric disorders began to be questioned and debated. According to McGihon (1998, p. 22), “abuse and inappropriate treatment were inflicted upon this group of individuals until activists began to promote legislation and develop laws that would guarantee their constitutional rights and ensure treatment or appropriate release.” It is not surprising that the use of seclusion came under scrutiny against this background and the use of seclusion began to decline markedly (Alty \& Mason, 1994; Angold, 1989). 


\section{REASONS FOR USING SECLUSION}

Seclusion of patients has been used in mental health facilities mainly for the control of disruptive and aggressive behaviour. Muir-Cochrane, Holmes and Walton (2002) wrote that psychiatric treatment should not require the use of force, but others have a more pragmatic view of seclusion. Marangos-Frost and Wells (2000) and Wynaden et al. (2001) both stated that seclusion was appropriate when all other options had been exhausted, and when all other less restrictive measures had failed or had been deemed inappropriate. Most writers considered the use of seclusion to be an emergency measure or as a method of last resort often as a result of threatened or actual violence (Kozub \& Skidmore, 2001a; Terpstra, Terpstra, Pettee \& Hunter, 2001; Wynaden, et al., 2001; Wynaden, et al., 2002). However, according to Mason (1997), reasons for using seclusion were based on a complex interplay of cultural and organisational factors, rather than the presentation of symptoms by the patient.

Violence, often directed at staff or other patients, has been reported as the most common precipitant of seclusion. Other reasons included threats, abuse, agitation and generally disruptive behaviour (Angold, 1989). In this way, it was used on utilitarian grounds - the greatest good for the greatest number - where a patient was secluded to protect other patients, visitors and staff on the ward from their aggressive behaviour (Farrell \& Dares, 1996; Fisher, 1994).

Hummelvoll and Severinsson (2001) explained that seclusion was a strategy to handle patients' needs for support in the acute phase of their psychotic disorder, that seclusion gave structure and set boundaries for patients in an acute and chaotic situation. They added that seclusion included decreased stimuli to help the patient achieve greater autonomy and to manage their daily living. It was also noted by these authors and also Valimaki, Taipale and Kaltiala-Heino (2001) that the purpose of seclusion was to manage aggression and to prevent aggressive patients from harming themselves and/or other patients and staff on the ward.

Wynn (2002) noted that seclusion had a less immediate effect on controlling the patient than physical restraint and so it was used in less dangerous situations. This 
was in contrast to both Griffiths (2001) and Stowers, Crane and Fahey (2002) who stated that seclusion should be used only as a last resort for the shortest possible time. These latter authors also stated that seclusion should not be used as a punishment or threat, as part of a treatment programme or because of staff shortages or where there was any risk of suicide or self-harm. But Alty and Mason (1994) concluded that any merits seclusion may have had related to its containment value only; it may have had a place for the protection of others, but not the patient him or herself. They said further that, "self-injurious behaviours and suicidal attempts and threats should be managed in a different manner with staff in attendance” (p. 102).

Several authors stated that patients were entitled to freedom from the use of seclusion and other restrictive practices (Bonner, Lowe, Rawcliffe \& Wellman, 2002; Kozub \& Skidmore, 2001b; Wynaden et al., 2001). Further, where it was necessary to intervene, several alternative de-escalation techniques should be attempted before resorting to the use of seclusion (Bonner et al., 2002; Wynaden et al., 2001).

In his thesis, which looked at factors related to seclusion use in a special hospital in the United Kingdom, Johnson (1997) identified particular themes within the literature that were associated with the decision to use seclusion. He identified the threat or presence of violence and other fear inducing behaviours as being the most important factors in deciding to seclude a person. However, he added that there were also other factors of potential importance noted in the literature. These were mainly external factors to do with staffing, the immediate environment and cultural and organisational concerns. Johnson identified seven broad themes as important in making seclusion decisions. These were (1) violence and threat of violence; (2) agitation, frustration and coping skills; (3) cognitive processes and functioning; (4) mood and affective functioning; (5) comprehension, understanding and perceptions; (6) compliance and conformity; and (7) external factors such as staffing, demographic, environmental and diagnostic variables.

There are many circumstances within the unit milieu that can lead to the need to seclude a patient. Marangos-Frost and Wells (2000) noted that the complexity in decision-making, nurses' emotional reactions generated by the situation, unit factors 
and professional attitudes all contributed to the outcome. The staff mix including experience, confidence and skill levels in managing aggression, staff/patient ratios, the number of male staff present, team cohesion and control issues between staff members were also some issues that needed to be considered (Griffiths, 2001; Terpstra et al., 2001) Other circumstances included patient/staff conflict, a disturbed environment, failed communication and inappropriate responses from staff (Bonner et al., 2002; Chabora, Judge-Gorny \& Grogan, 2003).

Normalising seclusion practice could increase the potential for infringement of patients’ rights. Wynaden et al. (2002) noted that where seclusion was considered a common or normal part of the routine of a unit, and where there was a cultural ideology regarding the use of seclusion, the justification for its use could become compromised. Seclusion became an institutionalised response to unacceptable behaviour, rather than staff considering possible alternatives. Seclusion then served the purposes of the staff and institution and could interfere with the unique and individualised needs of the patient (Griffiths, 2001; Harrison, 2002). Mohr and Horton-Deutsch (2001, p. 25) cited the example where "using restrictive measures such as keeping a person in seclusion all night simply for the convenience of the night shift staff could be seen as potentially abusive”.

\section{NuRSE Perspectives}

Most of seclusion initiation, monitoring and assessment was left to nurses (Mohr \& Horton-Deutsch, 2001). It was therefore not surprising that much of the literature investigated and described the issues for nurses in deciding whether to implement seclusion or not.

Generally, nurses perceived seclusion as an acceptable patient management strategy, and a legitimate and effective intervention. Nurses decided to use seclusion if they felt they were doing what was needed to ensure safety, however, some staff saw it as a procedure that violated patients' rights while others viewed it as punishment (Griffiths, 2001; Stowers et al., 2002; Wynaden et al., 2001). 
Nurses who thought critically about its use were faced with a dilemma when considering seclusion. While nurses had an interest in compulsory treatment, being the 'enforcers' of treatment and containment, their freedom to do the 'right thing by people' or act as patient advocates was sometimes questionable (Lakeman, 2000; Stowers et al., 2002). This then created dissonance in nurses when faced with challenges in clinical decision making and challenges in maintaining professional standards. Nurses were often in the position of having to make crucial decisions and set priorities in chaotic conditions, while maintaining an overriding duty of care to all people in the immediate environment. Being on high alert was essential and they needed to balance the standards for good patient care with negative responses from some staff members who saw de-escalation as increasing their work (Chabora et al., 2003). In addition, nurses were influenced by the culture of the working environment with its shared beliefs, values and norms, and expected working practices which sometimes did not correspond with official working policies. Mohr and HortonDeutsch (2001) considered that nurses were often unwilling actors with respect to seclusion due to external compulsion; they could be coerced or left with no choice but to follow orders and maintain the status quo. Wynn (2002) believed that there was a need for studies to give more detail about the deliberations of staff in such situations.

The reality is, I believe, that nurses are often left with the decision-making when confronted with patients who are violent and threatening. The nursing profession is the group most affected by violence from patient attacks and aggression and this can have devastating effects such as workplace stress, post traumatic stress disorder or physical injury (Needham, Abderhalden, Dassen, Haug \& Fischer, 2002). Hummelvoll and Severinsson (2001) also noted that emotional exhaustion correlated significantly and positively with demanding work, time pressures and feelings of job inadequacy. In addition, high levels of stress, often accompanied by lack of time and lack of support, could lead to depression, somatic complaints, sleep disturbance and burnout. 


\section{PREDictors FOR SECLUSION}

In their research paper, Valimaki et al., (2001) noted that there was a greater risk of seclusion among patients with personality disorders than among those with psychosis, although El-Badri and Mellsop (2002) found no patients with personality disorders were secluded during the period of their study. Other predictors have also had contradictory results. These included findings related to gender, age and ethnic group. Three papers compared the demographics of patients who were secluded or not secluded (Hammill, 1987; Kasper, Hage, Feucht-Haviar, Cortina \& Cohen, 1997; LeGris, Walters \& Browne, 1999). No gender or ethnic differences in the use of seclusion were found in these studies. However, they all reported that patients who were secluded suffered greater psychopathology, were more likely to be suffering a psychotic episode, were younger, had a longer hospital stay and were on higher doses of medication than patients who were not secluded during their hospital stay.

Hammill (1987) found that patients who were secluded were more likely to have had fewer hospital admissions, something that was possibly correlated with the younger age group. Kasper et al. (1997) however, reported that patients who were secluded had more previous hospitalisations. These contradictory findings may have related to the focus of these papers. The latter authors looked specifically at outcomes of treatment (medication) refusal. Refusers were more likely to be secluded and to spend a longer time there. They were also found to be more disorganised and more prone to assaultative behaviour than those who accepted medication. This suggests that they may also have been medication non-compliant leading to repeated admissions. A further possible explanation for this was the 10 year reporting difference between the two papers. Over this time there was a trend towards shorter hospital stays which may have led to more readmissions.

Other circumstances where seclusion has been used as an intervention included where a patient was rescued from the potential consequences of his or her behaviour, for punishment, where a patient was considered at risk of absconding, and where ward conditions were such that therapeutic nursing was difficult, for example in 
cases of insufficient staff, numbers of agitated patients, low staff morale, or a lack of experienced staff (McBride, 1996; Myers, 1990).

\section{STAFFING ISSUES}

The relationship between staffing and seclusion is complex. An early study (Thompson, 1986) suggested that seclusion episodes may be related to less experience and lower numbers of staff, and tended to happen more at mealtimes or when staff were having their breaks so less staff were on the ward. Thompson found that the overlap of two shifts when staff handover occurred did not correspond with any increased incidence of seclusion. Morrison (1990) agreed that seclusion events occurred at the busiest times of the day shift, for example during medicine rounds and staff handovers. In his examination of 109 records of seclusion, he also discovered, to his surprise and in contrast to Thompson, that higher rates of seclusion were linked to higher levels of staffing and that there were no links with mealtimes.

Donat (2002) investigated patient to staff ratios and concurred with Thompson (1986) that deficiencies in staff numbers could have contributed to unnecessarily high reliance on seclusion and other restrictive measures for the control of problem behaviours. Poor patient to staff ratios were also noted to be a common source of stress and an impediment to the development and implementation of behavioural treatment plans and other psychosocial treatment approaches. Valimaki et al. (2001) also found that a small workforce had an important impact on the use of coercion. Reed and Lyne (2000) noted that high levels of seclusion were unavoidable in areas with low staffing levels because more humane management of acutely disturbed patients was impossible particularly at times when staffing problems were greatest. Needham et al., (2002) found that the shortage of personnel and the haphazard way of dealing with situations were the main problems in the management of incidents of patient violence.

In a study of violence and aggression in five psychiatric units in Sydney, Owen, Tarantello, Jones \& Tennant (1998) found complex relationships between staffing, 
patient mix and violence. As may be expected, the use of seclusion was positively associated with violent incidents. Three factors - more female staff, more staff without psychiatric training and more staff absenteeism - were positively related to violence, whereas younger staff and staff with higher levels of psychiatric expertise were negatively related to violence. Bonner et al. (2002) commented on issues between permanent and casual/agency staff and found significant differences between individual nurses when making judgements about the imposition of seclusion. Lowe, Wellman and Taylor (2003) found that these differences were based on the experience of the nurses involved, with lesser experienced nurses tending to make the most restrictive judgements while more senior nurses used more confirming interventions. Terpstra et al. (2001) found a similar situation with staff with higher levels of education. These nurses felt conflicted between a person's right to self-determination and their own responsibility to provide the best care to patients. They preferred to calm patients using less restrictive methods and to provide a calming environment until the patient regained some control.

Staff experience was a factor in reducing the use of seclusion in two other studies (Morrison and le Roux, 1987; Morrison and Lehane, 1995). In the first of these studies, the authors suggested that a strategy for minimising the use of seclusion was to maintain staffing levels above an identified minimum and to ensure that an experienced charge nurse led the team. In the second study, increasing the number of staff on a ward was suggested as having a calming effect on disturbed patients, but other variables such as staff-patient interaction, gender, and experience of staff were also important.

de Cangas (1993) examined staffing issues, in particular the factors influencing unit environment and the personal attributes of staff members. By collecting shift by shift breakdowns of seclusion hours, staffing patterns, and workload, the author found that, as the full complement of staff increased, seclusion hours decreased, and as male staff increased, seclusion hours increased. Unit conditions that affected the use of seclusion included the physical layout, the degree of crowding, and the presence of noisy patients. 
Alty (1997) reviewed nursing attitudes towards the values and concerns about seclusion and concluded that nurses gained their understanding and opinions of seclusion from the culture of their practice. Issues raised by participants surrounding seclusion use included keeping safe, concern about seclusion abuse, the value of it in 'real world' practice, and role conflict. In this paper, Alty also looked specifically at the education and training of staff to determine how nurses gained experience and knowledge of seclusion practice. She found that 28 percent of subjects had training about seclusion while 34 percent had read articles about seclusion. This was in comparison with 73 percent of nurses who had, at some time, been involved in implementing or supervising seclusion practices. Fifty two percent of nurses interviewed and involved in seclusion, had no formal training or had not done any reading about seclusion. The main concern raised by participants was the need to have sound practical advice and information.

\section{THE NEW ZEALAND SCENE}

Until recently there had been a noticeable absence of published research related to seclusion in New Zealand. The only New Zealand writings before the year 2000 were a case study written by a former patient (Leibrich, 1997), a fictional, although largely autobiographical, account (Frame, 1961; Frame, 1982) and a collection of personal accounts of mental illness (Leibrich, 1999). In 2000, Lakeman published a paper that explored ethical issues in the use of seclusion.

Muir-Cochrane et al. (2002) in their article which outlined the regulation of seclusion in New Zealand, noted that she and her colleagues were unable to find any research on seclusion practice that had been carried out within a New Zealand context. Since then, a few papers have been published locally which have discussed the use of seclusion. O’Hagan (2003) and Read (2003) discussed tensions between human rights and the right to least restrictive treatment versus the power to enforce treatment and the use of seclusion; Yee and Bateman (2003, p. 3) identified seclusion as 'a ward management technique' rather than a form of treatment, then discussed the seclusion experience of service users and the findings from a seclusion 
survey by the Mental Health Commission. Both Yee and Bateman (2003) and O’Hagan (2003) compared seclusion use with a recovery philosophy and noted that seclusion practices did not sit comfortably alongside such initiatives:

One of the core beliefs and drivers in the recovery approach is that service users are by and large, able to take responsibility for their own lives. This differs from the core belief in traditional mental health services and in mental health legislation - that service users are victims of a condition that can deprive them of personal responsibility (O’Hagan, 2003, p. 9)

One further published research paper (El-Badri \& Mellsop, 2002) was a prospective study examining the frequency of the use of seclusion and the factors associated with its use in the Waikato area. The authors compared patients who were secluded with those who were not, over a nine month period in 2000. Their findings revealed that seclusion was used principally in relation to actual or threatened violence. Those more at risk of being secluded were male, non-European and had diagnoses of schizophrenia, mania or substance abuse. This was in contrast to overseas findings in papers referred to earlier where no gender or ethnic differences were found (Hammill, 1987; Kasper et al., 1997; LeGris et al., 1999). In New Zealand there is continuing concern about the disenfranchisement of Maori and Pacific Island peoples including within mental health services (Henare \& Ehrhardt, 2004). The report by El-Badri and Mellsop about the increased risk of non-European males being secluded may reflect the difficulties Maori and Pacific Islanders experience when they are treated within mainstream services or where the option of being treated within their own culture is limited.

In a recent descriptive study (O’Malley, Wijnveld, Kerr, Kennedy \& Frampton, 2003) the authors investigated the factors that impact on the use of seclusion and management of patients in seclusion in an acute mental health service. A conference presentation outlined their investigations which included looking at the events leading up to seclusion, interventions before and during seclusion and issues such as staffing levels and availability, time factors, and cultural and organisational factors. The results had not been published at the time of writing this report. 
Finally, a review by the Mental Health Commission (2004b) on seclusion practice in New Zealand has recently been published. This followed a survey of seclusion practice within District Health Boards (DHBs), an analysis of the literature on seclusion, a review of key policy documents that related to seclusion practice, and consultations and visits to selected DHBs. The findings were that seclusion was used widely and often across DHBs but usage varied over time and between DHBs. Factors that influenced seclusion practice included unclear policies and guidelines, overcrowding, poor ward design, low or inflexible staff numbers, inexperienced staff, poor staff retention, poor information sharing and service user acuity. The review proposed several initiatives which included better monitoring of seclusion use, and progressing towards substantially reducing its use.

\section{CONCLUSION}

Publications investigating seclusion in mental health services are extensive and cover a range of aspects of its use. In this review, I have focused on articles which investigated the reasons for using seclusion and predictors for its use. Within this context are included those articles that focused on nurse explanations for using seclusion and staffing issues. I have also included discussion on seclusion issues in New Zealand.

The main findings from this review are that seclusion is used for the containment of patients who present with violent, disruptive and aggressive behaviour. Seclusion was generally used when other less restrictive options had been exhausted and when it was the only means available of protecting others in the immediate environment. However, other circumstances could occur that could lead to the need to seclude a person and which indicated the complexity of such decision-making. These included diagnostic variables, demographics of patients, the environment, and the cultural ideology of the unit. Staffing issues which impacted on the use of seclusion included the number of staff, staff mix, gender, and experience of staff. Also noted was the timing of seclusion events with these more likely to occur at certain times of the day. 
Seclusion can constitute a dilemma in nurses' clinical decision-making. Often decisions need to be made swiftly in chaotic conditions and nurses have to balance their duty of care to the individual and to everyone else in the environment. They may feel pressure to practice within the confines of the beliefs, values and norms of the institution, and balance the conflict that arises between their roles as creators of a therapeutic milieu and as enforcers of treatment and containment.

Reasons for and predictors of seclusion use in New Zealand are similar to that found in other countries. In this present study I wish to determine the extent of seclusion practice in one acute mental health in-patient unit and to look specifically at precipitants for seclusion use and the processes nursing staff go through when they make the decision to use seclusion. The next chapter discusses the methodological issues that were considered in formulating this study. 


\section{CHAPTER 3: Methodology}

\section{INTRODUCTION}

Research methodology is the philosophical framework, or the fundamental assumptions and characteristics of a particular research perspective. It includes the general orientation, the view of knowledge and the meanings associated with or implied by a certain research method (Van Manen, 1990).

It has been claimed that nursing is a series of unique encounters between unique individuals so, to be truly effective, nursing needs to be flexible, creative and responsive, and lack preconceived structure (Rolfe \& Fulbrook, 1998). It follows that nursing research methodologies need to reflect this focus and be adaptable enough to meet the challenges of individual enquiry. This chapter describes the methodological considerations underpinning the direction of this study.

\section{NURSES AND RESEARCH}

Bailey and Tilley (2002) commented that early nurse-researchers were generally encouraged to do quantitative research, but since the 1980s nurses have developed skills in the use of strategies where 'meaning' rather than 'truth' is the legitimate end product of enquiry. This movement has occurred because quantitative research often led to limited benefits in discovering, explaining and interpreting the central and dominant domains of nursing phenomena especially related to human care, health, and well-being. Nurses began to realise that in order to know and understand human caring and health in different environments in which nurses worked with people, qualitative studies with their in-depth, new and valuable insights were important (Morse, 1994). 
Nursing research concerns those areas over which nurses have control of the decision-making in their practice. According to Roberts and Taylor (2002), such research should be directed primarily to the improvement of the quality of client care, with issues of professionalism, morale, education and nurse administration taking a more minor role. This primary type of applied research in nursing is concerned with the application of knowledge to specific situations.

\section{The QUALitative MeTHOD}

Qualitative research is centred around people, and the place, time and conditions in which it finds itself. It is therefore unique and context-dependent. Such research starts from a specific instance or set of observations, reflects on the quality of the issue under scrutiny, and moves, by inductive reasoning, to a general pattern of instances or observations. In this way, broader statements can be made about the topic under investigation (Roberts \& Taylor, 2002). Inductive research moves from observation, through generalisation to theory generation. Inductive approaches are appropriate for studying areas where little is understood and inductive theory is concerned with bringing knowledge into view (Davidson \& Tolich, 2003).

Qualitative research should, therefore, be used when there is little known about the topic or when there is the possibility that present knowledge or theories may be biased (Morse \& Field, 1996). It is often exploratory, seeking to describe a situation or to understand how a group of people live or cope with their lives, or provides an understanding of a series of events, and enables others to make sense of reality. According to Morse and Field, this development of description of a topic is then used to generate theory as an outcome or product of the research.

I have chosen to use a descriptive and interpretive qualitative approach for this research to provide a comprehensive, in-depth investigation into the reality of using seclusion in an acute in-patient unit for those who are most involved in its use. By using a qualitative design the facts can be presented in everyday language and there is room for unexpected or unanticipated situations to be incorporated into the overall 
description. This is in contrast to a quantitative design which has pre-set confines which limits what can be learned about the meanings people give to events (Sandelowski, 2000).

A qualitative method is appropriate to the aims of this study and the research question as described in Chapter One because the research base is confined to a context-dependent unit from which I wish to gather as much information as I can. From this information I can then describe and explore the particular set of circumstances that occur around seclusion events and expand on the understanding and meaning of this experience.

\section{A Descriptive APPRoAch}

Qualitative research that is descriptive provides a way of explaining and understanding an experience. According to Sandelowski (2000, p. 336), "the description in qualitative descriptive studies entails the presentation of the facts of the case in everyday language." People who conduct qualitative studies want to gather as much data as possible to ensure they have captured all of the details of an event or events. In this way, as much information as possible is available to enable sufficient description of the situation. Qualitative findings provide rich description so that readers can understand and make sense of the clinical reality. It provides a window into the world of other people, providing an empathic understanding of that world (Morse \& Field, 1996).

Sandelowski (2000) noted that in the vast qualitative methods literature, there was no comprehensive reference to qualitative description as a distinct method of equal standing with other methods. However, it was one of the most frequently employed methodological approaches to qualitative research. 


\section{AN INTERPRETIVE APPROACH}

All description encompasses interpretation. Knowing the facts about an event or circumstance involves the perceptions, feelings and responsiveness of the person who is describing that event. It is not possible to describe an event without putting your own interpretation on it. As researchers seek to describe an experience or event they inevitably select what they will describe and, by this means, feature certain aspects of it, or interpret the meaning of it (Sandelowski, 2000).

Interpretation includes identifying patterns, or commonalities by inference from examination of the specific instances or events, identifying the relationship between concepts and then creating theoretical explanations from it (Morse \& Field, 1996).

\section{Pragmatism AND EVAluation Research}

However, not all descriptive and interpretive qualitative studies need be theory based. It is possible to leave the world of theory and enter the world of practice and pragmatism. There is a practical side to qualitative methods that involves asking open-ended questions of people and observing matters of interest in real-world settings in order to solve problems, improve programmes or develop policies. Patton (2002) believed that a study could be framed as a qualitative, utilisation-focused evaluation research that specified intended users and uses for the study such as facilitating discussion about 'effective practices'. This then put the researcher in a tradition of generating practical and useful knowledge for action focusing on perceived patterns of effectiveness.

Swanson and Chapman (1994) in their discussion on evaluation research using a qualitative approach referred to the health field and nursing in particular, where, they said, people spent more time doing than knowing. They saw the purpose of evaluation research as increasing knowledge of the mechanisms that underlay successful interventions. 
I have noted earlier in this chapter that I favoured a qualitative methodology that is descriptive and interpretive for this study. After considerable thought I have also opted for a pragmatic approach to investigating seclusion use and management by framing it within a practical and evaluative paradigm rather than developing a theory-based outcome. Data collection methods were then developed from this qualitative approach.

\section{Data Collection}

Data collection methods are typically directed toward discovering the nature and shape of events or experiences. Researchers begin data collection by examining observations and reports of the topic of interest as they occur in the natural setting. These data are then interwoven into a cohesive whole (Morse \& Field, 1996).

Qualitative findings can grow out of different kinds of data collection. Patton (2002) described three types of data obtained from in-depth, open-ended interviews, from direct observations of the targeted events, and from the examination of written documents and artefacts. Using a combination of methods allows researchers to explore the common and unique manifestations of the event or experience across a range of structures (Sandelowski, 2000). This present study has a multi-faceted design that incorporates several of these methods as it includes a file audit, staff interviews, and reference to seclusion issues taken from my personal journal. By combining multiple methods and data sources, this goes some way to overcoming the intrinsic bias that can develop from single-method, single-observer and singletheory studies (Patton, 2002).

\section{INTERVIEWS}

A focused interview method was used for one part of this research so that more in depth material could be obtained in a setting where the participants had the freedom to explore fully the issues that they felt were relevant to the use of seclusion. In 
qualitative research, the purpose of interviews is to gather data about relevant issues, topics and experiences in a conversational, flexible and fluid style (Mason, 2002).

Mason (2002, p. 225) continued: "Interview methodology begins from the assumption that it is possible to investigate elements of the social by asking people to talk, and to gather or construct knowledge by listening to and interpreting what they say and to how they say it”. Therefore interviews should provide insights and knowledge into seclusion use from a social and human perspective that it would otherwise not have been possible to obtain.

\section{AUDIT}

A file audit was conducted to analyse the use of seclusion over a period of seven years. Audit is one form of document analysis that can include studying excerpts, quotations, or entire passages from organisational, clinical or programme records, official publications, and open-ended written responses to questionnaires and surveys.

I conducted a search of the literature for information on using audit as a method of data collection but I was unable to find much written on this subject. The only New Zealand reference to audit that I could find was in a discussion document (National Advisory Committee on Health and Disability Support Services Ethics, 2003). Audit was identified as a process to review the care provided to patients, with audit being achieved through a systematic evaluation of the care delivered. The benefit of clinical audits was to improve the quality of health care, thereby improving health outcomes.

In a discussion on documentary realities, Atkinson and Coffey (1997) noted that in order to understand contemporary society, it was important to look at the ways it represented itself through written documents and other forms of recording. The 
authors commented further that there were many research questions and settings that could not be investigated adequately without reference to the production and use of textual materials. However, documents do not stand alone. They referred to other realities and domains and to other documents so that a document analysis must, of necessity, be taken in the context of their relationships to other data.

\section{REFLECTION}

The starting point for this research was my own lived-experience of a seclusion event. My own experiences are immediately accessible to me in a way that no-one else's are, but my experiences may also be the experiences of others. This is described by Van Manen (1990) in a phenomenological sense in that descriptions of possible human experiences have a universal or inter-subjective character.

The use of reflection as a data source has also been described as a type of autoethnography (Patton, 2002). In this description, a person used their own experiences to describe insights about the subject of the research. This demonstrated selfawareness about and the reporting of one's own experiences and introspections as a primary data source.

On the other hand, Walkerdine, Lucey and Melody (2002) discussed subjectivity in the research process and the issue of emotion and unconscious processes. They commented that the issue of narratives of both the researcher and the participants became more complex than the telling of different stories. The subjectivity of the researcher in telling their story was matched equally by the subjectivity of the participant who placed their own interpretation on events. The authors continued by stating that "adding the researcher's voice in most cases is designed to fill some of the absences which 'difference' produces in order to construct a more complete, more 'real' ethnographic picture” (p. 184). In this way adding another voice to the data provided another perspective or another viewpoint on the topic under discussion which may either agree or disagree with other perspectives or which may tell a different story. 


\section{RIGOUR}

Rigour in any research is required to prevent error of either a constant or intermittent nature. One of the major criticisms of qualitative research in the past was the lack of control over validity and reliability of findings. According to Silverman (2000, p. 175) "unless you can show your audience the procedure you used to ensure that your methods were reliable and your conclusions valid, there is little point in aiming to conclude a research dissertation”.

In qualitative research the assumptions, experiences and perspectives of the researchers influence the findings of the research (Denzin \& Lincoln, 1994). For this reason the value of the concepts of reliability (that a study must be replicable) and validity (that the study measures that which it purports to measure) as criteria for rigour in qualitative studies have been debated for many years. Emden and Sandelowski (1998) have detailed the journey of reliability and validity being transformed to a criteria of goodness, to the concepts being exiled, to validity being redeemed while reliability was denied, to both concepts being surpassed by an emergent and expanded concept of rigour in qualitative research. In a second article, the authors accepted that there was no one set of criteria that could be expected to meet the demands of every research study (Emden \& Sandelowski, 1999).

Validity is another word for truth and relates to the trustworthiness of the research. It is the extent to which an account accurately represents the subject to which it refers. In qualitative research there are multiple realities so it is necessary to report the perspectives of the informants as clearly as possible (Morse \& Field, 1996; Silverman, 2000).

Reliability refers to the degree of consistency with which results can be achieved on repeated undertaking of the research project either by different researchers or by the same researcher on different occasions. This implies that results are generalisable across different populations (Silverman, 2000). Reliability from this standpoint is often not an issue in qualitative research as it is based on the idea that knowledge is 
relative and dependent on the people, place, time and context in which the research is placed (Roberts \& Taylor, 2002). However, the results should accurately reflect the opinions or actions of the people in the study. In order to establish internal reliability, for example, if two independent transcriptions and coding of interviews were performed, inter-coder reliability would be established if they both consistently reported similar patterns or findings (Silverman, 2000).

Sandelowski (2000, p. 336) noted that in qualitative descriptive studies, researchers stayed closer to the actuality of the data, "the surface of words and events" than in other qualitative methodologies. By this, she meant the depth of penetration and interpretation of reported or observed events, that researchers kept to the facts and the meanings participants gave to those facts and then conveyed them in a coherent and useful manner. Qualitative descriptive studies offer a comprehensive summary of an event in practical everyday terms. Researchers involved in qualitative description seek descriptive validity as an accurate accounting of events that most people observing the same event would agree was accurate; and interpretive validity which was an accurate accounting of the meanings participants attributed to those events, that those participants would agree was accurate (Maxwell, 1992).

Sandelowski (2000, p. 337) described qualitative descriptive designs as "typically an eclectic but reasonable and well-considered combination of sampling, and data collection, analysis and re-presentational techniques." Such a design has enabled me to obtain data in order to assist in providing answers to questions of relevance to health professionals. I chose to use a qualitative description approach to this study as I wished to develop a useful discussion around seclusion and its management without resorting to a conceptual or abstract interpretation of the data. In other words, I wanted to create a worthwhile end product that was of immediate practical use to the service within which I was working. I have undoubtedly placed my own interpretation and emphasis on events, and recorded events and situations in a different way to that of other researchers. However, the aim was to present an accurate description of the facts (descriptive validity) that would summarise both the audit and interview data in a way that would present a case that was clear, concise and honest in its evaluation (interpretive validity). 
A further approach to validity is the concept of triangulation which refers to the use of multiple data sources. Roberts and Taylor (2002, p. 232) defined the principle of triangulation: "that if you collect data based on more than one observation or measurement, the data are more likely to be valid because there will be less investigator bias.” During the file audit I looked at three separate data sources for the same information. According to Roberts and Taylor, this is 'unit of analysis' triangulation in which two or more approaches to analysing the same set of data are used. I also used two different ways of gathering the data, firstly by conducting the file audit, and secondly by carrying out semi-structured interviews. This is methodological triangulation (within-method) which involves combining two or more data collection methods within one study to measure the same variable.

During the file audit I coded the information obtained about reasons for seclusion use according to a thematic description provided by Johnson (1997). To assess the accuracy of my interpretation, and therefore provide a measure of internal validity, I photocopied each of the forms containing the information before coding. Then, approximately eight weeks later, I repeated the coding procedure and compared the results. I then reviewed any discrepancies and made a final decision about the coding.

Finally, as part of the interview process, transcripts of interviews were returned to participants for checking. They were asked to read the transcripts and return them to me if they wished to make any amendments or alterations to the information. This provided a monitoring system to ensure the interview transcripts reflected accurately what the participants intended to say and so provided a further measure of validity.

\section{CONCLUSION}

Nursing research tends to focus on qualitative methodologies although this was not always the case. The move from a quantitative paradigm occurred in the context of nurses recognising the limits that quantitative research placed on their ability to discover, and interpret the meanings of health and illness in people's lives. A 
qualitative approach with its inductive reasoning has become established in nursing research as a means of investigating and examining health issues.

Descriptive and interpretive designs allow a comprehensive and in-depth explanation of experiences; they provide a means of gathering as much relevant data as possible to enable an accurate interpretation of events or experiences. While many such studies aim to develop theoretical explanations, it is not always necessary. A pragmatic approach is often more suited to studies that wish to explain the world of practice in order to solve problems and improve programmes to ensure effective practice. This is often referred to as evaluation research.

Data collection methods can take one or more of several forms which may include interviews, direct observation and document analysis. A further way of providing data is through the researcher's own reflective experiences. While this may raise concerns about subjectivity, such reflection can also produce a more complete picture of the experiences being studied.

Rigour, and its companion concepts of validity and reliability, often cause debate between quantitative and qualitative researchers. One needs to maintain an awareness that the assumptions, experiences and perspectives of these researchers are different. There are many ways of determining rigour in a qualitative research study and the means by which this is done should be context-dependent.

Having now described the methodological assumptions behind the chosen framework for this study, it is now time to describe the research method, that is the way or the process that was used to investigate seclusion issues. 


\section{Chapter 4: The Research Process}

\section{INTRODUCTION}

This study has arisen from my personal interest in seclusion issues, firstly from my introduction to seclusion as a student. Secondly, I have had direct involvement in the seclusion of people with psychiatric disorders during my clinical practice as a registered nurse. This has encouraged me to investigate these issues further and contribute to the current debate regarding seclusion use.

Examination of the literature on seclusion revealed a large number of articles that covered many aspects of its use. I have focused on those articles that have discussed topics such as staffing issues, patient mix, debate about seclusion being treatment, containment or punishment, policies and guidelines, and clinical reasons for using seclusion. It is apparent that some seclusion use was not always appropriate and did not meet best practice guidelines (Standards New Zealand, 2001), and that its use needed to be closely monitored.

In developing this study, my overall intention was to put a human face to the practice of seclusion whilst investigating the realities of seclusion use in one acute in-patient unit. In this chapter I will discuss ethical issues and then explain the process for each of the facets of this study in turn.

\section{ETHICAL CONSIDERATIONS}

The local Ethics Committee, in their letter of 12 July 2004 (see Appendix D), approved this study. Several issues arose when considering ethical approval and these are now discussed. 


\section{FILE AUDIT}

Organising the file audit raised issues of individual privacy, anonymity and the use of unique identifiers. I considered whether permission needed to be obtained from patients to access their files. Because of the retrospective nature of the audit and the fact that it would be impossible to trace all the people involved, I did not seek patients' permission for this. Access to patients' files for research purposes is covered by the Health Information Privacy Code 1994 which states under Rule 10: Limits on use of health information, that information held by a health agency may be used if it: "is used for research purposes (for which approval by an ethics committee, if required, has been given) and will not be published in a form that could reasonably be expected to identify the individual concerned” (Burgess, 2002, p. 50). I have ensured, throughout this study, that the anonymity of patients has been preserved.

To enable access to patient files, it was necessary to use National Health Index (NHI) numbers to uniquely identify each person concerned. Data gathered from patient files was coded with an identification number based on the year and event number. This numbering system was matched in a separate file with the NHI number so that a means of tracing the file was available should this be necessary. The file with the NHI numbers has been retained separately from the study data and its whereabouts is known only to myself.

\section{STAFF INTERVIEWS}

I considered the possible conflict between my role as researcher, and my role as a staff member and colleague of the participants in this study. Because of this I ensured that participation in this study was completely voluntary and the study design ensured that my colleagues approached me in the first instance and asked to participate. I then provided them with information about the study.

The Ethics Committee approved information sheet, (Appendix E), which was provided to each person who approached me, introduced the study and explained the study aims. It then outlined the criteria for participants in the interview phase of the 
study and what their involvement would be. Confidentiality issues were discussed. It was explained that participation in the interview would be kept confidential by me, that all information shared with me would remain confidential and would not be used in any way that could identify a participant. Participants were advised that they could decline or withdraw from the study at any time without giving reasons for this and without any disadvantage to themselves. They were also advised that they could refuse to answer any particular questions or ask for the audiotape to be turned off during all or part of the interview. Consent from participants was obtained in writing on the Ethics Committee approved consent form (Appendix F).

\section{CONFIDENTIALITY OF FILES}

Data related to this study is stored on my home-based computer, secured with a password. Backup copies of computer files, paper copies of audit data and transcripts, and audiotapes have been securely stored in a locked cabinet. This data will be retained in secure storage for five years after which paper data will be shredded and computer disks and audiotapes will be erased. Until this time I will be responsible for its safekeeping.

\section{TREATY OF WAITANGI}

This study involved Maori participants in that the file audit included some Maori people who had been subject to the seclusion process. According to the terms of Article Three of the Treaty of Waitangi, there is an expectation of an equivalent state of health between Maori and Pakeha (Health Research Council of New Zealand, 2004). While this study could not directly address the issue of equivalency of Maori and Pakeha use due to the low number of Maori, it did identify seclusion events that involved Maori and noted any issues related to Maori. This study was discussed with the local Maori Adviser of the Maori mental health team who provided me with a letter of support (Appendix G). An agreement was reached that the Maori mental health team would be invited to any meetings or discussion related to this study and 
that they would be consulted and their input sought during data analysis should it be required.

\section{CONSUMER PARTICIPATION}

This study did not seek data from service users. However, because of the importance of having service user support for such a study I had discussions with the local Consumer Adviser who provided me with a letter of support (Appendix H). A recent consultation document noted that the present day focus on recovery from mental illness was built on the personal empowerment of service users and people-centred initiatives. For recovery to be a reality services must be focused on the needs of service users and it was therefore important that they were involved at all levels of support services (Ministry of Health, 2004). The Consumer Adviser is an integral part of the management team of the mental health service and was informed of progress throughout the development and data gathering stages of this study. The Consumer Adviser was also available for consultation during data analysis.

\section{The File Audit}

A retrospective audit of patient files over the years 1997-2003 was conducted. The purpose was to establish an accurate picture of seclusion use over this period. Records for each person were scrutinised and information was recorded. An audit form, divided into four sections, was developed on which to record this information (see Appendix I). A separate form was used for each seclusion event.

Information gathered and recorded in the first section of the audit form included demographic data (age, gender and ethnicity), date of admission, diagnosis and the unique hospital record number.

The second section related particularly to each seclusion event. It included the date and time the person was secluded, the date and time seclusion was terminated and 
the length of time of the seclusion event. Information about whether seclusion was part of the admission process was also gathered as seclusion events that occurred on admission could have different precipitating factors to those events that occurred within the therapeutic milieu of the in-patient unit. It was also established and recorded whether a person had repeat seclusion events during their admission or if a person was secluded over repeat admissions.

Thirdly, details of each seclusion event were recorded. This included medications administered at the time of the event and a person's status under the Mental Health (CAT) Act 1992 (MHA) at the time of seclusion. This was noted in order to differentiate between nurses using their holding powers under Section 111 of the MHA and seclusion of persons already detained under the MHA. There was also the possibility of persons being improperly held in seclusion without being involuntarily held under the MHA. This section also noted the responsible clinician at the time of the event and the staff members involved as detailed in the seclusion register.

Information about the reasons for a person being secluded was also included in the third section. This information provided details of the behaviours displayed at the time and any noted precipitating events. From this information the data could be coded according to the seven themes identified by Johnson (1997). There were three sources used to record these reasons: the seclusion register, the seclusion recording form and the nursing progress notes of the person concerned.

In the fourth section a space was left for any extra notes, or so that anything of special significance or any unusual circumstances could be noted about the event.

\section{PATIENT INFORMATION}

It was first necessary to determine which files needed to be audited. Information was obtained from two sources to gather this initial detail, the seclusion register and the admission register. 
The seclusion register was a hard-covered book maintained manually by nursing staff to meet the requirements of the MHA (Section 129(1)(b)) that specifies a register of restraint and seclusion must be kept. Information contained in this register included the name of the person, date and time seclusion commenced, the reasons for seclusion, the people (staff) who initiated the event, the date and time seclusion was terminated, the total hours in seclusion and the outcome of the seclusion event.

The admission register was contained in hard-covered books kept manually by nursing staff and compiled from admission information. Information available from this source included the name of the person, date and type of admission (e.g. whether acute or respite), their NHI number, date of birth, age at admission, their address, phone number, name of their general practitioner, their clinician while an in-patient, their identified contact person, diagnosis at admission and the discharge date.

Names obtained from the seclusion register were matched with admission information. From the data collected from these two record books it was possible to compile basic information required to identify the individual files that needed to be accessed and to obtain demographic data and a beginning overview of seclusion events, the number, and the relevant times for each person. This information was recorded on spreadsheets for each of the years being audited.

\section{PATIENT Files}

Psychiatric files for most patients were kept on site and were able to be accessed easily either from the general filing room or from current files kept in the in-patient unit, the community and out-patient area, or the alcohol and other drug service files. A few files needed to be retrieved from the basement as they had been archived due to the persons having died. One set of files was obtained from the adjoining district as the person had transferred there, and a further set was obtained from the nearest forensic service where the person was currently an in-patient.

Files were obtained to access the record of events during each person's admission to the in-patient unit in which the seclusion event occurred. Information contained in 
the files included admission details, clinical assessments, nursing and other progress notes, correspondence, medication charts, medical and laboratory procedures, legal papers including those pertaining to the MHA, seclusion documentation and any other relevant papers.

Six specific documents were viewed on the files. These were the admission form as this was often the only place where ethnicity or any reference to cultural background was recorded; the discharge summary related to the relevant admission to obtain the current diagnosis; MHA papers to establish a person's MHA status at the time of a seclusion event; seclusion documentation which included observation forms and the seclusion recording form; nursing documentation in the form of progress notes; and medication charts to confirm medication administered at the time of the seclusion event. The difficulty accessing ethnicity data indicated the extent to which Maori are still invisible within the services despite the documented responsibility to provide a culturally safe service for takata whaiora in partnership with mainstream services noted in the local Mental Health Service Plan (District Health Board, 2004b).

Seclusion documentation was recorded on the seclusion recording form (Appendix J) and the seclusion observation forms (Appendix K). The seclusion recording form was a one page sheet which was signed for each 24 hour period by the responsible clinician (usually the psychiatrist). It contained information about the reasons for seclusion and comment about the seclusion event outcome. The seclusion observation forms recorded the 10 minute checks that were carried out by nursing staff during a seclusion event. These forms noted the current observed physical and mental status of the patient at the time of the check and any cares carried out during the seclusion event.

It was anticipated that nursing documentation in the progress notes would provide information that would include precipitants for seclusion, attempts at de-escalation, events leading up to seclusion and the reasons for seclusion itself. Most of this information was available for each event and the progress notes often provided more depth of detail about the events than was available from the seclusion register and the seclusion recording form. 
Once completed, the audit form contained all the relevant information for each seclusion event: the patient's personal details, details of the seclusion event, and the reasons for seclusion. Information from three separate sources, the seclusion register, the progress notes and the seclusion recording form, meant I had three separate written commentaries on each event to utilise during the coding process.

Information gathered on the audit form was then transferred to two spreadsheets for each year. Information contained on the first spreadsheet related to each person placed in seclusion that year. This contained a numerical identifier, their date of birth, gender, ethnicity, and diagnosis. It also recorded the amount of time (in minutes) each person had spent in seclusion (total for the year regardless of number of seclusion events), and the number of times they had been in seclusion that year. The second spreadsheet related to each seclusion event in a particular year. It included a numerical identifier, their age, and their admission date. Information about the seclusion event included whether it occurred at admission, the date and day they were secluded, the time seclusion commenced, the amount of time (in minutes) spent in seclusion, their MHA status at the time of seclusion and any medication administered at the time of seclusion. There were two columns for coding and a comments column for any extra details noted about the event.

\section{Data ANALYsis}

Data collected from the audit of patient files was first analysed to provide a demographic and diagnostic profile of people who were placed in seclusion during the years investigated. Numerical data can demonstrate patterns or common themes from within the group. Part of the analysis of an audit is the need to count, something that is often seen as the antithesis of qualitative research. However, as Sandelowski (2001, p. 231) stated, “... numbers are integral to qualitative data, and skill with numbers is essential to good qualitative research ... numbers are used to establish the significance of a research problem, to document what is known about a problem, and to describe a sample.” 
Information related to the documented precipitants and reasons for seclusion was thematically coded according to the seven identified areas described by Johnson (1997). A full description of these themes is provided in Appendix L. Coding was achieved by considering the written reports taken from the seclusion recording form, the nurses' progress notes and the seclusion register. I then made an informed decision based on information available into which thematic code (1-7) each individual event fitted, and circled the number on the audit form. The codes were then entered onto the spreadsheet.

In order to provide a measure of internal validity, before coding the audit forms, I made a photocopy of each one. Approximately eight weeks later I repeated the coding procedure and then compared the results. Discrepancies were then reviewed and a final code decided upon.

\section{STAFF INTERVIEWS}

Six interviews with registered nursing staff were carried out. Criteria for participation in these interviews included that the staff member was a registered nurse and that each person had been involved in a seclusion event within the twelve months prior to the interview. Exclusion criteria were enrolled nurses as their scope of practice requires them to be under the direction and supervision of a registered nurse (Nurses Act 1977; Nursing Council of New Zealand, 1999).

Nursing staff were informed of this study when I led discussion of seclusion issues and provided information about the study at two staff meetings, and by a notice (Appendix M) on the nurses' office noticeboard requesting volunteers for the study. This notice asked nursing staff to approach me if they wished to take part in a oneto-one interview on seclusion issues.

Those people who approached me were given a copy of the information sheet (Appendix E) to take away and read, and I answered any questions that they had at that time. They were also invited to approach me again should they wish to take part. 
When people approached me to take part I invited them to nominate a time for the interview to take place. We also discussed where interviews should occur. They all opted for the interview to be carried out at their workplace.

At the appointed time I met with the participants and we discussed and completed the consent form (Appendix F). I then ensured the participants had the opportunity to ask any questions. Confidentiality issues and the use of an audiotape were also discussed. All participants agreed to have the interview audiotaped.

The interview format (Appendix N) was used to guide the interview. Each interview lasted approximately 30-40 minutes. At the end of the interview participants were asked if they had anything further they wanted to discuss. The procedure for transcribing the tapes and returning the transcripts for checking for accuracy was explained.

The audiotapes were transcribed by me and transcripts were returned to the participants for checking. Participants were asked to read the transcripts and return them to me within seven to ten days if they wished to make any amendments or alterations to the information. I did not receive any requests for changes to the transcripts and several participants commented that they were happy for me to continue with the information as it was.

\section{Data Analysis}

Transcripts from interviews were analysed and thematically coded. At the time of transcription and later, when reading and reviewing the transcripts, I noted key phrases and salient points in order to begin the process of analysis. An exploratory analysis of transcripts resulted in the identification of a number of themes and subthemes. Such themes were discovered by searching and identifying key words or phrases within each transcript, extracting these and the immediate context, and building theme files. In this way transcripts were then compared and contrasted to identify similarities or differences in the participants' viewpoints. 
The information obtained from the interviews was compared with the information obtained from the audit analysis and the congruency of the data sets assessed.

\section{Personal Journal}

During my clinical practice I have kept, on an intermittent basis, a personal journal that includes a record of my own involvement in some seclusion events, and I believe that these personal experiences add personal and contextual meaning to the study data. This information was recorded in my capacity as a staff member, and is a record of my impression of events as they occurred. As, at the time these events were recorded, I did not have the intention of carrying out this research, I believe that this information has as much relevance as a commentary and reflection of seclusion events as the information gathered from other staff members in the interviews for this study.

Benner (1984) argued that the process of reflection should become an ingrained part of nursing care and should underpin nursing practice. In this context, I see the central component to reflective practice as being the specific practice event that is experienced uniquely and differentially by one person or a small group of people. It is my belief that such reflection in mental health nursing is critical to practice, and is especially important in what should be regarded as an uncommon or unusual event such as seclusion.

One school of thought described reflection as a processing phase, a time for nurses to recapture an experience, think about it, mull it over and evaluate it (Boud, Keogh \& Walker, 1985). This, of necessity, occurred after the event. Johns (1998) however, saw reflective practice as a method whereby nurses could reflect on a situation and its meaning as it was happening. Johns believed that by having a deep sensitivity to the smooth running of an activity and a constant monitoring of the self within the situation it was like having an "internal supervisor" enabling conscious reaction and response to what is occurring. 
When considering reflection based on time, Evans (1997) offered his opinion that the two key times were past and future. His reasoning was that most good practice was derived from thinking before the practice event, and then it was necessary to allow sufficient time after an event for appropriate reflection. I believe that it is important that nurses, when involved in an immediate situation such as Johns (1998) described, do critically evaluate their actions and monitor the situation in a meaningful way throughout the process. However, I concur with Evans' statement that thinking and reflecting on situations both in the past and transferring that learning to that which may occur in the future is also important. When critically analysing and evaluating a seclusion event those persons involved may find themselves considering their inner doubts and dilemmas around seclusion practice in general and their experience of the particular incident in which they were involved. They need to have the opportunity to explore their reservations and develop responses to their inner dissonance that can then be applied to future events.

Important ways for nurses to discuss an event, to unburden themselves of their doubts, uncertainties and possible discomforts, and to explore and develop their understanding of seclusion events include personal supervision and staff debriefings. The requirement for staff debriefing following a seclusion event is contained in the local District Health Board's Service Provision Framework (2002) (Appendix A). However, it was my personal experience that this was often carried out in a perfunctory manner immediately following the placing of a person in seclusion when nursing staff had not had time to consider or inwardly process the event fully, or debriefing did not occur at all.

For this reason I found that producing a written record of an unusual experience or event was a time for me to consider and examine more deeply what occurred and gave me the opportunity to reflect and explore my thoughts and feelings. By examining aspects of my practice in this way, I believed I could gain further insight into seclusion issues with the aim of improving patient care through the delivery of more thoughtful and insightful nursing interventions.

Where my experiences were relevant to the material under discussion, I have therefore included a brief reflective description of the event. 


\section{Process Reflections}

A number of issues were raised for me during the process of this study. Because this study was carried out within my workplace, it proceeded alongside a quality project in the unit. I also continued to be an integral part of the nursing team in the in-patient unit for the four months during which I conducted the file audit and interviewed staff. Many people were aware of the study and showed a great deal of interest in it. I believe this had an impact on staff when they were considering the use of seclusion. They became more aware of their actions and thought more about the use of seclusion and whether it was appropriate or not.

When I was coding the reasons for seclusion, I found that I was very familiar with some of the events having been either directly involved or having been a party to discussion about them. I had to be careful not to put my personal interpretation on events and code them accordingly. I concentrated on ensuring the codes related only to the written information that described the event in the various documents and did not reflect my personal perception of the event where this differed from the written record.

During the interview phase I felt I gained a better understanding of how people thought and considered the use of seclusion. I was occasionally surprised that the seclusion events that had stood out for me were not necessarily the ones other people remembered. For the most part, people who were interviewed had similar views to my own about some local issues around seclusion use, but there were also revelations with people discussing things I had not considered or that they saw in a different light to me.

One of my initial concerns was that I would find it daunting interviewing people with whom I worked but this feeling was soon dispelled and people were generally willing to discuss the issues openly. I believe that, at times, there was some reticence in discussing personal issues they may have had with particular events or staff because of my connection with everyone involved. However, because people 
approached me to be interviewed, I believe this made the process easier than if I had made the initial approach.

\section{CONCLUSION}

The focus of this chapter has been on the process of carrying out the study and the issues that arose. An important part of any study is addressing those ethical concerns that need to be considered. In obtaining ethical approval I considered issues of privacy and confidentiality in accessing patient files, and the possible conflict between my roles as staff member, colleague and researcher. I considered the importance of the Treaty of Waitangi and Maori participants, and the position of service users.

The gathering of information for the file audit proved to be a challenge, in part because I became aware that there were a number of seclusion events unaccounted for in the main register. It is also possible that there were seclusion events documented in files but these events were not found and so they were not included in this audit. For this reason I believe that my findings are a conservative estimate of seclusion use. The results of this audit are contained in the next two chapters.

Staff interviews revealed the human side to seclusion use from a nursing perspective. Interviews were audiotaped and later transcribed by myself. Information gathered from these interviews is contained in Chapter Seven. I have also included my personal reflections on seclusion use in this chapter. 


\section{Chapter 5: Results - File Audit}

\section{INTRODUCTION}

A file audit of patients who had been involved in a seclusion event was conducted to ascertain seclusion use over a seven-year period, 1997-2003. A total of 104 files were audited. An earlier quality project that surveyed seclusion use had shown that there had been a large increase in the number of people secluded in the years 20022003 compared with previous years. Concerns were raised by management of the mental health service within which this research has been conducted about this increase. It was considered important, therefore, before undertaking further investigations into seclusion use, to determine how accurate the previous data was, as this had been obtained by taking the total use from the seclusion register records without any verification of its accuracy.

\section{FILE EXCLUSIONS}

Two files were excluded from the analysis as the people had not been diagnosed with psychiatric illnesses. Both people were in the end stages of an organic brain disorder and had been admitted to the unit because their aggressive behaviours could no longer be adequately managed in the available residential facilities in the region. At the time of each admission it was acknowledged that their placement in the unit was inappropriate as they did not meet the criteria for a psychiatric disorder. Admission was agreed to because of the lack of other facilities to meet each person's needs and to deal satisfactorily with their behaviours. This included the risk of harm to themselves through their behaviours, the risk of harm to unqualified staff who did not have the training or expertise to deal with aggression, the lack of training in deescalation skills among available staff in other facilities, limited professional input into appropriate or necessary medication regimes when rapid decisions needed to be 
made, and the lack of facilities to deal with aggressive outbursts. As the reason for admission to the unit was their potential for aggression, and the possibility of their behaviours being treated and cured through an improvement in their mental state was not an expected outcome, it was felt that including the data from these files would skew the results. The aggressive behaviours declined only as the people entered the end stages of their disease and became more physically compromised.

\section{OVERVIEW Of SECLUSION USE}

Once all the data were gathered, the overall use of seclusion was determined by totalling the number of events and determining the total time spent in seclusion each year. Table 1 below provides this information and the average time for each seclusion event. There is considerable variation in both the number of events and the time per event when the years are compared:

Table 1

Seclusion Events Per Year

\begin{tabular}{|l|c|c|c|c|c|c|c|c|}
\hline $\begin{array}{l}\text { Annual } \\
\text { Analysis }\end{array}$ & $\mathbf{1 9 9 7}$ & $\mathbf{1 9 9 8}$ & $\mathbf{1 9 9 9}$ & $\mathbf{2 0 0 0}$ & $\mathbf{2 0 0 1}$ & $\mathbf{2 0 0 2}$ & $\mathbf{2 0 0 3}$ & $\begin{array}{c}\text { 7-Year } \\
\text { Tally }\end{array}$ \\
\hline No. of events & 43 & 25 & 44 & 19 & 27 & 66 & 60 & 284 \\
\hline Total minutes & 21,480 & 28,975 & 36,815 & 27,665 & 34,135 & 52,725 & 50,210 & 252,005 \\
\hline $\begin{array}{l}\text { Average minutes } \\
\text { per event }\end{array}$ & 500 & 1,159 & 837 & 1,456 & 1,264 & 799 & 837 & 887 \\
\hline $\begin{array}{l}\text { Average hours } \\
\text { per event }\end{array}$ & 8.33 & 19.32 & 13.95 & 24.27 & 21.07 & 13.31 & 13.95 & 14.78 \\
\hline
\end{tabular}

The following graph (Figure 2 below) illustrates the difference between the reported total seclusion use for each year following the quality project in 2003 (survey data), and the present file audit (audit data): 


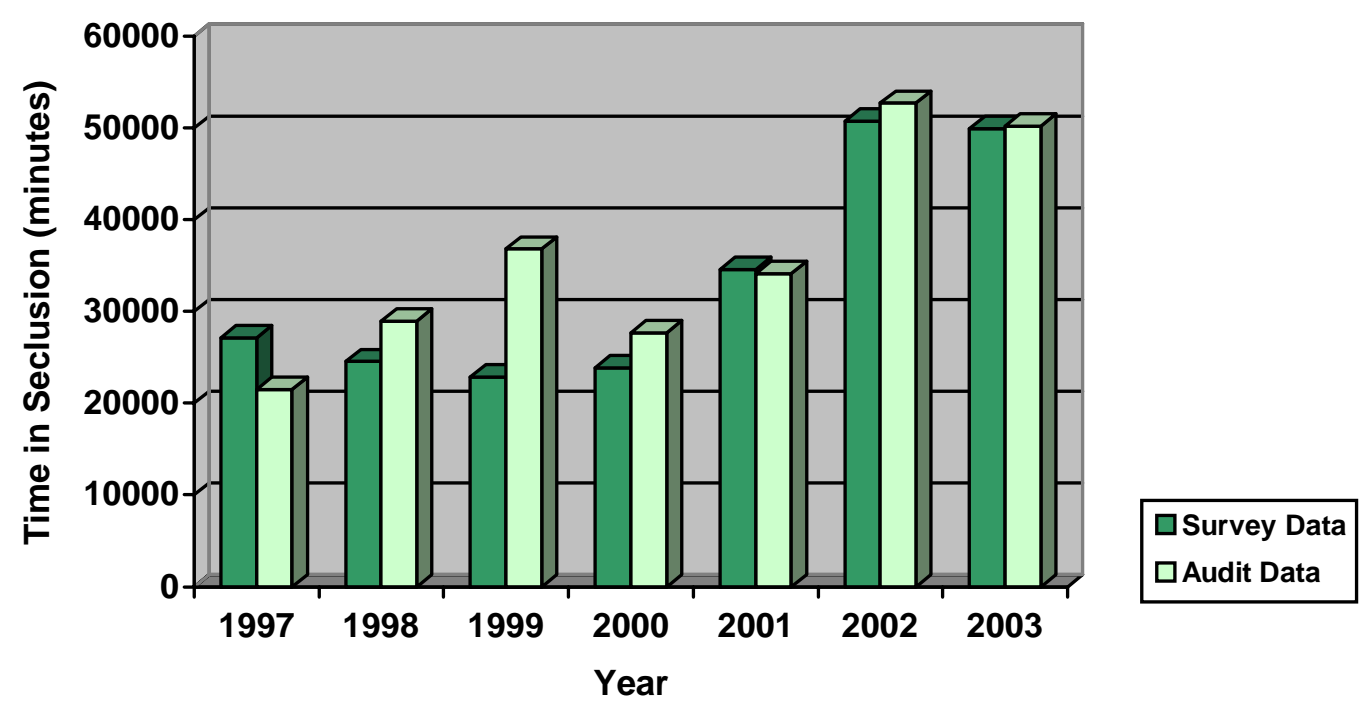

Figure 2: Comparison survey and audit data (in minutes)

This shows that the increase in seclusion in recent years is still present, but it is not as dramatic as previously believed. Actual numbers, with differences between the survey and audit data each year, are displayed in Table 2 below:

Table 2

Audit Data Compared with Survey Data

\begin{tabular}{|l|c|c|c|c|c|c|c|}
\hline \multicolumn{1}{|c|}{ Data } & $\mathbf{1 9 9 7}$ & $\mathbf{1 9 9 8}$ & $\mathbf{1 9 9 9}$ & $\mathbf{2 0 0 0}$ & $\mathbf{2 0 0 1}$ & $\mathbf{2 0 0 2}$ & $\mathbf{2 0 0 3}$ \\
\hline Survey & 27160 & 24550 & 22860 & 23885 & 34590 & 50760 & 49955 \\
\hline Audit & 21480 & 28975 & 36815 & 27665 & 34135 & 52725 & 50210 \\
\hline Difference & -5680 & +4425 & +13955 & +3780 & -455 & +1965 & +255 \\
\hline
\end{tabular}

In only two years are the audit data results lower than the survey data. In 1997 this is mainly due to the removal of one patient excluded from the data as reported above under the heading 'File Exclusions'. Other differences are the result of a combination of factors including inaccurate record-keeping and the omission of seclusion events from the seclusion register.

As the audit progressed, it was noted that the seclusion register often contained inaccurate recording of times of seclusion events commencing and concluding 
compared to that shown on actual observation sheets. The total recorded time of each event was also often inaccurate, a result of arithmetic errors. A count of the number of times the total time was reported inaccurately is shown in Table 3 below:

Table 3

Inaccurate versus Accurate Time Reporting

\begin{tabular}{|l|c|c|c|c|c|c|c|}
\hline \multicolumn{1}{|c|}{ Events } & $\mathbf{1 9 9 7}$ & $\mathbf{1 9 9 8}$ & $\mathbf{1 9 9 9}$ & $\mathbf{2 0 0 0}$ & $\mathbf{2 0 0 1}$ & $\mathbf{2 0 0 2}$ & 2003 \\
\hline No. of Events & 43 & 25 & 44 & 19 & 27 & 66 & 60 \\
\hline $\begin{array}{l}\text { Events inaccurately } \\
\text { recorded }\end{array}$ & 10 & 5 & 15 & 7 & 10 & 16 & 10 \\
\hline Percent inaccurate & 23.3 & 20.0 & 34.1 & 36.8 & 37.0 & 24.2 & 16.7 \\
\hline
\end{tabular}

In only the final year were the errors in recording total times below 20 percent of the number of events.

It was noted during the audit process, that there were a number of seclusion events not recorded in the seclusion register. As the keeping of this register is a mandatory requirement under the Mental Health (CAT) Act 1992 (MHA), this was a concern. Table 4 illustrates the number of seclusion events found during the audit that were not recorded in the register:

Table 4

Events Not Recorded in the Seclusion Register

\begin{tabular}{|l|c|c|c|c|c|c|c|c|}
\hline \multicolumn{1}{|c|}{ Events } & $\mathbf{1 9 9 7}$ & $\mathbf{1 9 9 8}$ & $\mathbf{1 9 9 9}$ & $\mathbf{2 0 0 0}$ & $\mathbf{2 0 0 1}$ & $\mathbf{2 0 0 2}$ & $\mathbf{2 0 0 3}$ & Tota \\
\hline Total Events & 43 & 25 & 44 & 19 & 27 & 66 & 60 & 284 \\
\hline Events not recorded & 9 & 5 & 7 & 0 & 1 & 4 & 0 & 26 \\
\hline Percent not recorded & 20.9 & 20.0 & 15.9 & 0 & 3.7 & 6.1 & 0 & 9.2 \\
\hline
\end{tabular}

There was a noticeable improvement in the recording of events in the seclusion register in the final four years compared to the first three years. However, one event not recorded in the register in 2002 was found when perusing a file during an enquiry unrelated to this research. As the audit only examined files where there was 
a known seclusion event and not all files of admissions to the unit, it is possible that there were other events that were also not found.

\section{Person Analysis}

The number of files analysed, and therefore the number of people involved in this study, was 102 (104 less the two files excluded from the study). However, as this study examined seclusion on an annual basis, the number of people events exceeded the number of files audited. Table 5 provides the numerical detail for this:

\begin{tabular}{|c|c|c|}
\multicolumn{3}{|c}{$\begin{array}{c}\text { Table } 5 \\
\text { Number of Years Each } \\
\text { Person Involved in Seclusion Events }\end{array}$} \\
\hline Years & No. Persons & Percent \\
\hline 1 & 85 & 83 \\
\hline 2 & 13 & 13 \\
\hline 3 & 3 & 3 \\
\hline 4 & 1 & 1 \\
\hline Total & $\mathbf{1 0 2}$ & $\mathbf{1 0 0}$ \\
\hline
\end{tabular}

While most people had only been involved in one or more seclusion events in any one year, 17 percent (17 people) had been secluded over two or more years usually on separate admissions. Where a person was secluded in more than one year, they were counted as a separate person in each year. Therefore, although 102 separate files were audited, there were 124 person events over the seven years.

Where a single seclusion event spanned two years (a person was in seclusion 31 December/1 January) the total for that event was calculated to midnight for one year, and the period after that was recorded in the next year. This ensured the total time seclusion was used was as accurate as possible for each year. 
When the number of people secluded each year was displayed graphically (see Figure 3 below), there appeared to be a rising trend in the data although it was not possible to make any firm assumptions because of the low overall numbers:

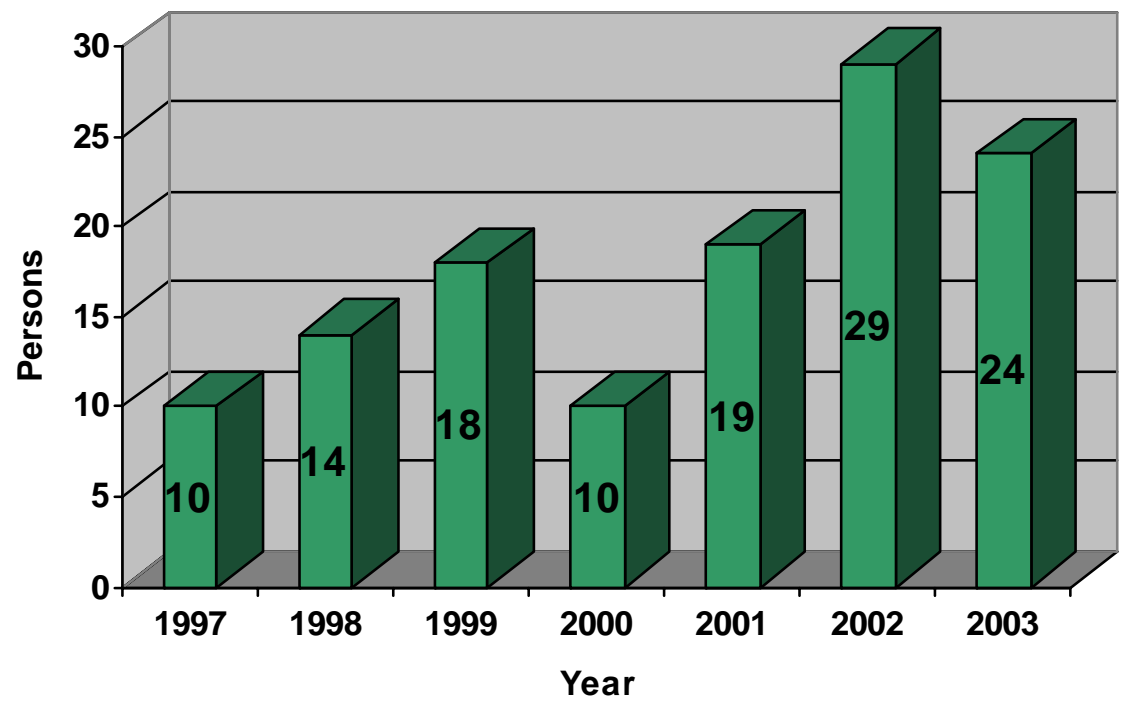

Figure 3: Number of persons secluded per year

Table 6 details the number of seclusion events for each person on a yearly basis:

Table 6

Number of Seclusion Events per Person per Year

\begin{tabular}{|l|c|c|c|c|c|c|c|c|}
\hline No. of Events & $\mathbf{1 9 9 7}$ & $\mathbf{1 9 9 8}$ & $\mathbf{1 9 9 9}$ & $\mathbf{2 0 0 0}$ & $\mathbf{2 0 0 1}$ & $\mathbf{2 0 0 2}$ & $\mathbf{2 0 0 3}$ & Total \\
\hline 1 & 4 & 8 & 9 & 8 & 14 & 20 & 15 & 78 \\
\hline 2 & 4 & 3 & 3 & 1 & 3 & 4 & 2 & 20 \\
\hline $3-5$ & 1 & 3 & 4 & 0 & 2 & 2 & 4 & 16 \\
\hline $6-10$ & 0 & 0 & 2 & 1 & 0 & 2 & 2 & 7 \\
\hline $11-20$ & 0 & 0 & 0 & 0 & 0 & 1 & 1 & 2 \\
\hline 20 or more & 1 & 0 & 0 & 0 & 0 & 0 & 0 & 1 \\
\hline Year Totals & $\mathbf{1 0}$ & $\mathbf{1 4}$ & $\mathbf{1 8}$ & $\mathbf{1 0}$ & $\mathbf{1 9}$ & $\mathbf{2 9}$ & $\mathbf{2 4}$ & $\mathbf{1 2 4}$ \\
\hline
\end{tabular}

Within each year, most people for whom seclusion was used, were only secluded once and 92 percent of people were secluded five or less times. It was, therefore, an unusual event for persons to be secluded more than five times. At the other end of 
the scale, the highest number of seclusion events recorded for one person was 26 in 1997, followed by 16 and 11 for the years 2002 and 2003 respectively.

Once the information related to the number of people and the number of times each person spent in seclusion over the years audited were assessed, the total amount of time people spent in seclusion for each year was examined and averaged on a per person basis for the year. This is detailed in Table 7:

Table 7

Seclusion Use per Person per Year

\begin{tabular}{|l|c|c|c|c|c|c|c|c|}
\hline $\begin{array}{l}\text { Annual } \\
\text { Analysis }\end{array}$ & $\mathbf{1 9 9 7}$ & $\mathbf{1 9 9 8}$ & $\mathbf{1 9 9 9}$ & $\mathbf{2 0 0 0}$ & $\mathbf{2 0 0 1}$ & $\mathbf{2 0 0 2}$ & $\mathbf{2 0 0 3}$ & $\begin{array}{c}\text { 7-Year } \\
\text { Tally }\end{array}$ \\
\hline $\begin{array}{l}\text { No. of people } \\
\text { Secluded }\end{array}$ & 10 & 14 & 18 & 10 & 19 & 29 & 24 & 124 \\
\hline \begin{tabular}{l} 
Total minutes \\
\hline
\end{tabular} & 21,480 & 28,975 & 36,815 & 27,665 & 34,135 & 52,725 & 50,210 & 252,005 \\
\hline $\begin{array}{l}\text { Average minutes } \\
\text { per person }\end{array}$ & 2,148 & 2,070 & 2,045 & 2,767 & 1,797 & 1,818 & 2,092 & 2,032 \\
\hline $\begin{array}{l}\text { Average hours } \\
\text { per person }\end{array}$ & 35.80 & 34.49 & 34.09 & 46.11 & 29.94 & 30.30 & 34.87 & 33.87 \\
\hline
\end{tabular}

When the average time each person spent in seclusion was shown graphically (see Figure 4), it was apparent that the year 2000 stood out as a time when people were contained in seclusion for much longer than in other years, an increase of more than 10 hours (600 minutes) per person: 


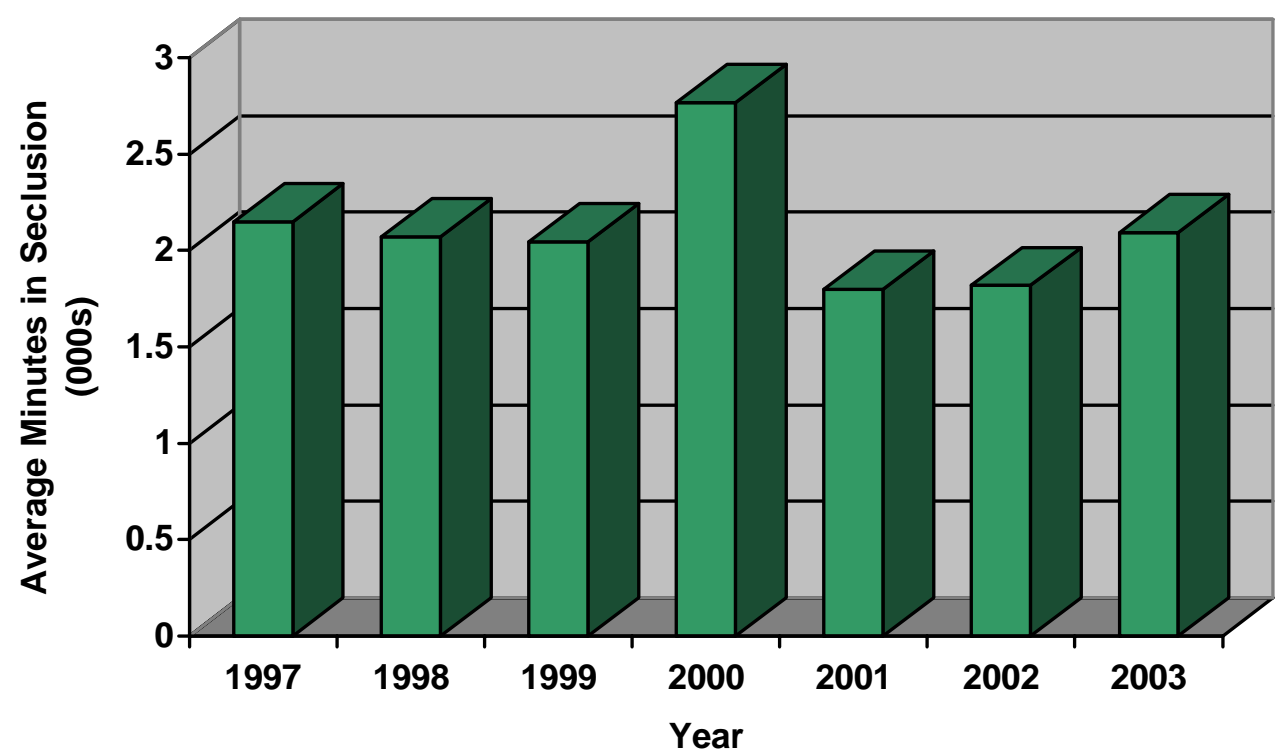

Figure 4: Average time spent in seclusion each year

The data were also analysed according to the total length of time each person spent in seclusion each year. Table 8 shows this:

\section{Table 8}

Time Spent in Seclusion in Minutes

\begin{tabular}{|c|c|c|c|c|c|c|c|c|}
\hline Time (Minutes) & 1997 & 1998 & 1999 & 2000 & 2001 & 2002 & 2003 & Total \\
\hline$<100$ & 0 & 0 & 2 & 0 & 0 & 2 & 1 & 5 \\
\hline $100-249$ & 0 & 2 & 3 & 1 & 2 & 1 & 2 & 11 \\
\hline $250-499$ & 2 & 2 & 1 & 0 & 4 & 3 & 1 & 13 \\
\hline $500-999$ & 4 & 4 & 3 & 1 & 3 & 9 & 2 & 26 \\
\hline 1,000-1,999 & 3 & 5 & 3 & 4 & 5 & 6 & 10 & 36 \\
\hline $2,000-4,999$ & 0 & 0 & 3 & 3 & 4 & 6 & 6 & 22 \\
\hline $5,000-9,999$ & 0 & 0 & 3 & 0 & 0 & 2 & 2 & 7 \\
\hline $10,000+$ & 1 & 1 & 0 & 1 & 1 & 0 & 0 & 4 \\
\hline Total & 10 & 14 & 18 & 10 & 19 & 29 & 24 & 124 \\
\hline
\end{tabular}

The time ranged from a minimum of five minutes to 17,485 minutes (over 291 hours) for one person. This latter time occurred over three separate seclusion events. 


\section{DEMOGRAPHIC DATA}

The demographic details recorded during the file audit were gender, ethnicity, and age at each seclusion event. Full data tables are included in Appendix O (Tables A.1, A.2, and A.3 respectively).

\section{Gender}

The distribution according to gender for each year is shown in the graph below (see Figure 5). The number of males and females involved in a seclusion event over the seven year period were equal at 62 each, therefore no gender differences were found in the use of seclusion in this study:

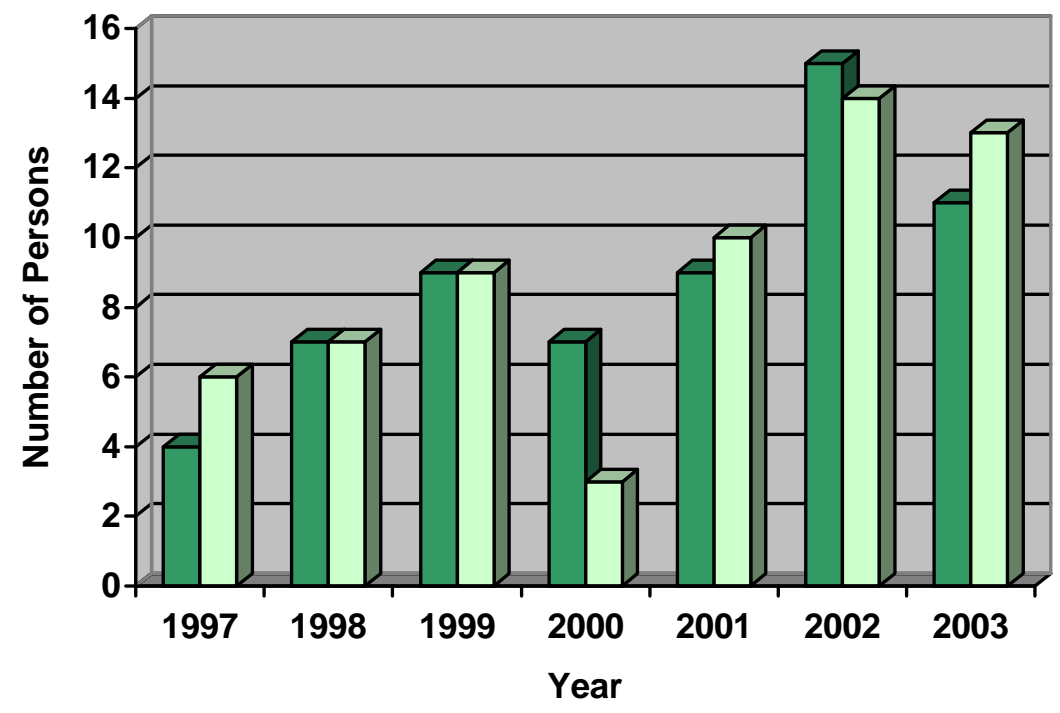

Figure 5: Gender distribution per year

\section{Age}

The age of people secluded ranged from 17 to 84 years. The graph below (Figure 6) illustrates clearly that the people most likely to be secluded were aged 20-29 years with a steady decrease in seclusion rates as people got older: 


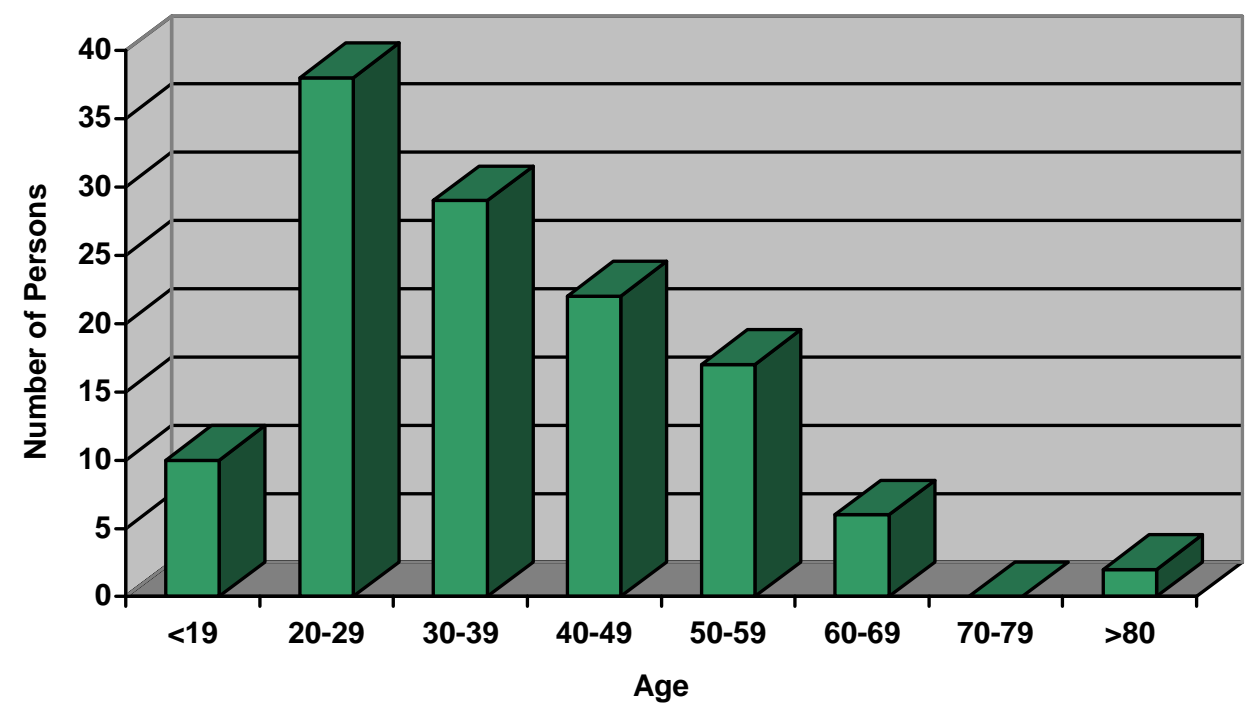

Figure 6: Age distribution for total seclusion events

As this was an adult unit, people under 20 years old were aged 17-19. If the number in this three year age group was extrapolated to 10 years then the number of people secluded would approximate that of the next age group.

\section{Ethnicity}

The ethnicity of people involved in seclusion events was obtained from admission information and reflected the predominantly European population of the area. Close to 89 percent (110 people) were recorded as New Zealand European with nine percent (11 people) recorded as Maori. The remaining three people were from the Middle East, the Pacific Islands and Australia (see Figure 7 below): 


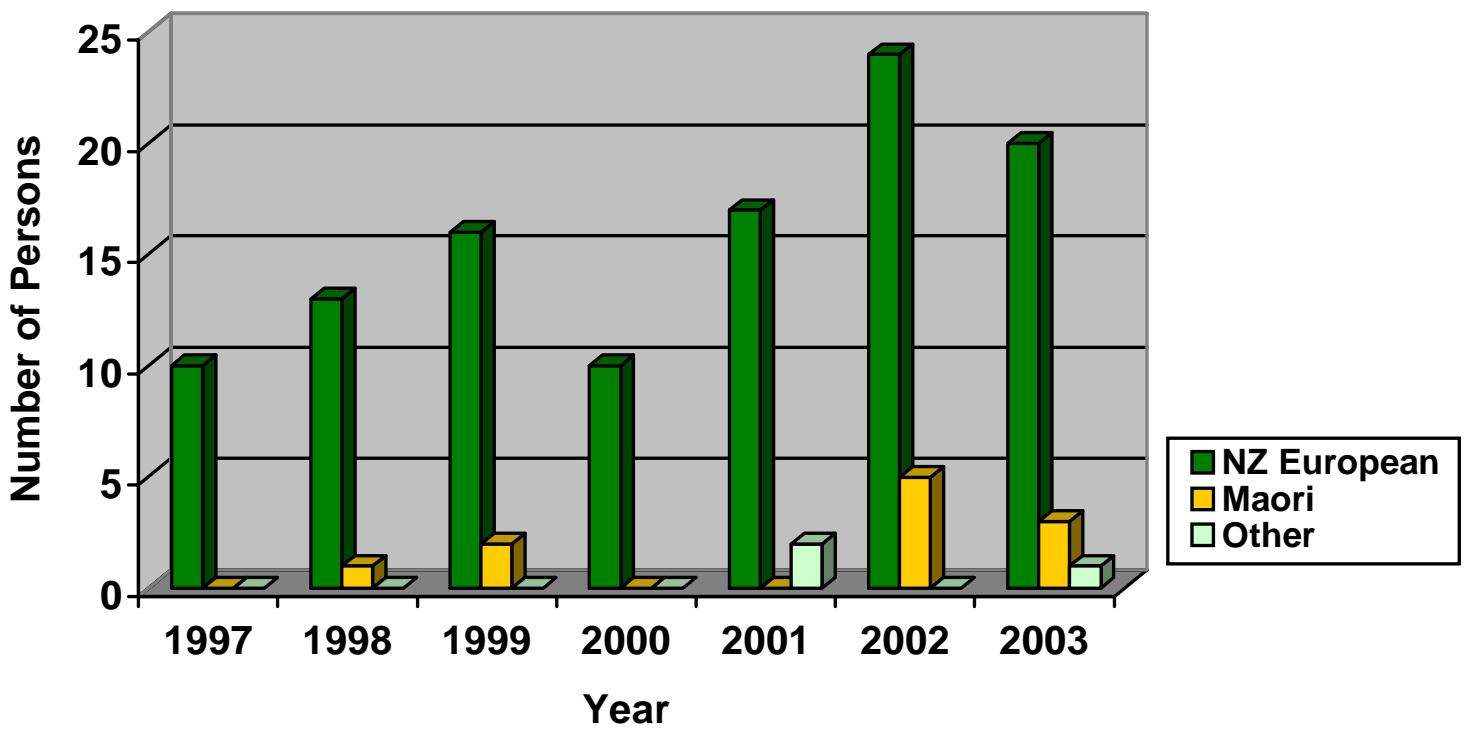

Figure 7: Ethnicity distribution each year

\section{CLINICAL INFORMATION}

During the audit, clinical information obtained included the psychiatric diagnosis for each person, medications administered at the time of the seclusion event and the MHA status of each person. Tables presenting the following information on an annual basis are attached as Appendix O (Tables A.4, A.5 and A.6 respectively).

\section{Diagnoses}

The psychiatric diagnosis for each person in this study was collected from the discharge summaries completed at the end of each admission. The data is displayed in the following pie graph (Figure 8): 


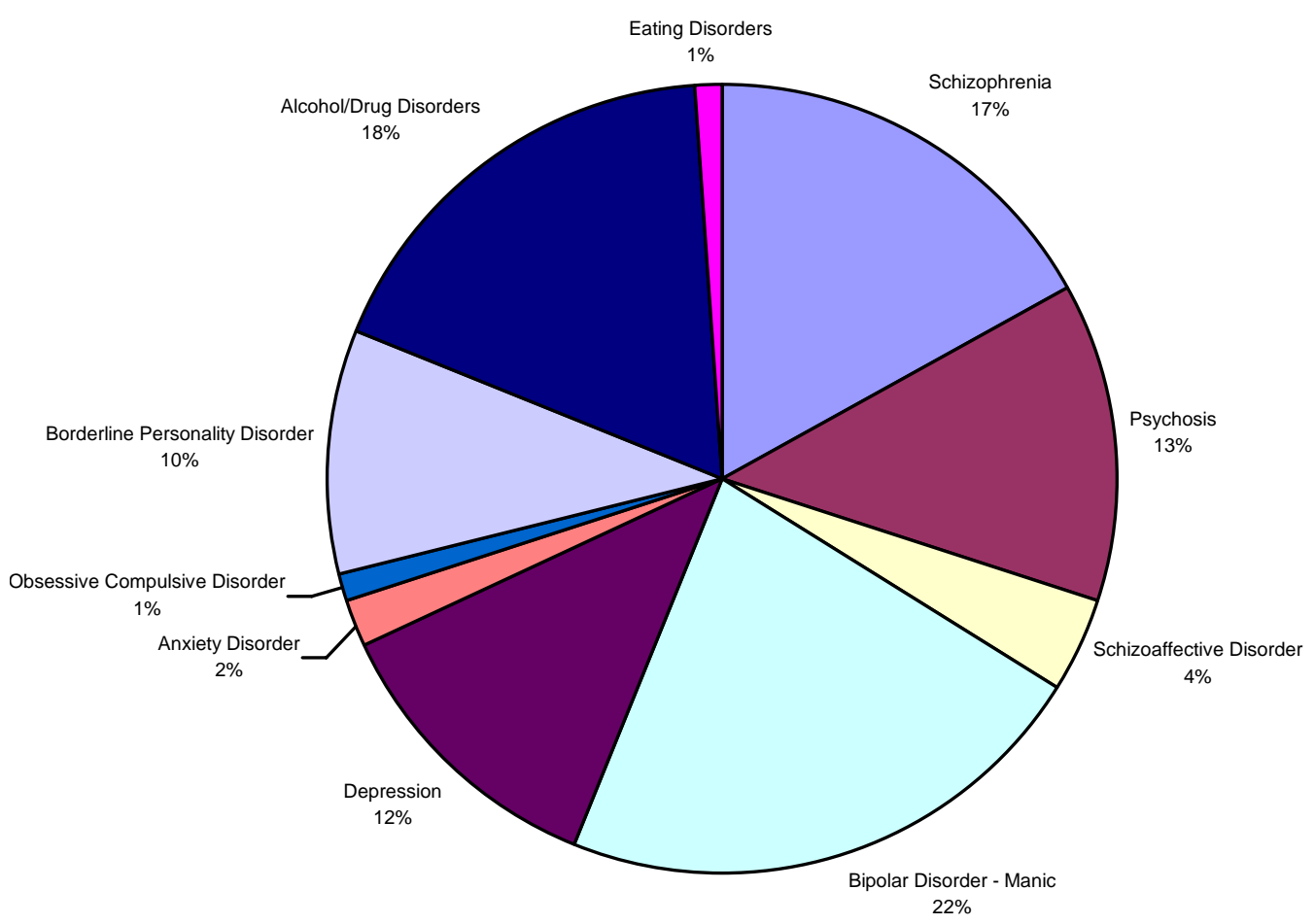

Figure 8: Diagnosis at discharge

The three largest groups, those which represented people with schizophrenia, bipolar disorder (manic episode) and alcohol and drug diagnoses, made up 57 percent, or more than half of all people secluded within the audit period. Thirty-five people had a dual diagnosis and two people had three psychiatric diagnoses. Of those with comorbid diagnoses, 24 had a second diagnosis of alcohol or drug abuse or dependency, and a further six people had a diagnosis of major depression with psychosis.

\section{Emergency Medication}

Medication administered was generally an anti-psychotic or a benzodiazepine. The purpose of this medication was for calming, sedation and anti-psychotic effects during an emergency or crisis situation, most often when a person was first secluded. The information presented here does not include regular medications that a person may have been given during a seclusion event. Emergency medication was used 116 times over the 284 seclusion events audited. This represented 41 percent of all 
seclusion events. The following graph (Figure 9) illustrates the various medications utilised and their frequency:

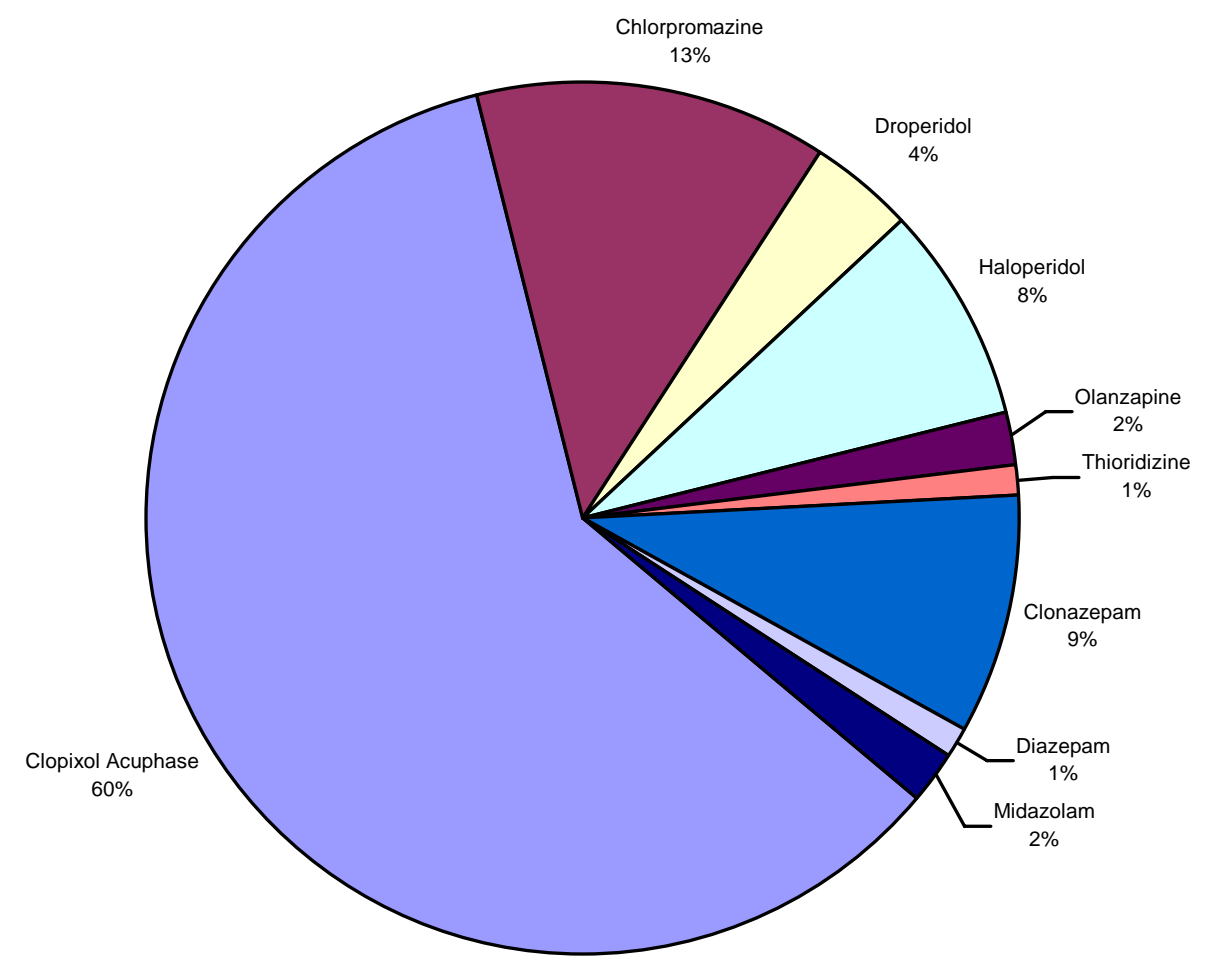

Figure 9: Emergency medication administered

The medication that was most often used was Clopixol Acuphase (zuclopenthixol acetate), an injectable anti-psychotic with an onset of action within 2-4 hours. Maximum serum concentrations are reached, on average, 24-36 hours after injection, followed by a gradual decline, with a duration of action of 2-3 days following a single intramuscular injection (Drug Monograph: Zuclopenthixol, 2001).

Medication was used in combination on rare occasions: 15 times over the seven year period or in 11 percent of all medication administrations. 


\section{The Mental Health (CAT) Act 1992}

Seclusion may only be used if a person is being held involuntarily under the MHA. The following graph (Figure 10) details the sections of the Act that people were held under at the time of the seclusion event:

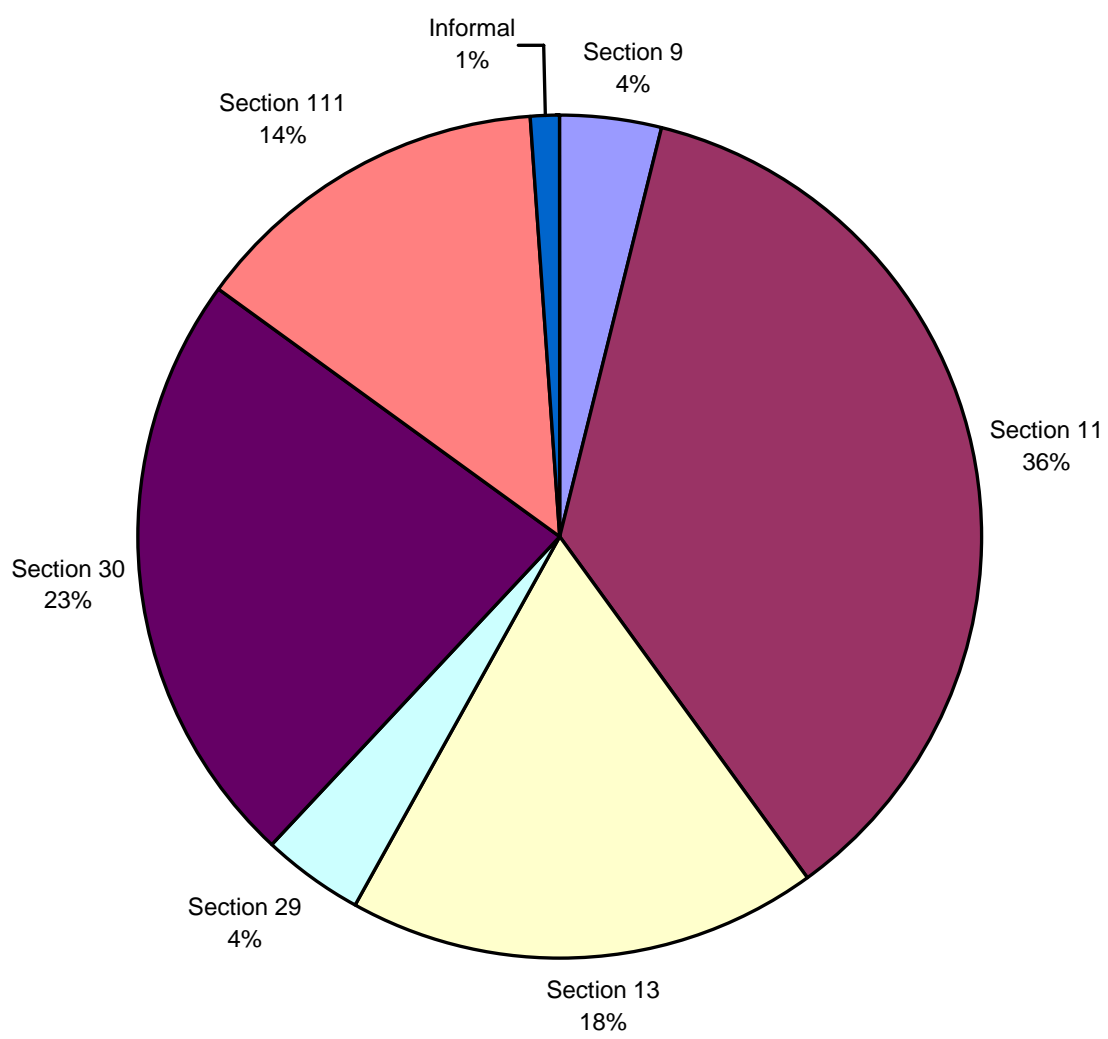

Figure 10: Mental Health (CAT) Act 1992 status at time of seclusion

Over half (58\%) of seclusion events occurred while the person was on Sections 9, 11 and 13 of the MHA. These are the sections of the MHA used during the initial compulsory assessment and treatment phases. A further 14 percent of events occurred when an informal patient was held under Section 111, which sets out the powers of a registered nurse where an urgent assessment of a patient is required. On one occasion a person was held in seclusion under Section 111 for over 13 hours. This was in contravention of the MHA which states that: "no person shall be detained under this section for more than 6 hours from the time when the nurse first calls for a medical practitioner to examine the person” (Section 111(3)). 
In four instances, the person was not being held under the MHA at the time of the seclusion event. These instances were also in contravention of the legislation. On one occasion there was no record of the relevant papers on the person's file, possibly because the papers went with the person when transferred to another centre. In 2002 there were three instances of an informal patient being secluded. Two events occurred on the same day with the same person who had previously been held for assessment and treatment on Section 11. This section had lapsed at the time of the seclusion events and the MHA process was restarted the following day once the error had been detected. The final event occurred in the same year when a person was held in seclusion for a short period (40 minutes). It was unclear from the file why the MHA had not been commenced.

\section{Admissions and Seclusion}

Occasionally, a person was admitted to the unit directly into seclusion. The following table details the number of admissions that resulted in an immediate seclusion event and compares this to the number who were secluded after a period of time had elapsed following admission. The number of admissions is higher than the actual number of people secluded as some had two or more admissions:

Table 9

Seclusion Event Occurring at Admission

\begin{tabular}{|l|c|c|c|c|c|c|c|}
\hline \multicolumn{1}{|c|}{ Description } & $\mathbf{1 9 9 7}$ & $\mathbf{1 9 9 8}$ & $\mathbf{1 9 9 9}$ & $\mathbf{2 0 0 0}$ & $\mathbf{2 0 0 1}$ & $\mathbf{2 0 0 2}$ & $\mathbf{2 0 0 3}$ \\
\hline Total no. people secluded & 10 & 14 & 18 & 10 & 19 & 29 & 24 \\
\hline Number of admissions & 11 & 15 & 22 & 10 & 22 & 33 & 27 \\
\hline Number secluded at admission & 4 & 6 & 7 & 5 & 8 & 15 & 15 \\
\hline Percent secluded at admission & 36.4 & 40.0 & 31.8 & 50.0 & 36.4 & 45.5 & 55.6 \\
\hline
\end{tabular}

From the above table, therefore, seclusion was initiated at the time of admission for one-third to one-half of all people with a seclusion event. 


\section{SECLUSION EVENT ANALYSIS}

Two further ways in which seclusion events were analysed in the literature were by day of the week and by time of day. Full tables showing the annual data for these details are attached in Appendix O (Tables A.7 and A.8).

\section{Day of the Week}

The day of the week seclusion events commenced for the total audit period are shown in the graph below:

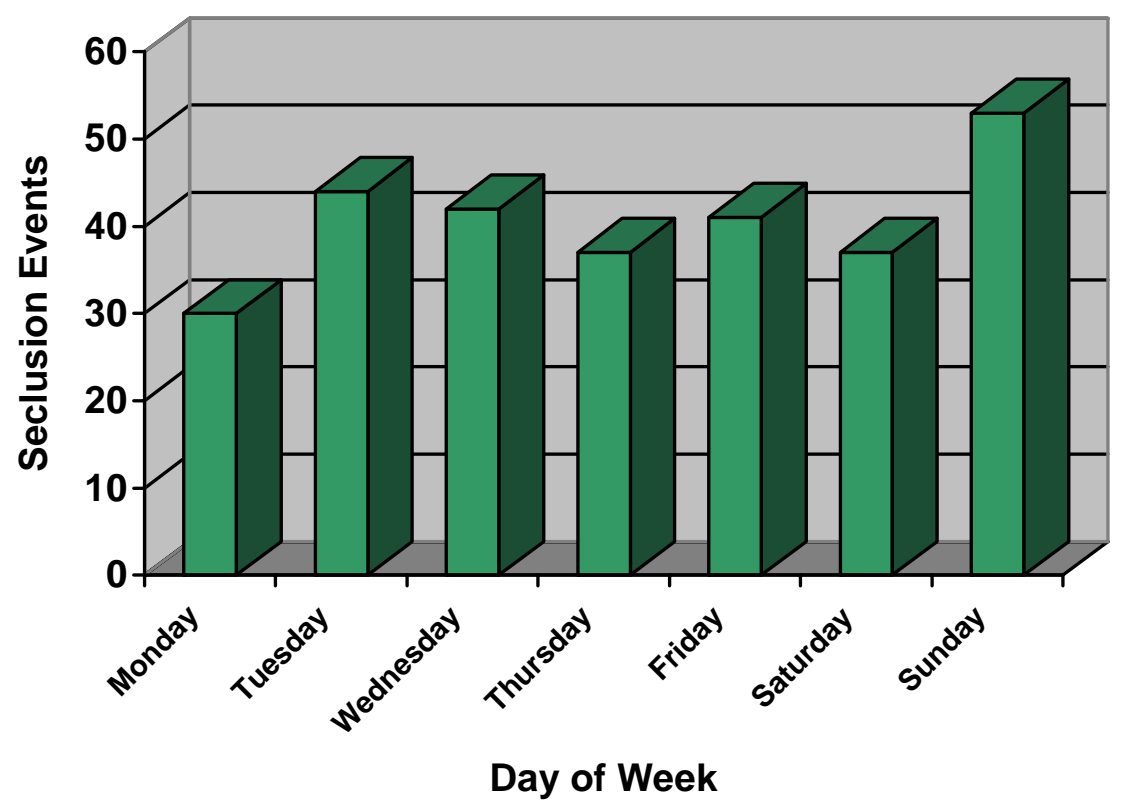

Figure 11: Seclusion events by day of the week

If seclusion events were divided evenly over the seven days then 40-41 events would have occurred each day. The Monday total of 30 events is well below this, and this is balanced out by the high number of events (53) occurring on Sunday. Other days approximate the expected average. 


\section{Time of Day}

Events were analysed over the seven year period according to the time of day they occurred. The results are displayed graphically below:

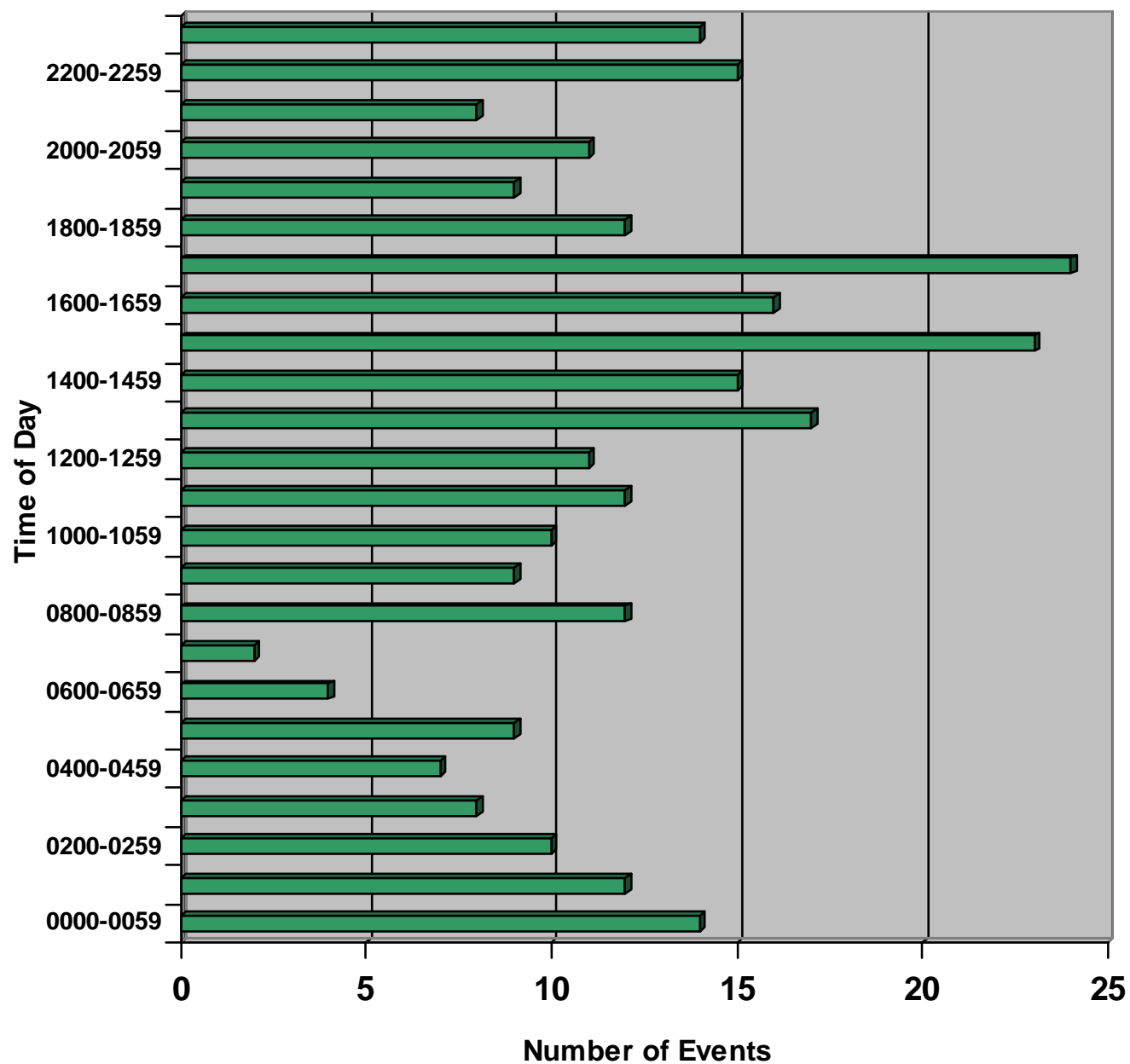

Figure 12: Time of day for seclusion events

The most crucial time of day for seclusion events appeared to be the afternoon between the hours of $1.00 \mathrm{pm}$ and $6.00 \mathrm{pm}$. This was followed by late evening between the hours of $10.00 \mathrm{pm}$ and $1.00 \mathrm{am}$. 


\section{CONCLUSION}

This chapter comprises the results of a file audit of seclusion events over a seven year period 1997-2003. Information analysed included the number of people involved in seclusion events, the number of seclusion events themselves and the time seclusion was utilised, analysed by both the people involved and individual events over the audit period. No clear pattern of use emerged during this analysis.

When the people involved in seclusion events were compared by age there was a clear and marked decrease in use as people aged. Comparison by ethnicity showed most people were of New Zealand European origin, a factor related to the population distribution of the area. Seclusion was utilised equally for both males and females. Clinical indicators analysed included diagnosis, emergency medications administered and MHA status. The majority of people who were secluded were suffering a psychotic disorder or experiencing a manic episode, while alcohol and illicit drugs also played a large part. Clopixol Acuphase was the medication of choice for emergency administration. Most people secluded were in the early stages of assessment and treatment under the Mental Health Act.

The seclusion events themselves were analysed according to day of the week and time of day. Sundays had more seclusion events occurring than any other day, with Monday having the lowest number. Afternoons and late evenings were the peak times for people being secluded.

During the file audit, information related to the reasons for seclusion was gathered. The results from this part of the audit are contained in the next chapter of this report. 


\section{CHAPTER 6: RESULTS - RATIONALE FOR SECLUSION}

\section{INTRODUCTION}

For any seclusion event the major question that must be asked is why was seclusion deemed necessary, or what was the justification for its use? The previous chapter described who is put in seclusion, how many times and for how long seclusion is used. This chapter will look at the findings of the file audit regarding the reasons or rationale for seclusion use.

There are strict controls on the use of seclusion. It should be used only when all other alternative, practical interventions have failed. The following box outlines the standards for seclusion use according to the New Zealand standard for restraint minimisation and safe practice:

\footnotetext{
(a) The control of violent behaviour occurring during the course of a psychiatric illness which cannot be adequately controlled with psychosocial techniques and/or medication;

(b) Disturbance of behaviour as a result of marked agitation, thought disorder, severe confusion, hyperactivity or grossly impaired judgement;

(c) To reduce the disruptive effects of external stimuli in a person who is highly aroused due to their illness;

(d) To prevent violent or destructive behaviour, using specific indicators of impending disturbance which may be identified by either the individual or the staff, and which should wherever possible be part of an agreed management plan.

Standards New Zealand (2001, p. 34)
}

If seclusion use is to be reviewed against the standards, then a checklist to focus the activity onto specific aspects of a person's characteristics, behaviour or functioning is needed to decide why seclusion was utilised. It is also important that safeguards are in place to ensure seclusion events are minimised and that people are released from seclusion as soon as it is appropriate to do so. 
Johnson (1997) formulated a review checklist to focus on those aspects considered important in deciding whether to continue or terminate a seclusion event within a special hospital in the United Kingdom. He developed this checklist by reviewing the literature to identify factors associated with the decision to initiate seclusion, by surveying colleagues to identify what factors they recognised as being important, and by identifying the weight of importance attached to each factor in the decision to continue or discontinue seclusion.

Seven themes were identified that Johnson (1997) then broke down into smaller component factors or items. These are set out in Appendix L. These themes have been used to determine the reasons for seclusion use from the descriptions obtained during the file audit conducted for this study.

\section{REASONS FOR SECLUSION}

Seclusion is used for particular aspects of patient behaviour, characteristics or areas of functioning that give rise to concern about the safety of the patient, other people in the immediate environment and staff. The seven themes Johnson (1997) identified were violence and the threat of violence; agitation, frustration and self-control; cognitive processes and functioning; mood and affective functioning; comprehension and understanding; conformity and compliance; and external variables.

During the file audit, the description of each seclusion event was obtained from three separate sources of information: the seclusion register, the seclusion recording form and the nursing progress notes. This information was used to decide within which theme the event best fitted. All the seclusion events were coded according to the seven available themes and recoded eight weeks later. Discrepancies were found between the first and second coding for 21 percent of all events. After carefully considering the available information, a final decision was made on the most appropriate code for these events. 
The following table sets out the reasons for seclusion use during the seven years of the file audit:

Table 10

Reasons for Seclusion

\begin{tabular}{|c|c|c|c|c|c|c|c|c|c|}
\hline Code & Description & 1997 & 1998 & 1999 & 2000 & 2001 & 2002 & 2003 & Total \\
\hline 1 & $\begin{array}{c}\text { Violence, threat of } \\
\text { violence }\end{array}$ & 15 & 14 & 26 & 9 & 11 & 40 & 29 & 144 \\
\hline 2 & $\begin{array}{c}\text { Agitation, } \\
\text { frustration, loss of } \\
\text { control }\end{array}$ & 23 & 6 & 4 & 5 & 4 & 7 & 15 & 64 \\
\hline 3 & $\begin{array}{l}\text { Cognition and } \\
\text { functioning }\end{array}$ & 3 & 1 & 3 & 3 & 6 & 5 & 3 & 24 \\
\hline 4 & $\begin{array}{l}\text { Mood and affective } \\
\text { functioning }\end{array}$ & 2 & 4 & 9 & 2 & 1 & 6 & 2 & 26 \\
\hline 5 & $\begin{array}{l}\text { Comprehension and } \\
\text { understanding }\end{array}$ & 0 & 0 & 2 & 0 & 4 & 5 & 11 & 22 \\
\hline 6 & $\begin{array}{l}\text { Conformity and } \\
\text { compliance }\end{array}$ & 0 & 0 & 0 & 0 & 1 & 2 & 0 & 3 \\
\hline 7 & External variables & 0 & 0 & 0 & 0 & 0 & 1 & 0 & 1 \\
\hline Total & & 43 & 25 & 44 & 19 & 27 & 66 & 60 & 284 \\
\hline
\end{tabular}

Each of the themes identified by Johnson (1997) is now described individually, and the results of this study when compared with these themes are discussed.

\section{1: ViolenCE AND THE THREAT OF ViOLENCE (AgGRESSiON)}

The primary reason for the use of seclusion has been identified as a response to
violence. The threat of violence is seen as a valid and important criteria for its use.
The use of seclusion has been identified as relating directly to the perception of
personal threat, and nursing staff use seclusion because they perceive themselves or
others to be under threat, usually in the case of actual or threatened violence. Johnson (1997, pp. 29-30)

Slightly more than half the events (51 percent) were categorised within this theme. Events that contained evidence of actual physical violence towards a person or to property, where there were threats to harm either a person or property, or where there was verbal aggression, abuse and/or hostility, were included here. Exceptions to this were less severe incidents where the primary reason was, for example, to abscond 
from the unit and there may have been some property damage during the process of attempting to leave.

The following are quotes from seven separate incidents taken from the seclusion documentation descriptions of behaviours leading up to the seclusion events categorised here:

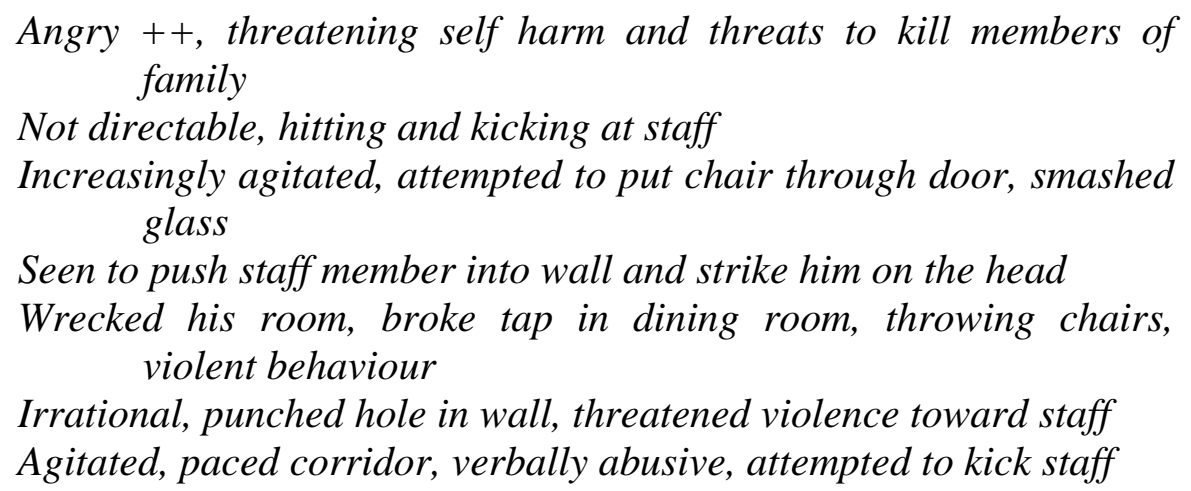

The above descriptions indicated that violence and the potential for violence was very real within the in-patient unit and that nursing staff were at risk from people presenting with unstable mental states. People with schizophrenia and bipolar disorder were the main users of seclusion in this category, followed by people with substance abuse and borderline personality disorder.

\section{2: Agitation, Frustration ANd Coping SKILls (ANXIETy)}

Agitation can cover many aspects of mental state and physical behaviour. Some aspects include motor agitation, irritability, loud and pressured speech, demanding behaviour, anxiety, euphoria, anger, lability of affect, memory impairment and disorientation. Agitation has also been recognised as a potential precursor to violence. Seclusion may be used to enable the restoration of self-control. Key indicators of selfcontrol are the ability to tolerate frustration, the ability to control impulses and a willingness to agree to contractual behaviours.

Johnson (1997, p. 31)

Johnson (1997) discussed the concepts of agitation, restlessness, tension and irritability as potential precursors to violence. He did not explicitly consider other aspects of behaviour that have been important in deciding on seclusion use in the unit that is the focus of this study. These behaviours included disruption to the 
milieu, dangerous acts to self, deliberate self harm and absconding from the unit. Unless specifically related to cognitive, perceptual or affective processes which are discussed below, these behaviours have been included in this category.

Seclusion events placed in this category number 64, or 23 percent of all events in this study. The following nine quotes from separate incidents taken from the seclusion documentation descriptions are a representative sample of the behaviours encountered:

Anxious, pacing, strong suicidal thoughts, wanting to smash window and cut throat

Preoccupied, anxious, agitated. Unable to gain control

To maintain safety, wanting to cause harm to self and self-discharge Attempted to strangle self with ripped counterpane

Missing from ward, had been in sea, unable to be contained

Disruptive behaviour, slamming doors, yelling in corridor, unable to maintain set boundaries

Wants to die, agitated, unable to give assurance of safety, wanting to leave

Repeated attempts to abscond, searching for something to cut self with

Safety concerns following suicide attempt after absconding from ward

Diagnoses for people involved in these seclusion events covered the spectrum of major mental disorders, personality disorders, and substance abuse and dependency.

\section{3: Cognitive Processes And Functioning (Cognition)}

Active symptoms of severe mental illness can increase the risk of violence. Those experiencing symptoms such as delusions and hallucinations have been involved in violence. The presence of psychosis should make one take threats of violence very seriously and makes the assessment of violence potential essential.

Johnson (1997, p. 32)

According to Johnson (1997) many studies suggested that people with schizophrenia could become violent during the acute phases of their illness when they were actively experiencing delusions and hallucinations. Further, they were overly represented in groups of patients who were violent toward other people just before 
and/or during psychiatric hospitalisation. It is important, therefore, to continually assess people in the active phase of their illness for the presence of delusions, hallucinations, odd or bizarre thought patterns, suspiciousness and paranoia.

The number of seclusion events in this category was 24 or 8.5 percent of all events. Most people had a schizophrenic illness, with one person experiencing a psychotic depression and another person experiencing a manic episode with psychosis. The following are quotes from six separate incidents taken from the seclusion documentation descriptions and detail reasons for seclusion associated with specific behaviours related to psychosis:

Acting on delusions, voices telling him to leave the ward Believes has bug in stomach (microphone) has cuts to abdomen in attempt to remove same

Angry gestures, pacing, paranoid ideation re being murdered on ward

Threw table through a window then jumped through the window believes all nursing staff "should be in hell"

Hallucinating ++ , agitated, believes he is the devil and dead, feeling unsafe and afraid

Suspicion, mistrust of staff, intimidating, increasingly deluded, intent to leave ward

The above examples illustrate that people in the acute phase of a psychotic illness are a risk to themselves as well as to other people. This group of people also had longer stays in seclusion than those in other categories. The percentage of events where the length of stay in seclusion was greater than 1000 minutes was 30 percent overall compared to 67 percent of events in this category. 


\section{4: Mood and Affective Functioning (Mood)}

Manic and hypomanic patients can become hostile and violent when faced with sensory overload. Introducing a low stimulus environment or the removal from frustrating social interactions can help a patient regain the ability to tolerate incoming stimuli. Euphoria, irritability and lability in affect may indicate that a patient is having difficulty maintaining control.

Johnson (1997, p. 33)

People with mania and hypomania are easily aroused, hyperactive, have a loosening of boundaries and often become physically agitated in response to frustrating social interactions and high sensory input. This can lead to disturbed and violent behaviour (Johnson, 1997). When people become over-stimulated and their level of arousal cannot be decreased by other de-escalation techniques, then seclusion may become an option to introduce an enforced low stimulus environment.

This category represented nine percent of all seclusion events in this study. People involved in these seclusion events had all been diagnosed with schizoaffective disorder or bipolar disorder (manic episode). Common reasons for seclusion use as documented in the files were aimed mainly at providing a low stimulus environment and promoting a person's dignity. The following are quotes from six separate incidents taken from the seclusion documentation descriptions of behaviours leading up to the seclusion events:

Requires low stimulus for safety of self and others as acutely manic and agitated

At risk as behaviour disinhibited, actively seeking male company, provocative

For own dignity, going into other peoples' rooms and through their personal effects

Increasingly unsettled, said would stay awake all night, low stimulus environment to promote sleep

Throwing food about unit, inappropriately touching clients and staff

Labile in mood, laughing, yelling, tearful, flight of ideas and rapid speech

Mood remains elevated, remains impulsive, verbally abusive and unable to follow direction

There were difficulties in establishing appropriate sleep patterns and maintaining a low stimulus environment, particularly in the evening and through the night, for 
people who were manic. This was demonstrated when the rates of seclusion were compared for people in this category and the overall rates of seclusion between the hours of $8.00 \mathrm{pm}$ and $5.00 \mathrm{am}$. The overall percentage of all seclusion events was 35 percent between these hours, but for people in this category the rate was 77 percent.

\section{5: CoMprehension, Understanding ANd FeElings (PERCEPTIONS)}

Psychotic disorganisation and disorientation can give rise to agitation, reducing a patient's understanding and awareness. Current perceptions and comprehension are relevant or potentially important in determining future short-term behaviour.

Johnson (1997, p. 34)

Understanding and awareness can be potentially important in influencing a person's behaviour. If a person does not understand the behaviours expected, feels restricted by behaviours deemed acceptable and does not understand the impact of their behaviour on other people in the environment, then their actions may be intrusive, inappropriate and they may pose a safety risk to themselves.

Eight percent of seclusion events (22) were classified as being a result of a perceptual disturbance. The most common diagnostic reasons for this were due to the onset of a psychosis induced by stress, substance abuse, or other unspecified reactive or functional psychoses. This resulted in persons being disinhibited, confused, distressed, being unable to comprehend or retain information and lacking insight into their situation. People needed to be secluded for their own safety and to maintain their dignity and self-respect. Four typical examples from separate incidents taken from the seclusion documentation descriptions of behaviours leading up to the seclusion events are:

Disinhibited sexually, wanting to take clothes off, unable to be redirected

Danger of exposure and physical collapse due to standing in rain, soaking wet, not willing to come inside

Agitated with odd behaviour - barely able to follow direction

Ran out door, running up middle of road, attempting to stop cars for help 
The transitory or short-lived nature of many such disturbances was apparent as all but two of the people involved in the events within this theme were either currently on an initial five day assessment period under Section 11 of the Mental Health (CAT) Act 1992 (MHA) or were required to be detained under Section 111, which gives registered nurses the right to hold a person for compulsory assessment.

\section{6: COMPLIANCE AND CONFORMITY}

This is a controversial reason given for the use of seclusion. It implies its use as a means of discipline and social control rather than for the containment of disruptive behaviour or the treatment of clinical symptomatology. Compliance and conformity can be important aspects of the regime in some institutions.

Johnson (1997, p. 35)

The traditional culture of some institutions was based on power and control, and the use of seclusion was a means of ensuring discipline through conformity and compliance (Johnson, 1997). Such things as adherence to staff requests, accepting medication, accepting the routine of the unit and agreeing to contractual behaviours were ways in which a person could demonstrate that they had a level of self control. If they refused to agree to these regimes they could be seen as out of control and seclusion was often the outcome. The use of seclusion for failing to conform to the norms of the unit is now often seen as punishment and its use for such reasons is strongly discouraged.

There were three seclusion events that corresponded to the compliance theme. Two of these events resulted from people absconding from the unit, being returned and immediately placed in seclusion. It was not stated whether there were extenuating circumstances for seclusion based on clinical grounds, therefore a compliance theme was assumed.

An application for assessment examination had been made under the MHA for the third event. Under Section 9, a person is required to attend a specified place for assessment. Given the person's history of absconding from the unit and that he/she was refusing to remain in the unit or to see the responsible clinician, seclusion was 
deemed the only place available to hold this person pending assessment. The unit was an open environment and the risk of the person absconding again was considered to be high.

However, the person who was the subject of this third event was brought to the unit under Section 9 of the MHA in the early hours of the morning. The unit was locked due to the hour so there was little risk of the person absconding. It was noted from the file that the responsible clinician had given instructions that this person was to be held in seclusion until the assessment could be carried out in the morning.

\section{7: EXTERNAL VARIABLES}

A number of other factors can influence seclusion use. These have been widely debated in the literature and have given rise to some contradictory and conflicting opinion and argument. These include demographic variables of the patient, diagnostic categories, staffing issues, and environmental factors.

Johnson (1997, p. 36)

The decision to initiate seclusion is a complex one, and includes factors which are motivated by concerns which do not have a clinical basis. External variables include those related to the patient, to staffing and to the environment. A decision to categorise an event under this theme was made if there was no obvious clinical explanation for seclusion use.

Only one event was categorised according to this theme and the reason for the decision to use seclusion related to staffing issues. Seclusion was utilised with the authority of the responsible clinician and in consultation with nursing staff. The patient was not exhibiting any ongoing safety issues at the time but the previous night there had been a violent incident involving the same person that had put the two female night staff nurses at considerable risk. The patient agreed to seclusion overnight as the same two night staff were on duty and it was believed that their fears for their safety and being at continuing risk should be allayed. 


\section{CONCLUSION}

As a means of categorising seclusion use, Johnson's (1997) seven themes were a useful way of working through each event and determining why seclusion was considered necessary.

Half the events were because of violence or the potential for violence, while a further quarter of the events were due to agitation and to impulsivity related to absconding and self harm. Cognitive and perceptual processes, and affect accounted for the final quarter of seclusion events. Only 1.5 percent of events were related to compliance issues or external variables.

The results obtained from the audit tool have provided a useful insight into the rationale for seclusion use over a seven year period 1997-2003 for the acute inpatient unit described in this study. This was then followed up by discussing seclusion with a number of nursing staff in the unit. The results of these interviews are reported in the next chapter. 


\section{CHAPTER 7:THE INTERVIEWS}

\section{INTRODUCTION}

Interviewing is the most common way of conducting qualitative research. Indeed, it has been estimated that 90 percent of all social science investigations use some form of interview as a means of generating information (Holstein \& Gubrium, 1997).

In this chapter, I will describe the information gathered in interviews with six registered nursing staff each of whom had been involved in one or more seclusion events over the past 12 months. The interviews were semi-structured in that they were guided by a previously determined interview format that outlined the areas of enquiry I wished to pursue (Appendix N).

Interviews were audiotaped and then transcribed by myself. They were then thematically coded. Five major themes were distinguished during this process, with four of these themes having several sub-themes. These were the seclusion process (the event, reasons or clinical indicators for use, and decision points), the seclusion decision (admissions, inappropriate use, de-escalation and specialling), nursing issues (staff experience, practice decisions, debriefing and documentation), the unit environment (an open unit, the acute area and privacy) and the recovery approach. I have also incorporated my own reflections on seclusion practice where they were relevant to the themes being discussed.

Because of the small number of participants and the amount of local knowledge about the research, and the potential for participants to be identified by their colleagues, no demographic data have been presented. In order to further preserve confidentiality, gender neutral pseudonyms have been assigned to each person. 
The actual process of seclusion use is first discussed and this is followed by some decision-making issues around utilising seclusion to maintain a level of safety and control in people who are mentally unwell. Several nursing and practice issues became apparent during the interview process and this is the third theme that will be considered. Environmental issues are explored, and the final section will look at the role of recovery when seclusion is used.

\section{The Seclusion Process}

Participants were asked to recall an actual seclusion event that had an impact on them and the process that was worked through during the initiation of seclusion. This included examining the reasons for its use and the decision points that were made during the process. Participants were also asked to discuss what they believed were the main clinical indicators for using seclusion.

\section{A SECLUSION EVENT}

Each of the participants was able to describe an event that had a particular impact on them. Notable among the descriptions was the lack of control the nurses felt they had at the time of the event and their experiences of being in a volatile situation:

If I remember rightly the guy was agitated and anxious and we didn't have any control. He wouldn't listen to us, he was non-directable and he ended up breaking a window, and it wasn't very dignified (Chris).

The one that I'm thinking about at the moment was one where the behaviour escalated over a period of time, and despite all types of interventions continued to escalate with somebody who was manic and needing some firm boundaries about their behaviour and it ended up that they just became violent and was throwing furniture (Sam).

Violence and/or the threat of violence were described in all the incidents discussed. Other factors were also mentioned: 
He was actually quite manic at the time and quite thought disordered and was all over the place. There was concern that he had a bit of a violent history or that he had the potential to be quite violent (Alex).

Of importance here was a reported history of violence, the person's mental state and the need for a low stimulus area. Environmental factors are discussed in a later section of this chapter.

\section{INDICATORS FOR SECLUSION USE}

The safety of patients and others in the environment and aggressive behaviours directed towards other patients and/or staff were the two things that were predominant in participants' understanding for seclusion use:

Patient safety, as far as a patient being at risk of harming himself or absconding off the ward, or maybe harming other patients ... that's for everybody's safety really because when he is unwell (Lou).

So he was getting quite distressed and he was verbally threatening and certainly he punched a hole in the wall ... He was obviously unwell and distressed and he was verbally and physically threatening (Lou).

He said that he had lots of voices in his head telling him to leave. At some point the patient went to the front door and tried to get out, hitting it then went off to his room. The next thing we heard a large bang coming from his room - he had hit the window frame buckling it and breaking the catch. He refused to go to seclusion when requested and started pacing in the reception area. We talked to him for some time and eventually he agreed to go into seclusion (personal journal).

The risk of absconding was mentioned frequently and the following illustrate how this could have the potential for serious consequences:

Probably because he was a risk of actually going AWOL (absent without leave) and also a risk of not being able to look after himself properly ... and that he was reluctant to take any meds and quite paranoid about actually being there so it was probably safety in that we couldn't really manage him in an open ward situation with a lot of other people around and needed to be somewhere quieter (Alex).

The first thing we had to think about was his safety, the safety of us because he came barging at us, and the safety of everybody else because then he broke the window and then when he did get out of the ward he was running up the middle of the road in 
the traffic so we needed to contain him (in seclusion) until we knew he was okay (Chris).

Two participants made special mention of the fact that seclusion was generally used as a last resort measure and that the motivation for it was for the right reasons:

I think it is always used as a last resort really, I personally don't think we abuse it ... in hindsight we might think well we didn't need to do it, but I think we use it with the best of intentions (Lou).

Other factors that indicated the need for seclusion included verbal abuse and threats, disruptive behaviour, disinhibition and a lack of control.

\section{Decision Points in the Seclusion Process}

Discussion about the main decision points when it is decided to seclude a person brought up a number of issues:

The main decision I would say would be when medication was offered, number one. Number two was deciding whether that person would last in that environment in the future and they weren't able to. Because I think, if they had accepted medication and they were able to be contained in a low stimulus area it wouldn't have been disturbing to patients, but that just didn't happen. And the other decision was the Mental Health Act, that was a key decision point when the person is not able to make any rational decisions really either, themselves and are putting others at risk, and the other key point was the danger really (Sam).

One issue was that there should be the least amount of physical intervention by nursing staff, so causing the least amount of distress to the person. This was amply demonstrated when a person became unwell on two consecutive days:

Within a very short time, he appeared irrational, unable to be reasoned with. One of the staff chased him round the unit, brought him down in a tackle and got hurt in the process. He was eventually restrained by staff and placed in seclusion. The next day just after lunch the patient began exhibiting the same irrational and aggressive behaviour as the previous day. A member of staff stood outside his room and stayed there as the patient ran up the corridor and back to his room repeatedly. I got staff from other areas and he was restrained in his room and things were allowed to calm a little before he was taken to seclusion. The two events provided a unique opportunity to compare them. The first event felt chaotic, disorganised and the 
actions of some people escalated the patient's disturbed behaviour. The second event was handled much more calmly and professionally and was over quickly causing the least amount of distress possible to the patient (personal journal).

Participants also discussed the decision to seclude a person in terms of historical risk, that is whether they were known to have a history of violence or aggression when mentally unwell. Also, the current risk to the patient and to the other people in the immediate environment was important when making a decision to seclude a patient.

Environmental issues were raised and the necessity of using seclusion for containment because the unit was unlocked:

Well it's safety and the other one given this environment is that it can be used as containment because it is actually an open ward and why lock the ward up for everyone else when it is only one person and they could still be disruptive anyway (Alex).

The open unit environment is discussed further later in this chapter.

Decisions about the use of seclusion were sometimes made at the pre-admission assessment stage. There were also alternatives to seclusion discussed, that is other ways in which a potentially volatile situation could be handled. The next section considers admissions into seclusion and possible alternatives to seclusion which could be considered in the decision-making process.

\section{THE SECLUSION DeCISION}

Decisions about utilising seclusion or not can be fraught with difficulty. That decision may not necessarily be made by nursing staff, but when it is questions related to inappropriate use, the use of de-escalation techniques and specialling become relevant. 


\section{AdMISSION INTO SECLUSION}

The decision to seclude a person was not always made within the unit environment but occasionally occurred before actual admission. When people were admitted immediately into seclusion, the assessment and decision for this was made prior to the person arriving in the unit. On these occasions there was often police involvement:

If they are totally unreasonable and they don't have any insight at all and they have tried to be dealt with in the community and they have obviously had a very difficult time, they probably come in with the police that time, then they're usually escorted directly into the seclusion room and the decision has already been made by the psychiatrist (Pat).

Well usually when they come in via the Police, they will go straight to seclusion. I think that is part of the assessment as well, and I think (consultant psychiatrist) has said they're to go straight into seclusion (Lou).

The involvement of nursing staff, in these instances, often began when they assisted with putting the person in seclusion and were required to administer prescribed medication. Their role became a monitoring and assessment one with no opportunity to establish a rapport with the person prior to the seclusion event.

\section{INAPPROPRIATE USE}

In their survey report of the mental health service, Clark et al. (2003) noted that "On review of the seclusion register it is clear that staff are not clear about the policy as seclusion is being used for inappropriate reasons on occasion ... the seclusion register also highlighted instances where a client was put in seclusion for several hours for continually attempting to leave the unit ... seclusion was only ended once the client agreed to staff requests not to leave the unit” (p. 540 and p. 542).

However, participants were clear that they agreed in principle with the need to place someone in seclusion if they posed a risk of absconding: 
It's a tricky one. Certainly I would far rather know that someone was in seclusion for a day longer than they had to be but safe than let them out a day early and have them take off and harm themselves ...I would far rather that, I mean given the whole set up of the ward, given that we don't have an ICU, given that once they are out of seclusion they are in an open ward, I think that we do pretty well (Chris).

I think that we had the benefit of the risk assessment and there was a history of overdosing so there's quite a high probability I would have thought that if they had absconded off the ward they would have overdosed (Lou).

While the prevention of a person absconding from the unit appeared to be the reason for seclusion in the cases cited by the accreditation team, a more in depth look into the documentation would have revealed that the underlying concern was the risk of self harm and suicidal behaviours should a person have left the unit. However, there were also seclusion events that generally occurred when a person was admitted that were directed by the psychiatrist and nursing staff struggled to understand the rationale behind:

I remember one where I was thinking why have we got this guy in seclusion, I can't remember and it was basically (psychiatrist) saying you'll stay in seclusion until you have an injection. I remember him lying on the mattress, and he was quite paranoid about things. There was no aggression or anything, he was just refusing medication (Lou).

This and other comments reported in this chapter revealed the need for improved communication between the medical and nursing staff.

\section{DE-ESCALATiON}

Of particular concern to participants was the way in which they handled potentially volatile situations and their use of de-escalation techniques to calm a situation so that seclusion did not need to be implemented. In particular, participants referred to the need to ensure consistency in maintaining boundaries for acceptable behaviour. Participants generally recognised the usefulness of good communication, developing a therapeutic relationship, setting boundaries, and the considered use of 'prn' (as required) medication: 
It's all about communication and recognising when you can use de-escalation techniques, when people are highly agitated it is not as effective. Making sure people are aware of the boundaries, in my experience ... people like to know where they stand (Lou).

I think on the whole most of us are pretty good at that. I think we all know the way you talk and the tone and the way you stand, I think we're all pretty good at deescalation, we're pretty good at that, we know about de-escalation (Chris).

You've got to be able to engage with that person, to form the trust, and to be able to help them with choices, and if they are not able to choose then kind of an ultimatum type thing but you must be able to follow it through (Pat).

Two of the participants above made specific reference to maintaining firm and clear boundaries with patients, and one of these continued on:

People knowing what is acceptable. If we put a boundary in for one person we should put it in for everyone. I think in the past people have not been consistent with boundary setting and that has led to all sorts of problems (Lou).

A lack of consistency in setting limits for patients is often related to nursing staff experience and, in a more general comment about de-escalation, Alex referred to nurses’ ability to handle difficult situations:

Well I think that there's probably been times when it's been used really well and that there's been other times when it hasn't been used well at all and I think that comes down to having the experience of being with those more volatile and more unwell because it can be quite frightening from the perspective of the nurse and it has got the potential to go slap in your face and having the patience and the tolerance to talk to that person. It can be quite threatening (Alex).

Staff experience is considered further later in this chapter.

\section{SPECIALLING}

Participants discussed the issues around specialling or providing "one-to-one" nursing for patients, both as a means of preventing the use of seclusion and for better management of seclusion itself. Some participants felt strongly that people in 
seclusion should not be left on their own, that if they were unwell enough to require seclusion then they needed to have a nurse constantly observing them:

Or we could, when we have someone in seclusion, allocate a nurse, we usually give them one or two other patients as well, they should have maybe just in seclusion one nurse and they could spend time with them, it's just an idea. Or just outside and they know the nurse is just outside (Lou).

But there does need to be someone regularly, I mean if you've got people in seclusion you just about need to have someone outside that door all the time. Because the biggest thing I find with seclusion is that people are put into seclusion when things are pretty out of control, and they've put themselves or others at risk and if we had somebody there at least that development of rapport can start prior to them coming out of seclusion (Sam).

It was noted that there had been a move away from carrying out special or one-to-one observations particularly when someone was posing a risk for absconding:

And there are occasions when they should have a constant person with them and they can be with them as opposed to having them in seclusion ... it's not often thought of because it's not used that often. And that's probably an experience thing and a mode of practice (Alex).

Yes, but the other thing I think is, I don't know why they don't bring in specialling more often, you've got someone who is an AWOL risk, you need staff really to monitor on a special basis (Sam).

When you think about it, it's a joke (present practice). Well that's my belief anyway, they should be watched all the time. It is a more user friendly technique I think. If I was that sick person I would like somebody to be with me all the time (Glenn).

\section{NURSING ISSUES}

Other more general issues related to nursing patients who were either in seclusion or had the potential to be secluded were raised by participants. Work pressures, the amount of documentation, staff experience, debriefing and other practice decisions were some of the matters that were discussed. 


\section{STAFF EXPERIENCE}

Participants acknowledged that staff experience and other related factors such as their confidence and anxiety, played a large part in successful de-escalation or the appropriate use of seclusion:

I do notice that depending on the staff member and depending on their confidence and depending on their anxiety it has a lot to do with how that situation goes ... if you go in there and you're quite tense yourself say it doesn't go so well. Obviously experience has a lot to do with it, but also the other staff you have got working with you (Chris).

I think that has a great part to play is actually staff experience, and how they actually interact with clients and whether they are actually trained in that way of deescalating ... and to get that rapport with that client, and being aware of what the triggers are too (Alex).

Part of the nursing staff experience is being able to work well together as a team and to respect colleagues' decisions which help to make the seclusion initiation run smoothly:

If you've got staff that are consistent it is much easier, and are willing to follow a plan, it is much easier ... it's got to be a consistent approach, and you've got to have one person who's the key communicator too (Sam).

One participant related an occasion when working with a staff member who failed to appreciate the need for a key communicator made the experience more difficult than it might have been:

If you've got another staff member who's wanting to contradict you when you've got it all going on. I can remember somebody, we were in a restraint, so I was the allocated talking person, and the other person was saying, no this is what we are going to do, no we're going to do this, and I was trying to direct it ... fair enough to go later listen, I didn't actually agree with what you did, or you could have done this, but at the time it's not the time to do it (Chris).

Other participants discussed how a perceived lack of collegial support may influence the decision to seclude a person or otherwise: 
I know one particular lady and to me I would rather have walked round and round the carpark with her instead of dragging her back and putting her in seclusion which was what ultimately happened ... but I felt uncomfortable because it was not the done thing to do. But I know that if I had the support from my colleagues I would have been happy to do that, and who knows what the outcome would have been (Pat).

I personally know how hard it is to stand up for what you believe when you feel unsupported by your colleagues. The decision I made in the following incident had the potential to go wrong but I felt I had enough understanding of the person concerned to take the chance:

The psychiatrist decided that a person needed to be put on the Mental Health Act and given an anti-psychotic injection. In order for this to happen he said we should call the police and put the person in seclusion as it was believed he would be resistant to this treatment. I believed this was not necessary based on my knowledge and experience of working with this person but other staff did not agree with me. However, I stuck with my decision and fortunately there was a good outcome as, a few minutes later when I went to his room, I found the patient sobbing and very upset, and embarrassed I had found him like that. After talking quietly to the patient for a few minutes he agreed to have the injection and was more settled for the rest of that duty. However, I was left feeling isolated and unsupported by my colleagues (personal journal).

The lack of restraint training for nursing staff was referred to and comment was made on what this meant for the future:

More often now people are not trained in restraint, and with the turnover of staff it is getting to the stage where very few are trained, and some shifts where there aren't any very experienced staff ... and I also think that puts barriers up to treatment you know. If you, are you going to confront someone if you don't have the skills, at the end of the day, to carry through a process. I don't think so (Sam).

Two people discussed what they saw as a new policy or approach where, instead of staff restraining a person or attempting to detain them in the unit and placing them in seclusion, the police were called in to assist:

I thought the flavour of how we operate seclusion now was that yes, we will let you go but the police will bring you back. Because we are not going to be tackling you (Glenn). 
And if somebody we believe has been intent on hurting themselves or been too dangerous and others have been at risk ... are we at risk as the staff, whereas not terribly long ago we were expected to put ourselves between the client and the one being hurt. Well, not so much now (Pat).

However, other people did not agree with this approach and believed that their duty to care as nurses was compromised:

The police do not work from a health model. The way that they restrain people is very violent. There is going to be a time when the police cannot respond because they are stretched to the limit too and if we're going to say I'm not dealing with that, we'll let the police deal with that, where's the health model in that, where's the strengths model in that. Some of the police that come to the ward to restrain people, they don't have a clue. They've never ever seen anything like this before, they're quite blown away by the whole thing really and they want it done as quickly as possible ... The idea that somebody's acting out and needs to be restrained, and that we just open the door and let them go and then call the police to deal with it just horrifies me. I think what am I here for and what have I been trained for. It would be interesting to see how the Health and Disability Commissioner would see that, if there was somebody acutely unwell on the ward who is starting to act out and we open the door, how would they see that when we know that person is unwell and has impaired judgement (Sam).

One participant described what the presence of the police was like on one occasion when called to assist nursing staff in the unit:

And because we expressed to the police that he was already aggressive in manner they came looking like some horrid riot squad with shields and padded things, and batons. So they took charge and it was almost as if we were secondary which I now know when the police come in we are in charge ... We could have taken better control if the staff that were there then had known that, we could have asked them a) not to be so many in numbers, and b) get rid of the batons and I think they had some pepper spray, because, I think the pepper spray didn't work on him (Glenn).

I was present during another incident that involved the police:

Police assistance was requested to return an acutely psychotic patient to the unit. The police led him into the seclusion room and the door was closed while we waited for an injection to be prepared. When the door was opened two police officers grabbed the patient, banged his head up against the wall, put his left arm up his back then dragged him to the mattress and forced his head down onto his chest and onto the floor. Once the injection had been administered, the police left, leaving everyone feeling shattered and distressed over what they had seen (personal journal). 
After these incidents several issues were clarified one of which was mentioned by Glenn above. Nursing staff were encouraged to take more control and to understand that they were the ones in charge of the process at all times when the police were in the unit.

Nursing staff experience is one factor in using seclusion in the most appropriate way possible. Their attitudes and practice are also influenced by the position, beliefs, judgement and directives that come from management and other staff.

\section{Practice Decisions}

One of the most difficult decisions that nursing staff have to make is the actual decision to seclude someone for whom they are caring. This raises issues around the therapeutic relationship and a nurse's supportive role, versus the need to act as a control agent over unacceptable behaviour. Additionally, there is the cultural climate of the organisation that either accepts seclusion as a necessary part of the unit milieu or positions itself as disapproving, albeit subtly, the use of seclusion. If nursing staff have a sense that seclusion should not be used then this can lead to decisions being made too late to prevent a violent incident or to preserve a person's dignity:

I've seen some people (nurses) that might try and avoid seclusion and let things go on and it's ended up happening anyway. Whereas in hindsight, get it in, get it sorted, and then get on the right road (Chris).

On several occasions I have seen instances where the seclusion decision has been delayed and the situation has further escalated so that the patient has eventually caused a public scene, their dignity and safety has been compromised and nursing staff have been hurt. Things can get out of control to the detriment of the patient if inappropriate behaviours are allowed to continue too long.

Once a person was secluded, consideration then needed to be given to how long they should be kept there and at what point they would be deemed safe enough to be integrated back into the open unit: 
You've got good eye contact, you've got a good relationship and you've only been dealing with them through the door ... you talk with them and if they are rational and you are able to talk with them and have a plan then surely that's a good stepping stone to getting them out sooner (Pat).

Several people discussed their feelings when they received instructions that a person was to be held in seclusion for a long period of time before being reassessed and what they felt would be the repercussions for them if they did not heed that decision:

I wanted her to come out but you have to have total support from the psychiatrist who said she's going to stay in for the next 24 hours then he will assess her ... so if you let her out and it all goes to custard well there's not much support (Pat).

I would have liked the person to have been reviewed much earlier than they were. It shouldn't matter whether it be night or day, it should be a matter of when it is appropriate, not "I will see this person in the morning". I don't believe that's always okay (Glenn).

The need for a multi-disciplinary team approach to seclusion decisions was discussed. Participants were dissatisfied with the fact that they were sometimes expected to keep a person in seclusion until a pre-determined time for reassessment.

\section{DEBRIEFING}

After any unusual incident, it is important for everyone involved to have the opportunity to discuss their thoughts and feelings about the event. The opportunity to debrief should be offered to nursing staff, patients, their families and anyone else involved in the incident. As noted earlier (p. 55) staff debriefings are a procedural requirement following seclusion events although not done well. During the interviews, those participants who mentioned debriefing focused on carrying out this activity with patients.

Following the seclusion event, it was felt that discussing what had occurred with the person who had been secluded was a good chance to examine the incident from their viewpoint. This not only gave the person the opportunity to tell their story, but also provided further insight for nurses from a different perspective: 
I have often talked to them a lot about it, because I haven't been there when they've gone in but I've been there it might not be that day but the day after and they've been my patient and I hear it because I truly want to know and then I hear it from their side which can be quite different from how staff see what happened but it doesn't matter how they see it as long as they can talk about it. I don't see that interferes with the strengths model or recovery model. Some people would say oh no, there's no case for it (seclusion) at all, but we're working in acute psychiatry (Pat).

But most participants felt that nursing staff were not very good at debriefing the person after seclusion had been utilised. Their belief was based on the fact that such debriefing of the person was very rarely discussed among nursing staff.

\section{DOCUMENTATION}

During the interviews, participants made reference to the accreditation team findings of inappropriate use of seclusion discussed earlier in this chapter (Clark et al., 2003). Generally, they felt that this may have been more a documentation issue than reality:

There is a place for paperwork in this job, we need to make sure that we have clear and concise notes, but having too much paperwork we can end up cutting corners if we had one place where we had to write things it might have gone down a lot clearer (Lou).

People indicated that the forms could be made more user-friendly or that they didn't provide room for all the necessary detail:

You could have different areas that you can tick like whether they have actually had food and a check list about what's actually going on and it's actually incremented for 10 minutes or 15 minutes or whatever the time whereas this one's quite repetitive because you have to write it, over and over again (Alex).

The green form, the special incident form you now only have to attach the audit form and when it goes through to management anyway they don't have a clear indication of what happened because it is just a tick box thing, so that one doesn't work very well (Lou).

During the audit of files discussed in Chapter 5, I found that more detail was usually provided in the progress notes. These often noted whether persons were threatening to self harm or had suicidal intentions should they leave the unit, whereas the record 
in the seclusion register may have referred only to the fact that a person wanted to abscond. One person believed that the accreditation team should have done more fact-finding:

Oh, that can't be taken into account. How can they say things in such an important report without looking at details (Pat).

If, as the report indicated (Clark et al., 2003), the accreditation team believed that seclusion should not simply be used to prevent a person absconding from the unit, then the wider issue of why absconding was an issue needed to be explored. This information was available in some of the documentation related to those seclusion events.

\section{THE UNIT ENVIRONMENT}

A further factor in the complexity of seclusion management was the environment itself and how it impacted on the reasons for seclusion use and the way it was utilised. Participants discussed things such as having an open unit compared to a locked one, how the acute area was set up, and privacy for people being admitted into the unit and into seclusion.

\section{An Open Unit}

The unit in which this study was carried out operated an open door policy, and all participants were in agreement with this, although some people felt that there needed to be better provision for monitoring access to the unit. It was noted that there were eight exit points that made it difficult for staff to monitor who was coming or going from the unit:

I think it's good that we have a ward that has an open ward policy, but you have to balance that, the rights of the patient, with security, there are so many accesses for people to get out, people can come and go and you wouldn't know ... from a health 
and safety point of view we should know who's on the ward and who's not on the ward (Lou).

When comparing the open door policy with other units who have a closed environment, people felt that a closed unit created its own set of problems:

Because they feel closed in and they're not given the empowerment of actually taking responsibility for some of their behaviours when they can and their mental state allows them to ... I think it is a huge, positive way of dealing with what's actually happening with them and processing it and giving them some sense of responsibility (Alex).

I believe it is more beneficial to have an open ward because if the doors are locked people are trying to get out, if they are open I believe that want diminishes ... if the ward was locked, they are only going to continue to escalate possibly so the chances of you being secluded for whatever reason may increase with the ward being locked (Glenn).

However, one person believed that there could be times when the unit should be locked:

I think there is a place for when the unit needs to be locked. I do think that and I don't agree with locking people up in seclusion because they pose an AWOL risk (Sam).

Generally, the feeling among participants was that the unit should be unlocked most of the time. However, one participant thought that there needed to be some flexibility for those occasions when a person needed containing but the situation did not necessarily warrant seclusion. Those people not restricted to the unit could always be informed of the situation and it would be the responsibility of the unit staff to ensure that they could have immediate access to the outside if they requested this. 


\section{The ACute Area}

The unit described here had a separate wing that contained the clinical leader's office, three single bedrooms and two seclusion rooms. The wing had its own communal bathroom facilities. This area could not be isolated from the rest of the unit and the only access was through the main doors and the public foyer of the unit. These opened into the foyer that had been converted into a lounge type area where both patients and visitors tended to congregate. Participants noted limitations to this type of access:

I've never worked in a unit like this where you come in through the main door and there you are really ... especially when people come in you've usually got patients on the couches and things like that, and to a new person, I'm guessing, I don't think I'd like it to have spectators when you come in, especially if you're quite distressed (Lou).

It's not an ideal setup, first of all having the seclusion rooms right next to the main door. In an ideal world there wouldn't be a lounge right there. It's mainly the design of the building, I mean we do our absolute best with what we've got, but if we had a better designed building (Chris).

I mean that's not appropriate either, bringing them into the main lounge which is always a high functioning area where there's lots happening (Sam).

During renovations carried out in 2003 a separate entrance for the acute wing was investigated but no changes were made. Some participants commented that it was unfortunate that this was not pursued:

I think there needs to be, especially with people coming in acutely, I think there needs to be an entrance where you can go through like other units that I've worked in, where there's an entrance for acute admissions where the patient can be kept quiet and is low stimulus (Sam).

Again, I feel it could be largely better but I believe it was a money issue when we were looking at the restructuring and we have come out with second best, which is a pity. Second best for the client. A separate entrance was looked at but nothing was done about it (Glenn). 
It was felt that if the acute wing was separated from the main part of the unit that there would be much more opportunity to maintain a low stimulus area and this could reduce the need to use seclusion:

I am quite in favour of using a quiet room, you know sitting outside with the door open. Depending on the person maybe they could just be in their own room, quiet with the curtains pulled (Chris).

I've always said that there needed to be a low stimulus area on the ward, and there's not, it's either one extreme or the other. And I think there should be an area that is kept low stimulus and nursed appropriately for that area. I would like to see that. And that's not just for people with mania, it's also people with psychosis ... close monitoring, be able to take away some of their stimulants, and gradually let them out to the ward when they are settling ... especially for people who are just sort of, discarding clothing, becoming quite disinhibited really and the only place you can put them is seclusion because it's the only place you can keep them (Sam).

We couldn't do it on our ward, just the way the building's built, where people can come in, in different stages like open seclusion and yet they can still be in an area that is safe and secure (Lou).

Discussion also included the situation where a person was actually in seclusion and the difficulties that arose having other people in the bedrooms of the acute wing:

Ideally, if you have someone in seclusion, you'd have that complete wing empty, you know, because people when you have the seclusion door open we have people walking up and down to their bedrooms and that and why shouldn't they, it's not their problem (Chris).

The above statement addressed the rights of other people who were currently patients on the unit, and indicated how these rights could conflict with the rights of the person in seclusion, particularly their right to privacy.

\section{PRIVACY}

The above discussion about the acute wing extended to privacy issues for the person in seclusion. For these reasons, it was felt that the acute wing was not placed in the most appropriate area: 
The only thing I don't like is, if we have people in those other two rooms and we're in seclusion and they're passing ... maybe we should have someone in that corridor not letting people through, because we are all busy with that assessment process and maybe someone on the door keeping people in the room, we should have a fourth person somewhere so people can't get down there, just for that person's dignity (Lou).

What this area is like particularly, it is not in the best spot. The other seclusion rooms around the country are not likely to be in the thoroughfare of another area (Alex).

I mean the seclusion room would be way down there somewhere wouldn't it, with its own entrance ... I mean we do our absolute best with what we've got, but if we had a better designed building (Chris).

The accreditation team also made reference to the privacy of people in seclusion and noted that "Access of public view into the seclusion room must be addressed to ensure client privacy and dignity” (Clark et al., 2003, p. 537). It was further stated in the executive summary that: "There was a priority recommendation to provide screening from public view of the seclusion room. This recommendation has been actioned at time of writing the executive summary" (Clark et al., 2003, p. v). This action consisted of curtains being placed over the windows of the two doors to the seclusion rooms. At a later date curtains were also placed over two side windows thus completely blocking off views both into and from the inside of the seclusion rooms. Participants felt that this action, while achieving the goal of preventing people from seeing in, had adverse effects on the person inside the seclusion room:

I know it is done with the best of intentions but it stops that person, they've not got access to the clock on the wall outside. I'd hate to be locked in there and can't see out (Lou).

To be boxed in must be very distressing as well ... I don't agree with that then, I don't agree with that at all. I liken myself to being in there or one of my family and if I don't see that as satisfactory then no, I'm not happy with it, or the process at all. The treatment I deliver and what I expect my colleagues to deliver is what I would expect for me or mine (Glenn).

I think that's just a cop-out really. How on earth that is supposed to preserve people's privacy. I don't know. Even the seclusion rooms themselves are not soundproof, if you have people in there acting out then you can hear that happening (Sam). 
I agree with the above statements as I have seen and heard people kicking and banging at the seclusion rooms' walls and doors. Such disturbances were very apparent in public areas of the unit, and any visitors were acutely aware of these, and were often upset and anxious by what was occurring. Equally importantly, the disturbances had the effect of alarming and distressing other patients who were already in a fragile and vulnerable state.

A final concern expressed about the seclusion environment related to toileting facilities:

It's archaic, absolutely disgusting, that we expect people who are so unwell to use cardboard containers to toilet in. Newer places at least provide a safe toilet ad washing area (Sam).

There was no direct access to a bathroom from the seclusion rooms so cardboard pots and urinals, and toilet paper were placed in the seclusion room for patients' use. Staff therefore escorted patients to the nearest bathroom as soon as it was safe to allow them to leave the seclusion room.

From the above comments and my own observations, it was apparent that the limitations of the acute wing impinged on the rights, privacy and dignity of people either in seclusion or requiring a low stimulus environment. Such limitations should be considered as serious and in need of improvement, and are difficult to reconcile with a recovery environment.

\section{A Recovery Approach}

The final topic that participants were asked to talk about related to the recovery approach (Ministry of Health, 2001) of working with people with mental health disorders, and the use of the strengths model (Rapp, 1998) as a recovery tool that was used in the in-patient unit discussed in this study. The principle question raised was whether the participants felt the recovery approach was compatible with the use 
of seclusion. One person felt that both seclusion and recovery could sit alongside each other:

I think you can reconcile one with the other because a goal is a goal at the end of the day. It may not necessarily come from them initially. But it gives them a sense of hope if this is what I can achieve. It is better to have the presence of a goal as opposed to the absence of one. Because no-one wants to stay in seclusion forever and a day, and it's about empowering them and it is better for a person to have a small goal as opposed to nothing altogether (Alex).

It was recognised that recovery was an important concept that nursing staff needed to be working on from the moment the person stepped inside the door but that it was guided by the staff until the person was well enough to take control:

Obviously you're the trained staff and you know how to be to ensure that the situation is handled most appropriately. But they need to know what the plan is all the steps of the way. And if they're not making good decisions then there is a time where you step in and make sure that it works the best it can towards their recovery. So, say you've got someone who is extremely depressed, or extremely fragile following their seclusion experience they still require a lot of guidance and you are caring for them but at the same time enabling them to just grasp the reality of the world and take on bits as they feel able to ...good in that their dignity was preserved and they felt safe and that someone was taking over the decision-making, and their exposure to too many people was minimised (Pat).

Other participants discussed the recovery approach from the strengths model perspective where staff were expected to carry out a strengths assessment and goal planning as early as possible in a person's admission. One of the major principles behind the strengths model approach was that people took control of their own recovery and drove the process. Participants did not believe that seclusion and such a recovery approach were able to be reconciled:

Myself, I use the strengths model in two phases. I don't use that until people are really really settled and people are co-operative and people are really more interested in learning about their recovery. When people first come into hospital in the acute phase they're generally, they've got very poor concentration or poor judgement, or physically or verbally aggressive there's no hope, it's not rocket science is it ... I've seen people talking to people in seclusion saying you do this that or the other and that will be your goal for today. I don't believe that's got anything to do with it, that's not the patient doing it at all, that's the nurse putting words into their mouth. It's basic, you know learning things, when people have got poor concentration they're not going to learn things are they (Lou). 
Well they're kind of the opposite end of the spectrum really, I think sometimes in order to have that wellness and control, goals and what have you, someone has to take control for them and say listen we need to kind of do this. And that's just the way it is (Chris).

I liken it to somebody who has had a general anaesthetic. There is a point where they need to be cared for and then there comes a point when they can participate in their care and recovery. I liken it to that really... If a client is that unwell and that type of care needs to be delivered (seclusion) then they are not ready to enter into the strengths momentum. I think the two need to be separated because you're dealing with more of an emergency situation of some sort (Glenn).

I actually believe when people are acutely unwell and acutely psychotic and requiring seclusion it is very difficult to go about doing strengths to start with. Because the first call of treatment is for the psychosis or their mania or whatever they are in there for. And to be setting goals while they are in seclusion is not appropriate because they are not even able to comprehend what is happening to them or to be making logical steps. So if they are to start strengths it needs to be subacute (Sam).

One person went on to discuss how they believed the strengths assessment should be used, that it should start when the person is able to take responsibility for writing it up, and it should not be at the expense of building rapport with that person:

You just bide your time, you get to know people even when they're in seclusion but they're not able to take an active part in strengths or goal setting ...I think that the patient should take responsibility for that (writing the strengths assessment). I don't believe we should be really filling that in at all. I know management have got to show we're recovery based but I think that there's too much emphasis put on getting things put on paper when I think we should be, what's the word, building a therapeutic relationship with a person or getting to know them, talk to them and building trust and all that, that's all really important but in the rush to get everything done that seems to go on the back burner at times (Lou).

Further, a person must be well enough to cope and must be able to set goals that are reality-based:

If we've got someone who is acutely depressed, to actually sit down and try to get goals out of them, these people may be living hour by hour, day by day. To try and future plan is just devastating for them (Sam).

The goals need to reflect what they would like when they're well or far down the road to recovery. It's no use asking someone who's manic to set realistic goals for 
the future as these probably will be driven by their mania and will probably be completed different to what they would want if they were well (Pat).

I provided examples of similar situations where attempts to set goals with people who were acutely unwell created disruption to the recovery process in an article about using the strengths model in an acute inpatient unit (Mosley, 2002b).

The participants all agreed that a recovery approach was fundamental to their work but the method of doing this must be centred around the needs of the person at the time. This was regardless of whether they could express those needs themselves or whether they required others to make decisions for them.

\section{CONCLUSION}

The six participants interviewed for this study gave a comprehensive overview of how they considered seclusion was used in their work environment. Their contributions were divided into five major themes with several sub-themes. Process issues were considered with participants outlining some of their experiences of seclusion use by describing an actual event that had an impact on them and discussing what the reasons were for initiating seclusion. These included the decision points along the way and what they saw, generally, as the clinical indicators for seclusion use.

The decision to utilise seclusion can be a difficult one to make. On some occasions the decision was made before the person was admitted to the unit and then it was a matter of carrying out the correct procedures for someone in seclusion. A recent accreditation report that included seclusion practice noted some inappropriate uses of seclusion. This was discussed by participants. When a decision about seclusion needed to be made for a person who was already an in-patient a number of things needed to be considered and these were also discussed. They included the use of deescalation techniques and specialling or one-to-one nursing. 
Other nursing issues that could arise during the seclusion process included staff experience, practice decisions related to the appropriate care of people in seclusion, debriefing of persons following a seclusion event and appropriate documentation. The unit environment was also a consideration. Participants discussed their views on operating within an open unit environment compared with a locked unit and how they believed an acute area or wing should be set up and managed. Particular issues that were considered included the privacy of persons and the need to have a separate area with its own entrance to provide the optimum level of care and safety. They believed an acute area that could be separated from the main unit would enable the provision of a low stimulus area that could prevent the need to use seclusion in some instances.

The final topic raised from the interviews was the role of a recovery approach, particularly using the strengths model, when a person was acutely unwell and possibly requiring seclusion. While participants felt that a recovery approach was important at all stages of the process, the practical use of the strengths model approach with its assessment and goal planning stages, should be reserved until the person was well enough to follow the intent of the model which was that the persons themselves should take charge of the process.

The results of this study have now been presented in this and the previous two chapters. The following chapter will discuss these results in more depth and relate them, where relevant, to the literature. 


\section{CHAPTER 8: DiscuSSION}

\section{INTRODUCTION}

The previous three chapters have reviewed and analysed the research data. The information from the interview transcripts and the audit tool has been organised into topics and themes. In this chapter I shall provide an interpretation based on this analysis. Qualitative interpretation involves working with the analysed information so that statements can be made about what they mean bearing in mind the intentions, methods and processes of the research. This interpretation generates meaning by making sense out of things of interest by exploring, explaining and describing them (Roberts \& Taylor, 2002).

\section{Profile Of SEClusion}

A principle objective of this research was to establish the extent to which seclusion was used in one acute in-patient unit. This was achieved by auditing seclusion records and patient files to obtain an accurate assessment of use over the seven years 1997-2003. A previous survey had produced figures that were based on imprecise data for a number of reasons including inaccurate calculations, the absence of some seclusion events from the data source and incomplete information. The audit established that over 304 hours of seclusion use had not been recorded in the seclusion register, the keeping of which is a legislative requirement under the Mental Health (CAT) Act 1992 (MHA).

It is possible that events have still been missed during this current audit. Files were only audited where there was a known seclusion event. If a seclusion event occurred with someone who had never had a recorded event in the seclusion register then this would not be included. Therefore, the information presented here should be regarded 
as a conservative estimate of all seclusion use. The only way of assessing a more accurate estimate of seclusion events would be to audit the files of all admissions during the years of interest - an undertaking beyond the scope of this study.

Record keeping was noted to have improved in later years and it appeared that nursing staff were more aware of their obligations to document seclusion events in the register. However, during the course of this study, I had occasion to complete the seclusion register when both the staff from the duty that initiated the seclusion event and the staff from the following duty that were responsible for the termination of the event had failed to record the information. While the reasons for this omission were not clear, it suggested a continuing systems failure. Further education was clearly still required to ensure that all nursing staff were familiar with the requirements for documentation of such events. It was possible that new staff were not being oriented as well as previously or that the staff on duty were less experienced. It also reinforced my belief that there were other seclusion events over the audit timeframe of the study that remained unaccounted for.

The documentation required when a seclusion event occurred was extensive with six different pieces of paper needing to be filled out. Other duties resulting from the event included making contact with family and possibly other community and hospital staff, and meeting the requirements of the MHA if this had been activated at the same time as the seclusion event. The primary nurse with responsibility for the management of the event often continued to have responsibility for other patients as well as maintaining regular 10 minute observations on the person in seclusion. Clearer guidelines regarding the number of patients each nurse should have responsibility for, especially when a patient is being held in seclusion, could eliminate some of the problems that may arise around equitable sharing of the caseload. There should also be some flexibility about transferring patients to other nurses should a patient become more unwell during a duty or should they require seclusion.

The years 2002 and 2003 showed a marked increase in seclusion use compared with the previous five years. The increase was noted in both the number of people secluded and in the actual number of events that occurred. Therefore, this precluded 
explanations such as one or more persons being responsible for multiple events. In fact, the largest number of events for one person occurred in 1997. Issues to do with staffing, the environment or organisational expectations were all possible explanations, or it could have indicated that people with higher acuity were being admitted to the unit over those two years. It was a time of change in the unit with the introduction of a more proactive recovery approach with the focus being much more on the individual person, while group programmes and the more structured environment of the past had been dismantled. Whatever the reasons for the dramatic rise in the seclusion rate, they are likely to be complex.

Once the overall use of seclusion had been determined, the events were examined on both a person and event basis.

\section{The PeOPLe}

In the seven years of the audit 102 people were placed in seclusion. As some of these people were secluded in more than one year and were included in the data separately for each year, there were 124 person events over the seven years. Being involved in a seclusion event for more than two years was a rarity (four people of the 102 people audited). This suggested that there were people whose mental disorder was relatively unstable compared to most others and they could possibly benefit from closer monitoring and assessment to determine the reasons for such a pattern of presentation.

The average time spent in seclusion for each person over the seven years was fairly consistent with the exception of the year 2000. In this year people were contained in seclusion for more than 10 hours per person above the average time for any other year. One possible explanation was that 2000 was the only year where there were more than twice the number of males than females placed in seclusion. None of the literature reviewed for this study investigated gender in relation to length of time in seclusion. Several possibilities exist for males being held in seclusion longer than females, they may be more aggressive or take longer to calm down, or they may simply be perceived as being more dangerous, whereas females may appear to settle 
more quickly and easily. It may also reflect the staffing situation at the time: if there were mainly female staff in the unit then males may be held longer in seclusion as they could be seen as more of a threat. This is something that could be explored in the future.

\section{PREDictors FOR SECLUSION}

Gender was not a predictor for seclusion use in this study with males and females equally involved in seclusion events. It was not clear whether this was related to the admission rates for males and females as these figures were not available. As schizophrenia (the most common diagnosis for people with seclusion events) is more commonly diagnosed in young males it could be expected that more males than females would be secluded, but this was not the case. One possibility is that males may have been admitted to the unit more readily than females as they may have had a clearer diagnostic picture. If females, who tended to be more involved in self harm behaviours and to exhibit borderline traits, had their admissions delayed then they may have had a higher acuity at the time of admission. The gender of people who are placed in seclusion has been discussed in the literature. The results here were similar to other studies where no gender or ethnic differences in the use of seclusion were found (Hammill, 1987; Kasper et al., 1997; LeGris et al., 1999).

In contrast to these studies, El-Badri and Mellsop (2002) identified that male patients and non-European patients were more likely to be placed in seclusion. The results of this study also confirmed the findings by El-Badri and Mellsop that the most frequent diagnoses were schizophrenia, mania and substance abuse. LeGris et al. (1999) also reported that people were secluded more often if they had substance abuse problems.

However, in contrast to this study, no patients with personality disorders were secluded in the study by El-Badri and Mellsop (2002), and the authors reported extensive use of specialling patients on a one-to-one basis. While they did not provide details of the relationship between specialling and gender, it is possible this was used more for females, hence the higher number of males being secluded. 
I have not analysed the present data on the basis of ethnicity due to the low numbers of Maori and other populations. People who identified as Maori were only involved in seclusion events in four of the seven years audited with people from other ethnic origins involved in only two years.

This raises an issue related to cultural safety and the need to ensure that due respect is paid to people's cultural identity. As the unit mainly serviced a white population and frequently did not have people from other cultures as in-patients, staff awareness of cultural identity and the need to ensure a person's cultural needs were met may not have been as developed as in some other units. The reality is that in a unit that functions primarily for a white population there will be subtle institutional practices that work more for the white population than for a racially mixed population. The unit should encompass the Maori mental health in a holistic manner so that a deeper understanding of Maori culture is developed and incorporated within the unit.

This study confirmed earlier findings (Hammill, 1987; Kasper et al., 1997; LeGris et al., 1999) that the younger people were, the more likely they were to be secluded, and that there was a steady decline in seclusion use as people got older.

\section{The Mental Health (CAT) Act 1992}

Generally, MHA processes were in place at the time of the seclusion event. On the rare occasions where it was noted that a person was an informal patient at the time of the seclusion event, this related to failures in administrative processes where the MHA had been allowed to lapse or the papers were not contained in a person's file.

There was one instance where a person was held under Section 111 for longer than the stipulated time in the MHA of six hours. It was unclear from the patient's file why the initial processes leading to committal (Sections 8A, 8B and 9) were not started. However, on the particular night in question the on-call psychiatrist was 160 kilometres away and only available by phone. This was not a situation that was occurring at the time of this study because visiting psychiatrists were travelling to the area when required for on call work. 


\section{AdMissions INTO SECLUSION}

On frequent occasions (43 percent of admissions with a seclusion event) a person was admitted directly into seclusion when they arrived at the unit. This indicated that many people were in the early acute stage of their illness when seclusion events first occurred. Participants noted that acuity was an important factor for seclusion use. They discussed that often there was police involvement on these occasions which indicated that the person was so unwell and with such little insight into their illness that they were not co-operating with the mental health team. But there were other occasions where the decision was made by the consultant psychiatrist that a person should go into seclusion that nursing staff did not agree with or understand the rationale for, but felt they had to comply with this direction.

The New Zealand Standard states that "The decision to use seclusion should be based on the assessment of the individual consumer. It should not occur as part of a routine admission procedure” (Standards New Zealand, 2001, p. 34). The number of people admitted directly to seclusion appeared high, however, no literature on this subject was found with which to compare these results. While participants discussed times where the use of seclusion seemed to be appropriate, there were also occasions where they felt its use at admission was questionable. This could occur where the decision for seclusion was made based on an assessment being made in the community but the person settled once they realised they were in hospital - a place that some people recognise as a safe environment when they are unwell. On other occasions seclusion was determined necessary by the psychiatrist because of a person's continued risk of absconding although the person had been returned after dark when the unit was locked. This made it unlikely (from the nursing staff's knowledge and experience of the patient) that some people would make serious attempts to leave the unit.

\section{TIMING OF EVENTS}

Two ways in which seclusion events were further analysed related to the day of the week and the time of day. Monday was a day where seclusion was used less often 
with Sunday being a high usage day. The reasons for the fluctuation from the average in this study were unclear although it was possible that the low numbers on Monday were a reflection of the higher than average seclusion events that occurred on Sunday. People could be more settled on Monday following weekend leave or because of the more interactive environment compared with the weekend. Other possibilities included that people left in hospital at the weekend were usually those who were more unwell, or people who were admitted at the weekend had less attention or structure than they would have if they had been admitted during the week. Increased rates of visitors leading to higher anxiety or stress levels, or a lack of things to do leading to boredom could also have influenced seclusion use during the weekend. Staffing patterns and the use of casual staff may also have had an impact on the weekend rates of seclusion. All other days of the week approximated the expected daily average number of seclusion events when divided over the seven days. O’Malley et al. (2003) in their study concluded that although seclusion rates were higher on weekend days there was no significant trend and did not, therefore, provide any suggestions for such a pattern of use. Whatever the reasons for the Sunday and Monday rates of seclusion deviating from the average, they are likely to be a combination of several factors.

Some studies on the daily timing of events have reported correlations between seclusion and busy times in psychiatric units. Mealtimes (both for patients and staff), staff handovers and medicine rounds have all been postulated as times when seclusion events increase (Morrison, 1990; Thompson, 1986). Russell, Hodgkinson and Hillis (1986) also found seclusion events were related to staff mealtimes but did not find any correspondence with staff handovers. In this present study an increase in seclusion use occurred during afternoons and evenings compared with mornings, and there was another, smaller peak, in the late evening. The two largest peaks occurred between the hours of 1500-1600 hours (afternoon handover) and 1700-1800 hours (teatime). While it was possible that a peak in the number of seclusion events could be directly attributable to these activities, other possibilities included the timing of admissions being more often during the afternoon, and seclusion events being deliberately timed for handovers when there were more staff in the unit. Such activities would artificially inflate the figures at these times. In their conference presentation, O’Malley et al. (2003) noted that in their study they found that 
seclusion rates were consistently higher in the evenings between 1600 and 2400 hours but also that 45 per cent of admissions occurred during those times.

\section{REASONS FOR SECLUSION}

Seclusion is generally seen as an emergency measure when less restrictive measures have failed or are deemed inappropriate, and it is mostly used as a result of threatened or actual violence, or for the control of disruptive and aggressive behaviour (Kozub \& Skidmore, 2001b; Marangos-Frost \& Wells, 2000; MuirCochrane et al., 2002; Wynaden et al., 2001). In his dissertation, Johnson (1997) identified violent behaviour as the most important factor when decisions to seclude people were made. He also identified six other factors that were important in seclusion decisions and described each of the seven themes (see Appendix L).

During the file audit, I coded each of the seclusion events according to Johnson's (1997) seclusion themes. Data analysis produced a similar finding to Johnson and other authors noted above. This study identified that seclusion was most often used when there was threatened or actual violence, aggression and threatening behaviour. The participants in the interviews confirmed this finding and common themes that they voiced for putting persons into seclusion were the for safety of that person and for the safety of other patients, and for aggression and violent behaviour.

\section{AbSCONDing AND SELF HARM}

Johnson (1997) made no reference to the possibility of placing people in seclusion because they were at risk of absconding from the unit. This was most likely due to the fact that his research was conducted in a special hospital where the units were locked and there are high security measures in place. He also made only passing reference to self-harm behaviours. A possible further reason was that the objective of his study was to look at continuing or terminating a seclusion event rather than initiating an event. This posed a dilemma for me when coding the seclusion events. I 
made the decision to code these events according to the second of Johnson's themes as the definition related to self-control and included agitation, frustration, the inability to tolerate frustration or impulses and failure to keep to contracted behaviours.

Prominent during the discussion with participants was that seclusion was used to prevent persons absconding from the unit in the context of them possibly harming themselves or at risk of self-neglect. Prevention of absconding was apparent during the file audit and this was also raised in the accreditation report (Clark et al., 2003) where this was not deemed an appropriate use of seclusion.

The reason that concerns about people absconding from the unit assumed such a high profile was that the unit in this study was classified as an open unit and the doors were unlocked during daylight hours. It was also not possible to fully monitor who was entering or leaving the building, in part due to the large number of exit points. This made it difficult to assume a positive risk management position in maintaining people's safety. Further, public pressure, media attention and events of self-harm were also discussed both by participants and in documentation as reasons for containing people 'just in case'. This again spotlights the continuing dilemma faced by nursing professionals of needing to maintain the safety of both the individual and those with whom they come in contact against the right of the individual to freedom of movement and self-responsibility.

\section{THE OPEN UNIT}

Participants in this study discussed the open unit in the context of the environment. They all agreed that the open unit policy was a good one, that it generally made people feel more positive about their stay and allowed them some sense of responsibility for their care. However, when this was considered alongside the need to place someone in seclusion to prevent them from absconding there were diverse views expressed. Some participants did not have a problem with people being placed in seclusion because of this, while others felt that there was a case for the unit being locked for short periods rather than placing someone in seclusion. 
Participants felt that someone should be placed in seclusion if they posed a risk of absconding and there were serious concerns about that person's safety should they leave the unit. However, it should not be for an extended period even if the person continued to say they would leave the unit but appeared otherwise settled. The use of seclusion or not should be made after team discussion and should be based on an objective assessment. Important things to consider were assessment of risk, historical factors, and whether the person was known to the service. Staff knowledge, experience and confidence were valuable in handling such situations.

\section{NURSING ISSUES}

Issues for nurses were often highlighted in the literature because much of the work around seclusion initiation, monitoring and assessment came within their role. The dilemma between dealing with people being held compulsorily in an enforcement role and the desire to work as therapeutic allies and to promote self-responsibility was not easily resolved (Lakeman, 2000; Mohr \& Horton-Deutsch, 2001; Stowers et al., 2002). While participants acknowledged that making the decision to place someone in seclusion was difficult, they accepted that it was better to make an early decision than to let a situation get further out of control. This could lead to further distress, undignified or embarrassing behaviour or place either the patient or other people in the immediate environment in danger from potential violence and aggression.

The decision to seclude is a dilemma that is difficult to resolve. I believe that part of nurses' ambivalence about placing a person in seclusion stems from not knowing, once a person has been placed in seclusion, whether the situation would have resolved itself or whether it would have continued to deteriorate. Some people settle immediately they are placed in seclusion and this could be a response to staff taking control of a situation over which the person has lost control. On the other hand, some people react badly and dramatically to being placed in seclusion. Olofsson and Norberg (2001) advocated that staff should wait and see instead of acting prematurely, but this could lead to further deterioration in behaviour. Experience, an understanding and knowledge of the particular person involved and the nurse's own 
ability and skill in decision-making and handling delicate situations are all crucial if the most appropriate decision is to be made and a positive outcome is to be achieved.

Other influences that the literature identified as affecting seclusion events included staff:patient ratios, the number of casual staff, the experience of nurses, the ratio of registered nurses to other staff and the gender balance for each duty (Bonner et al., 2002; Donat, 2002). These factors were not examined in this study although participants spontaneously referred to staff experience, consistency among staff and the need to work together as a team to achieve a satisfactory resolution to events, and for nurses to feel supported and respected by both the management team and their colleagues.

A further concern raised during the interviews was the lack of restraint training being carried out. With the turnover of staff, more and more people were not trained in full restraint techniques and felt inadequate in situations that potentially could lead to a restraint and seclusion. There also appeared to be some confusion among nursing staff about what they should do when confronted with a person who was wanting to leave the unit or who was acting aggressively and needed to be physically detained. While some people believed the policy now was to let them go and involve the police in controlling the situation, others felt this was antithesis to their role as nurses working from a health model with a person who was unwell and had impaired judgement. In an article written in response to a United Kingdom enquiry into the death of a patient while in restraint, Paterson and Leadbetter (2004, p. 13) noted that the use of the police resulted in some very serious problems: "including the transmission of a value base and culture which have absolutely no place in caring services”.

Such confusion and lack of understanding of what was expected has detrimental effects on important factors such as the need for consistency, team work, support and respect of colleagues. If nursing staff acted from their own position without clear and specific guidelines of what was expected, then crises would be handled inadequately to the detriment of both the patients they care for and staff relationships. There has been some evidence to suggest that when units were staffed with people trained and experienced in proper restraint techniques, where staff worked together and 
benefited from good leadership, then staff related injuries were reduced and the units tended to be less violent (Paterson \& Leadbetter, 2004).

\section{Coding SECLUSION USE (Johnson, 1997)}

For the purposes of this study I chose to use a checklist developed by Johnson (1997) to code the reasons for seclusion use. His checklist was divided into seven themes (see Appendix L). While I found this method of grouping determinants for seclusion a useful guide it also had some drawbacks which made it difficult to code some items.

An initial reservation about using this checklist was that Johnson's aim was to focus on aspects that were important in deciding whether to continue or terminate a seclusion event. Notwithstanding this, I felt that the themes he identified were also relevant to initiating seclusion, partly because one of the ways Johnson identified these aspects was from literature about initiating seclusion. The main difficulty I encountered was coding those events where the main factor was related to a person absconding from the unit that occurred prior to the seclusion event.

Nowhere in his study did Johnson (1997) clearly outline a definition for each of the themes so the information in Appendix $\mathrm{L}$ is a compilation of statements contained within his text.

Another concern was that, although Johnson (1997) ranked the factors considered to be important after he surveyed colleagues, the seven themes did not appear to be mutually exclusive, nor were they ranked according to priority or gravity of the behaviour. The first theme of violence and threat of violence certainly had a higher priority than the other themes. The next theme seemed to be graded at a second level and related to agitation and frustration as a precursor to violence. The following three themes, though, each appeared to be related more to a particular mental disorder, these being psychosis, mood, and perceptual disturbances respectively. There was considerable overlap between each of these three themes and occasionally 
with the second theme. This made coding difficult at times and was the main reason for the discrepancies encountered in the coding procedure at time one and time two.

The final two themes related to compliance and external variables were much more clearly defined and easier to code.

Johnson's (1997) method of coding reasons for seclusion use has been useful in that it has enabled me to describe more succinctly what the precursors were to an event. However, if a similar study was to be repeated it would be an advantage to refine the coding system first to ensure that each theme is clearly defined and distinct from each of the others to ensure more accurate coding of seclusion events.

\section{PreferRed InTERVENTIONS}

Seclusion should not be the first choice in the management of escalating and unmanageable behaviour. There are other ways of dealing with this before more restrictive means are considered. De-escalation skills and alternative interventions are the means by which nurses endeavour to alleviate a situation or to prevent it from becoming overwhelming or out of control so that seclusion becomes inevitable. Techniques include good communication skills, developing a therapeutic relationship and being able to engage with a person, having patience and tolerance when talking with a person, setting boundaries and being consistent, the use of diversional activities, promoting low stimulus and quiet time, the considered use of appropriate medication, and involving family where possible.

A particular intervention that was discussed in relation to the unit in this study was the use of specialling or providing one-to-one nursing care for patients who required close observation. It was a concern of most participants that this type of intervention was not used as much as previously. It was considered a much more humane way of caring for someone who was unwell, and at risk of absconding or of self harm. Part of the reason for the low use of specialling appeared to be related to lack of nursing staff or the problems associated with trying to get staff at short notice. However, it 
was also possible that a lack of guidance in relation to such staffing issues had impacted on the use of one-to-one nursing.

Interventions that use good de-escalation and communication skills only work where there is a degree of co-operation on the part of the person involved. One comment during the interviews was that aggression never came out of the blue, that there was always a lead up to it and that it was up to nurses to recognise this and to deal with it. Such comments lay the blame directly on nursing staff when seclusion becomes necessary. In reality, in mental health settings pathological factors must be considered; there will always be some people who are impulsively aggressive, people for whom medication does not seem to work, who do not respond to nursing interventions and, more and more, people with mental health issues who are also under the influence of illicit drugs. These people continue to pose a risk of violence and aggressive behaviour towards staff and other patients alike (Castle \& Prescott, 2001).

The argument that nurses should recognise the precursors to aggression and take action to remedy the situation, is promoted by some service users and other advocates for abolishing seclusion use (O’Hagan, 2003; Smith, 1998). This also limits the opportunity for discussion on the choice of interventions for high-risk behaviours with others in the group of people for whom such choices have a huge impact. We, as professionals, do not have knowledge of a range of patient opinions regarding the choice of interventions to manage their high-risk or self-harm behaviour.

\section{A Suitable ACUTE ENVIRONMENT}

While accepting that seclusion is sometimes inevitable in the present environment, participants did not feel that the environment was conducive to adequate privacy and care of the person secluded due to the design of the building, layout of facilities and positioning of the acute area. Specifically, participants believed it was unacceptable that people were brought through the front door directly into a lounge area where 
patients and visitors congregated. They were concerned that the seclusion rooms were not able to be separated from the rest of the unit, that other patients had access to the acute area and that some general bedrooms were situated beyond the seclusion rooms.

If the acute area was to be more user friendly, it was noted that there should be a separate entrance, that other patients should not have access to the area and that it should be possible to close it off from the rest of the unit. A separate area would also enable the use of a quiet room and low stimulus facilities, something that was difficult to achieve in the current environment as the people most in need of this type of intervention (those with mania and some with psychosis) were the ones that gravitated towards high stimulus areas.

Privacy issues were also a concern due to the corridor being a thoroughfare to other rooms. In response to a reference by the accreditation team (Clark et al., 2003) curtains were placed over the windows of the seclusion rooms. Participants felt that this action infringed further on the rights of people in seclusion as it isolated them more by removing their ability to see outside the room which, participants felt, would be distressing for the person. It also prevented them from viewing the clock on the wall in the corridor. The New Zealand Standard (Standards New Zealand, 2001, p. 36) states it is desirable that: "assistance be given to providing a means of orientation (time, date, news, and other information).”

When a person was shut in the seclusion room it was difficult for other people walking in the corridor to look into the windows without it being very obvious what they were doing. The principle time that visual access was available to passers-by was when nursing staff were attending to the person in seclusion and it was staff practice to monitor the area to ensure that the person's privacy was maintained as much as possible. Of more concern was the lack of soundproofing of the area. When people were distressed and creating a lot of noise over extended periods of time then everyone in the environment was aware of it so the person's right to privacy was infringed, their dignity was compromised, and it could be very distressing to other patients in the unit. There was also concern at the way toileting needs were dealt with in the seclusion environment. 
While one participant tempered their comments by referring to the lack of money available for alterations, others felt that this issue should have been attended to when renovations were carried out in the months preceding this study. A better designed secure area that provided facilities to improve the quality of patient care should have been a priority at this time. Further, during the time these interviews were being conducted, the local District Health Board announced a surplus in mental health funding of $\$ 1.5$ million that the Board planned (subject to ministerial approval) to return to the Ministry of Health as repayment of equity (Pickering, 2004). It was felt that, even if this money was not originally to be spent on capital works, if approval could be given for it to be diverted elsewhere then it could have been diverted back in a way that directly benefited mental health.

\section{RECOVERY}

The focus on recovery in recent years has led to criticism of practices such as seclusion because they do not sit well alongside initiatives that encourage service users to take responsibility for their own lives (O’Hagan, 2003; Yee \& Bateman, 2003). The final objective of this study was to explore how nurses reconciled the use of seclusion with recovery and the strengths model as a recovery tool which was being used in the in-patient unit. During the interviews, participants were asked about the role of recovery and the strengths model during a seclusion event. Most participants felt that the use of the strengths model during a seclusion event was not an imperative. However, the emphasis should remain on the principles of recovery as the therapeutic basis for nurses working with people in seclusion. The aim was to work together to assist patients to regain control and for seclusion to be discontinued as soon as possible.

Part of the difficulty in reconciling the strengths model with seclusion lay with the model's emphasis on encouraging self-determined goals. Participants felt that when a person was acutely unwell with a mental disorder their ability to take control and to make decisions that were reality-based and suitable for their circumstances was 
largely impaired. This was most apparent in times of crisis where interventions such as seclusion needed to be used. Participants recognised the need for nurses to take control during this time but believed they could still remain recovery-focused. In this sense recovery was about encouragement, guiding the person towards improvement and ensuring they were fully informed along each step of the journey until the person was able to take responsibility again for their own decisions.

In discussion about the strengths model, participants felt that they could not use it as part of a seclusion event because of the person's impaired mental state. It was generally seen as a model that should be used more in the sub-acute stage of a person's admission rather than the acute stage. The main issue, as participants saw it, was that the strengths model was expected to be used within the service to conform with the requirements of the service and audit standards rather than being used in a way that was true to the developer's intentions. The strengths model with its strengths assessment and goal planning techniques was promoted as a technique that was initiated by the person, was person-centred, and driven by the individual. However, some participants stated that they often felt pressured to introduce it and direct its use in compliance with service standards rather than in response to a person achieving a suitable stage of recovery or to a person's willingness to engage in the actual process.

In my article (Mosley, 2002b) I addressed the issue of the most apt time to introduce the strengths model, and I developed a staged approach to its introduction based on acuity and the level of recovery of the person participating. This then left the decision to nursing staff and the person themselves to decide when and if the time was right to start strengths work. In any service where the core belief is that clients should take personal responsibility for their recovery, the impetus should be with the person, once they are at a stage of recovery to make a reality-based decision, to determine their rate and mode of involvement. It should not be driven by service requirements or standards. 


\section{SIGNIFICANCE OF THIS STUDY}

This study was practice-based and investigated matters of interest and concern to the in-patient setting in order to provide information related to seclusion use. The purpose of this was to establish the real rate of seclusion use, the reasons for its use and how nurses approached seclusion. This study has provided this information and has produced some useful and practical recommendations about seclusion practice (see Chapter Ten).

An incentive for this study was an expressed desire by management to engage in a process of minimisation or reduction in seclusion use as documented in the quality project (Appendices B and C). The information gathered for this study indicated that caution needed to be taken when encouraging a reduction in the use of seclusion. Efforts to prevent its use when the clinical indicators suggested seclusion was necessary should not impact negatively on the safety of everyone in the immediate environment.

A further concern was the discrepancies discovered between the reported issues raised by the accreditation team (Clark et al., 2003) and the responses of participants to those issues. Some issues presented by the team about absconding patients were negated by the comments from the participants and the findings of the file audit. The participants also noted that an over-zealous reaction to one of the team's findings by hanging curtains over the seclusion room windows further infringed on the rights of people placed in seclusion. Conversely, participants reported incidents connected with seclusion use that were of concern and of which the accreditation team appeared unaware.

\section{LIMITATIONS OF THIS STUDY}

A limitation of this study was the reliance on retrospective data obtained from patient files where the information was collected for purposes other than research. While the information was written at the time of the event it described, it was not 
possible to accurately determine the meanings the writers attempted to impart through the descriptions so interpretations have had to be made on the basis of the descriptions.

The participants who volunteered to be interviewed may be different to those who were not interviewed. The likelihood of volunteer bias had the potential to affect the results as the people who volunteered may be different in fundamental ways to people who did not volunteer.

As reported earlier, the audit may have produced a conservative estimate of actual seclusion use due to missing data. By examining only the files of known seclusion events, files with seclusion events which were not recorded in the seclusion register may have been missed.

The thematic coding of reasons for seclusion use (Johnson, 1997) were not fully compatible with the identified reasons for use in this study. It was thus necessary to amend the published themes to enable all the seclusion events to be coded to accurately reflect the incidents described.

Notwithstanding the above limitations, this study has demonstrated that seclusion use in the in-patient unit in this study closely followed the patterns described in other studies. I have not found any unusual patterns in the distribution of seclusion use by diagnosis, demography or by other relevant bases in the unit. The reasons for the increase in seclusion use in the two years prior to this study are not readily identifiable but are likely to be complex.

Following the conclusions in the next chapter, I set out a number of recommendations in Chapter Ten. These have been developed from the issues that have been raised in this study. 


\section{CHAPTER 9: CONCLUSIONS}

The decision to use seclusion as a clinical management option in mental health inpatient units is a complex issue that raises many questions around the need to provide treatment in the least restrictive manner but where the safety of other people within the unit milieu also needs to be considered. Balancing these two concepts can often be fraught with difficulty as nursing staff are expected to ensure that the rights of everyone involved are preserved to the utmost.

This study investigated the use of seclusion in one in-patient unit to determine the extent of seclusion use, the precipitants for its use and the processes nursing staff go through when making a decision to utilise seclusion. Personal, professional and environmental issues in the context of policies and protocols were raised by participants. In particular, the desire to work from a recovery and strengths based perspective was an important consideration.

A literature search and review was conducted to establish the factors that were recognised as being associated with the decision to initiate seclusion. Previous work on establishing themes for seclusion use was discovered during this search (Johnson, 1997) and this work was used and extended to provide a structure for exploring the reasons for seclusion use in the unit described in this study.

When investigating the availability of seclusion data for New Zealand it was noted that there was very little accessible and, where information was available, it was not possible to compare use with other units because of different sizes, structures and whether units were secure, locked or open units. Further, although it remains a legislative requirement that each mental health unit keeps documentary evidence of seclusion use, this is not collated at a national level. This is a serious omission that needs to be rectified if the true extent of seclusion use in New Zealand is to be identified and monitored. 
In order to determine the extent of seclusion use in the unit, a file audit was carried out and this provided sufficient data to investigate its overall use according to demographic and clinical information. This information revealed that in some areas education was needed, particularly in meeting legislative and performance requirements in recording and documenting accurate information. It also raised questions about clinical management and treatment of people who were noted to have repeated admissions where seclusion was utilised, sometimes over a number of years.

Demographic information was informative in that it largely concurred with published literature that males and females were likely to be secluded in equal numbers and that seclusion was utilised less as people get older. It also raised some questions including whether males were held in seclusion longer than females and whether there were demographic and clinical differences between people who were placed in seclusion compared to those who were not. This would require a far larger study that investigated all admissions to the unit.

When the clinical basis for nurses making seclusion decisions was explored, it was most often for aggressive and violent incidents and this concurred with evidence elicited from the literature review. Of note was the use of seclusion for persons who had previously absconded or were at serious risk of absconding, particularly in relation to suicidal or self harm behaviours. It was frequently used in these situations although this was a use of seclusion not entirely approved of by an accreditation team (Clark et al., 2003). Other important considerations were the need for a low stimulus environment, to decrease sensory input, and to ensure the safety of persons who were actively psychotic.

Practice issues that nursing staff raised included the use of de-escalation techniques, the use of one-to-one nursing for persons at risk, and the importance of experienced staff. The need for clinical training and education regarding professional standards and practical skills were identified, as was further clinical direction regarding seclusion use. A dedicated acute area that addressed privacy concerns was also discussed. Other performance improvement measures included monitoring all use of 
seclusion to identify the root causes for its use, and reviewing each incident as it occurred with debriefing, discussion and feedback for all nursing staff.

This study also explored the beliefs and attitudes of nurses to the use of seclusion when considered alongside a recovery philosophy and the use of the strengths model (Rapp, 1998) that promoted self-responsibility. It was agreed that all nursing work in an acute environment should be recovery driven, but the use of models that required the person to actively participate from a reality-based perspective may not be suitable for people in the acute stages of their illness. The timing of the use of the strengths model should coincide with a person being more able to take control of their own recovery when their cognitive functioning is not impaired by severe anxiety, an unstable mood or impaired thought processes.

While minimising seclusion use is a primary objective in the present recovery environment, this needs to be considered alongside ensuring the safety and dignity of everyone who may be at risk when a person presents with a major mental health issue. People who advocate for a seclusion free environment discuss this in terms of being able to rationalise the precipitating situation with the person concerned, and being able to de-escalate the situation before it becomes too far out of control. They also suggest that the trauma caused by being put into seclusion can increase the harm to the person secluded (Altenor, 2000; O’Hagan, 2003). However, sometimes a person is so mentally incapacitated that they cannot make an informed decision about treatment themselves, a fact often overlooked by those calling for the abolition of such methods (Green, 2000). The reality is that in an acute in-patient unit nursing staff continue to be challenged with people who are violent, aggressive or otherwise out of control due to the effects of their mental illness to an extent that they cannot be reasoned with and cannot respond rationally to anything said or going on around them. It is my experience that admissions of people with drug induced psychoses are also becoming more common and, while they continue to be under the influence of illicit drugs, they often are unable to be reasoned with and are unmindful of the effects of their behaviour.

It is possible to eliminate seclusion as a management option but it would need to be replaced with an intensive, focused facility that had the staffing, resources and 
professional expertise to deal with very difficult and challenging behaviours in the context of mental illness. Otherwise, seclusion will continue as a clinical option for people who are so unwell that they cannot be managed in any other way with the facilities available. But it must be used with the utmost consideration given to the dignity and privacy of the person concerned. However, it was also apparent from this study that there were many circumstances where patients, such as those who were at risk of self harm, of absconding, or who were anxious, agitated or disruptive, could have been managed in a more caring, sensitive and compassionate manner if the clinical and management focus was clearer, and sufficient resources and facilities had been made available.

The containment, management and treatment of people in the acute stages of mental illness is vital and potentially less damaging to their long term recovery than if their symptomology was left unchecked. Seclusion is one strategy that continues to be used in such circumstances where there is no other viable option. If in-patient units are going to make the seclusion experience the best that it can be for all persons concerned, and if they are going to work towards minimising the use of seclusion, then they need to provide the best facilities and resources available. Some options are discussed in the final chapter, which contains a list of recommendations for the unit investigated for this study. 


\section{CHAPTER 10: RECOMMENDATIONS}

The focus of this final chapter is on bringing everything discussed earlier together and making recommendations for the future management of seclusion in the unit where this study took place. These recommendations are divided into six separate topics. Firstly, I suggest some options for education and ongoing training for staff to enhance their interpersonal skills, develop strong therapeutic relationships and, if there is no alternative, to manage episodes of violence or aggression in the unit. The second group of recommendations is a response to the management of actual seclusion events while the third set of recommendations is about monitoring seclusion events and providing the emphasis that such events require if they are to remain 'unusual' or exceptional events. I then discuss some actions that could be taken to improve the seclusion facilities. One important consideration throughout this study has been the reduction of seclusion use and how this could be achieved. The fifth group of recommendations focuses on this. Some areas for future research have been suggested during the discussion chapter, and I have brought these together here in the final section.

\section{EDUCATION AND TRAINING}

There is always a risk of some people becoming violent or aggressive in the context of their mental illness. For this reason nursing staff need to be provided with adequate levels of training in the management of violence and aggression and in other important nursing areas such as cultural identification and awareness, deescalation, communication skills, therapeutic interventions, rapid tranquilisation, and an understanding of the policies and protocols in relation to seclusion. Training and education should be provided in the following areas: 
- Provide regular in-service training sessions to update, discuss and monitor seclusion practice (four-monthly but more often if there has been a rapid turnover of staff)

- Provide nursing staff with regular opportunities to update their de-escalation and communication skills (four-monthly or more often if there has been a rapid turnover of staff)

- Ensure staff understand their cultural responsibilities to Maori in seclusion and are fully aware of their obligations under the Treaty of Waitangi

- Provide in-service sessions regarding the appropriate procedure for rapid tranquilisation and ensure staff are aware of issues related to its use

- Encourage staff to express their opinions, views, attitudes to seclusion and ensure they have the opportunity to put to the proposed seclusion committee any concerns, problems or suggestions they may have

- Ensure that nursing staff have a full and comprehensive debriefing after each seclusion event

- Maintain training in calming and restraint as this is important for all staff if they are to feel confident in their ability to handle difficult situations.

\section{ManAgement of SECLUSion EVEnTs}

Every seclusion event should be treated as an unusual event that requires full intervention by nursing staff. It is important that:

- The patient in seclusion should have one nurse dedicated to their care each duty. This nurse should not have responsibility for other patients or for other duties. His or her primary focus is the patient in seclusion 
- The nurse should maintain close observations and remain in close proximity to the patient

- The Maori mental health team are fully informed and involved in any seclusion events with Maori

- A comprehensive assessment of the patient's mental state and current risk is carried out at least once per duty

- A dialogue with the patient is maintained where this is possible, and ensure the patient is kept aware that a staff member is available for their needs at all times. By maintaining direct contact with the patient, it is an ideal time to begin establishing a therapeutic relationship, to keep them fully informed about what is occurring and to focus on positive steps that can be taken towards recovery and the future

- Judicious use of available staff is made to eliminate the need to call for police assistance except in an absolute emergency when all other means of containing a situation have been attempted.

\section{SECLUSION MONITORING}

The seclusion policy sets out the requirements for regular seclusion meetings. To the best of my knowledge such meetings do not take place with staff who are directly involved in seclusion events. It is possible that such meetings are held at a management level. I recommend that a seclusion committee be set up with the following mandate:

- That the committee consists of at least the clinical leader of the unit, two registered nurses from the unit, the Maori adviser, and the consumer adviser 
- That the committee meets at least bi-monthly to maintain the impetus for improvement and reduction in seclusion use

- That every seclusion event is treated as an unusual event and the process of each event is reviewed individually by this committee

- That the committee ensures that proper policies and procedures are adhered to for each seclusion event

- That the committee reviews the required documentation for seclusion events. Both the paperwork required at the commencement of a seclusion event and that used for the duration of the event could benefit from reorganisation and amalgamation where possible. The objective would be to ensure documentation is more concise, specific and user-friendly

- That the committee maintains an overview of seclusion facilities and works towards ensuring that these are suitable for their purpose and are maintained to a high standard. Recommendations for seclusion facilities are included in this chapter

- That the committee maintains a dialogue with the accreditation team, takes an active role in any local or national seclusion initiatives, and ensures it makes use of opportunities to have input into any revisions, amendments or alterations to the New Zealand Standards

- That the minutes of the meetings are available to all staff.

\section{SECLUSION FACILITIES}

One of the important features of acute inpatient care provision is a suitable unit environment in which to maintain patient safety, privacy and dignity. This is especially important when a person is so unwell that segregation from the general 
areas of the unit or the use of seclusion needs to be considered. The short-comings of the present seclusion facilities have been described in this report. If improvements are to be made to the current situation, and the use of seclusion is to continue as a management option, then the following changes should be considered:

- The development of an intensive care suite (acute area) designed to meet the most recent safety standards should be the most desirable objective. This should include a quiet lounge area, bedroom and bathroom facilities and a seclusion $\mathrm{room} / \mathrm{s}$

- Investigate possible alternative sites within the unit complex for the acute area

- Provide a separate entrance for the acute area ensuring that it is away from public view

- The acute area should be separate from the rest of the unit and should be designed so that access is not available for other patients or for visitors to the unit

- Bathroom facilities, designed for maximum safety, should be provided in each seclusion room, bedroom and quiet room area.

This area would therefore provide a range of intensive care nursing options for those patients who are so unwell that integration with the main unit is not an immediately viable option, and would also provide the opportunity to achieve further reduction in seclusion use.

\section{Minimisation OF SECLUSiON}

While continuing to provide seclusion facilities for those rare occasions where there is no alternative, the main objective should be the reduction in use and the eventual elimination of seclusion. In addition to the improvements to facilities outlined above, the following are further ways in which further reductions could be achieved: 
- Identify those people with multiple seclusion events over a number of years. Closer monitoring and regular assessment of their mental state in the community may contribute to them presenting acutely on a less frequent basis

- Consider the use of one-to-one nursing or specialling patients who would benefit from such interventions. This may require some attention to staffing levels. If the patient is to benefit from such interventions then consideration must be given to the experience and professional expertise of people available for in such a specialised role

- If the ultimate goal is to eliminate seclusion practices, then staff:patient ratios of 2:1 or 3:1 may be required. Staffing levels may need to be adjusted to take account of this. Consideration may need to be given to establishing a larger pool of casual nurses

- The Maori mental health team should play a proactive role in the unit and be present as an integral part of the team both when Maori are present in the unit environment and at other times as their continued presence would maintain staff awareness of cultural issues

- If it is impossible to provide the number of staff needed to keep a person safe, and it is important that a person is not placed in seclusion, then locking the unit in accordance with written policies and protocols may be considered as a last resort

- In any situation where seclusion is considered due to compliance issues or such external variables as have been described here based on Johnson's (1997) thematic coding, then the issue and not the patient should be the focus of attention for improvement or action

- Leadership and direction is important if a reduction in seclusion is to be achieved. Following through on decisions, setting and keeping to plans by all 
staff and ensuring policies and procedures are adhered to will all help to ensure that nursing staff are clear about their roles and responsibilities

- Maintain a well-structured environment with appropriate activities and make full use of professional resources including occupational therapy and social work expertise

- Ensure there is an adequate mix of experienced and more junior staff on duty at all times. Senior staff will provide the expertise and skills necessary to deal with most crises while more junior staff will have the opportunity to learn and grow from such experiences.

\section{FUTURE RESEARCH}

The following suggestions for future research have arisen from this present study:

- If a more comprehensive understanding of seclusion issues is required, then this can only be achieved by conducting a research study that includes all admissions over the period of the research. In this way comparisons can be made between those people who are secluded and those who are not; for example, are there diagnostic, age, cultural or gender differences. For example, the seclusion statistics show males and females are equally likely to be placed in seclusion. Is this similar to total admissions or are there more of one gender than the other admitted to the unit?

- Consumer research exploring their issues, suggestions and feelings regarding ways to keep them safe when they are engaged in high-risk or self-harm behaviours. Much of the literature written by consumers in New Zealand comes from high-profile advocates who may not necessarily represent the views of most consumers of mental health services. 
- Comparison between patients who are placed immediately into seclusion at admission and those who are first placed in seclusion whilst a patient in the unit. Questions to be asked should include the basis for the decision for immediate seclusion, was this a multi-disciplinary team decision, was there police involvement, how did the person settle once they were in seclusion, how long were they held in seclusion compared with those who were not secluded when admitted to the unit but who later required such intervention.

- A further investigation from the present study could explore whether there was a difference in the length of time males spent in seclusion compared with females and, if so, what were the reasons for this difference. If there was a difference, was this related to acuity, to the precipitants for seclusion, were there diagnostic variables, or was it a perceptual difference about gender and dangerousness?

- The coding system for seclusion events used in this audit would benefit from modification and refinement before it was used in future research studies. It could be made more applicable to general acute units, and to precipitating issues that lead to seclusion.

One of the greatest challenges for mental health in-patient services is to reduce the need to isolate people from the general milieu. This will, inevitably, be a gradual process and the subject of continuing debate. While practices such as seclusion continue, then they must be provided in the most humane, caring and compassionate manner possible. Implementation of the above recommendations will go some way to achieving this.

Research and studies such as this, have an important role to play in ensuring that seclusion issues continue to be brought to the attention of those people that can influence and improve delivery of care to those affected adversely by their mental health. 


\section{REFERENCES}

Altenor, A. (2000). Seclusion and restraints. Psychiatric Services, 51 (10) 1318.

Alty, A. (1997). Nurses' learning experience and expressed opinions regarding seclusion practice within one NHS trust. Journal of Advanced Nursing, 25 (4) 786-793.

Alty, A., \& Mason, T. (1994). Seclusion and mental health: A break with the past. London: Chapman \& Hall.

Angold, A. (1989). Seclusion. British Journal of Psychiatry, 154, 437-444.

Atkinson, P., \& Coffey, A. (1997). Analysing documentary realities. In D. Silverman (Ed.). Qualitative research: Theory, method and practice, (pp. 45-62). London: Sage Publications.

Bailey, P.H., \& Tilley, S. (2002). Storytelling and the interpretation of meaning in qualitative research. Journal of Advanced Nursing, 38 (6) 574-583.

Belkin, G.S. (2002). Self-restraint, self-examination: A historical perspective on restraints and ethics in psychiatry. Psychiatric Services, 53 (6) 663-664.

Benner, P. (1984). From novice to expert: Excellence and power in clinical nursing practice. Menlo Park, CA: Addison-Wesley.

Bonner, G., Lowe, T., Rawcliffe, D., \& Wellman, N. (2002). Trauma for all: A pilot study of the subjective experience of physical restraint for mental health inpatients and staff in the UK. Journal of Psychiatric and Mental Health Nursing, 9, 465-473. 
Boud, D., Keogh, R., \& Walker, D. (1985). Promoting reflection in learning: A model. In D. Boud, R. Keogh \& D. Walker (Eds.), Reflection: Turning experience into learning, (pp. 18-40). New York: Nichols Publishing.

Burgess, M. (2002). A guide to the law for nurses and midwives ( $3^{\text {rd }}$ ed.). Auckland: Prentice Hall.

Castle, L., \& Prescott, L. (2001). More on seclusion and restraint ... "Veterans of abuse and daughters of the dark ...” Perspectives in Psychiatric Care, 37 (1) 4.

Chabora, N., Judge-Gorny, M., \& Grogan, K. (2003). The four S model in action for de-escalation: An innovative state hospital-university collaborative endeavor. Journal of Psychosocial Nursing, 41 (1) 22-28.

Clark, P., Akhtar, K., Bartlett, S., Burdett, J., Formby, D., \& Molloy, P. (2003). (Area) DHB: Survey report. Wellington: Quality Health New Zealand.

Craig, C., Ray, F., \& Hix, C. (1989). Seclusion and restraint: Decreasing the discomfort. Journal of Psychosocial Nursing, 27, 7, 16-19.

Davidson C. \& Tolich, M. (Eds.). (2003). Social science research in New Zealand: Many paths to understanding ( $2^{\text {nd }}$ ed.). Auckland: Pearson Education.

de Cangas, J.P.C. (1993). Nursing staff and unit characteristics: Do they affect the use of seclusion? Perspectives in Psychiatric Care, 29 (3) 15-22.

Denzin, N.K., \& Lincoln, Y.S. (1994). Handbook of qualitative research. Thousand Oaks, CA: Sage Publications.

District Health Board. (2002). Mental health services: Service provision framework. (City): Author. 
District Health Board. (2003). Quality project: Continuous reduction in the use of seclusion (stage one). (City): Unpublished paper.

District Health Board. (2004a). Quality project: Continuous reduction in the use of seclusion (stage two). (City): Unpublished paper.

District Health Board. (2004b). (City) Psychiatric Services: Mental Health Service Plan 2004/2005 and Quality Improvement Plan for (City) Psychiatric Services. (City): Unpublished paper.

Donat, D.C. (2002). Impact of improved staffing on seclusion/restraint reliance in a public psychiatric hospital. Psychiatric Rehabilitation Journal, 25 (4) 413416.

Drug Monograph: Zuclopenthixol. (2001). Retrieved 21 July 2002 from http://www.mentalhealth.comm/drug/p30-z30.html

El-Badri, S.M., \& Mellsop, G. (2002). A study of the use of seclusion in an acute psychiatric service. Australian and New Zealand Journal of Psychiatry, 36 (3) 399-403.

Emden, C., \& Sandelowski, M. (1998). The good, the bad and the relative, part one: Conceptions of goodness in qualitative research. International Journal of Nursing Practice, 4, 206-212.

Emden, C., \& Sandelowski, M. (1999). The good, the bad and the relative, part two: Goodness and the criterion problem in qualitative research. International Journal of Nursing Practice, 5, 2-7.

Evans, D. (1997). Reflective learning through practice-based assignments. Conference proceedings: The British Educational Research Association Annual Conference. University of York (11-14 September). Retrieved 18 February 2005 from www.leeds.ac.uk/educol/documents/000000468.htm 
Farrell, G.A., \& Dares, G. (1996). Seclusion or solitary confinement: Therapeutic or punitive treatment? Australian and New Zealand Journal of Mental Health Nursing, 5 (4) 171-179.

Fisher, W.A. (1994). Restraint and seclusion: A review of the literature. American Journal of Psychiatry, 151 (11) 1584-1591.

Frame, J. (1961). An Angel at my Table. Auckland: Random House.

Frame, J. (1982). Faces in the Water. New York: Braziller.

Green, C. (2000). Mental health care and human rights. Mental Health Practice, 4 (4) 8-10.

Griffiths, L. (2001). Does seclusion have a role to play in modern mental health nursing? British Journal of Nursing, 10 (10) 656-661.

Gutheil, T.G. (1978). Observations on the theoretical bases for seclusion of the psychiatric inpatient. American Journal of Psychiatry, 135 (3) 325-328.

Hammill, K. (1987). Seclusion: Inside looking out. Nursing Times, 83 (5) 38-39.

Harrison, D. (2002). Activities and multiprofessional teamwork on a psychiatric unit. British Journal of Therapy and Rehabilitation, 9 (2) 46-50.

Health and Disability Services Act 1993.

Health Research Council of New Zealand. (2004). HRC guidelines for researchers on health research involving Maori. Auckland: Author.

Henare, K., \& Ehrhardt, P. (2004). Support for Maori whanau and Pacific and Asian families and significant others who have been affected by suicide attempts an analysis of the published and grey literature. Wellington: Ministry of Youth Development. 
Holstein, J.A., \& Gubrium, J.F. (1997). Active interviewing. In D. Silverman (Ed.). Qualitative research: Theory, method and practice, (pp. 113-129). London: Sage Publications.

Hummelvoll, J.K., \& Severinsson, E. (2001). Coping with everyday reality: Mental health professionals' reflections on the care provided in an acute psychiatric ward. Australian and New Zealand Journal of Mental Health Nursing, 10 (3) 156-166.

Johns, C. (1998). Caring through a reflective lens: Giving meaning to being a reflective practitioner. Nursing Inquiry, 5, 18-24.

Johnson, D.J. (1997). Factors in the continuance and discontinuance of seclusion in a special hospital. (Masters Dissertation, University of Liverpool).

Kasper, J.A., Hoge, S.K., Feucht-Haviar, T., Cortina, J., \& Cohen, B. (1997). Prospective study of patients' refusal of antipsychotic medication under a physician discretion review procedure. American Journal of Psychiatry, 154 (4) 483-489.

Keltner, N.L., Schwecke, L.H., \& Bostrom, C.E. (1999). Psychiatric Nursing (3 ${ }^{\text {rd }}$ Ed.), St Louis: Mosby.

Kozub, M.L., \& Skidmore, R. (2001a). Seclusion and restraint: Understanding recent changes. Journal of Psychosocial Nursing and Mental Health Services, 39 (3) 24-31, 48-49.

Kozub, M.L., \& Skidmore, R. (2001b). Least to most restrictive interventions: A continuum for mental health care facilities. Journal of Psychosocial Nursing and Mental Health Services, 39 (3) 32-38, 48-49.

Lakeman, R. (2000). Negotiating the ethical minefield of psychiatric nursing practice. Nursing Praxis in New Zealand, 16 (3) 38-48. 
LeGris, J., Walters, M., \& Browne, G. (1999). The impact of seclusion on the treatment outcomes of psychotic in-patients. Journal of Advanced Nursing, 30 (2) 448-459.

Leibrich, J. (1997). College academic address: The doors of perception. Australian and New Zealand Journal of Psychiatry, 31, 36-45.

Leibrich, J. (Gatherer) (1999). A Gift of Stories: Discovering How to Deal with Mental Illness. Dunedin: University of Otago Press.

Lendemeijer, B., \& Shortridge-Baggett, L. (1997). The use of seclusion in psychiatry: A literature review. Scholarly Inquiry for Nursing Practice: An International Journal, 11 (4) 299-315.

Lowe, T., Wellman, N., \& Taylor, R. (2003). Limit-setting and decision-making in the management of aggression. Journal of Advanced Nursing, 41 (2) 154-161.

Marangos-Frost, S., \& Wells, D. (2000). Psychiatric nurses' thoughts and feelings about restraint use: A decision dilemma. Journal of Advanced Nursing, 31 (2) 362-369.

Mason, J. (2002). Qualitative interviewing: Asking, listening and interpreting. In T. May (Ed.), Qualitative research in action, (pp. 225-241). London: Sage Publications.

Mason, T. (1993). Seclusion theory reviewed: A benevolent or malevolent intervention? Medicine, Science and the Law, 33 (2) 95-102.

Mason, T. (1997). An ethnomethodological analysis of the use of seclusion. Journal of Advanced Nursing, 26 (4) 780-789.

Maxwell, J.A. (1992). Understanding and validity in qualitative research. Harvard Educational Review, 62, 279-299. 
McBride, S. (1996). Seclusion versus empowerment: A psychiatric care dilemma. Canadian Nurse, 92 (7) 36-39.

McDonnell, A., \& Reeves, S. (1996). Phasing out seclusion through staff training and support. Nursing Times, 92 (32) 43-44.

McGihon, N.N. (1998). Discharges against medical advice: Provider accountability and psychiatric patients’ rights. Journal of Psychosocial Nursing, 36 (1) 2227.

Mental Health (Compulsory Assessment and Treatment) Act 1992

Mental Health Commission. (1998). Blueprint for mental health services in New Zealand: How things need to be. Wellington: Author.

Mental Health Commission. (2004a). About the Mental Health Commission. Retrieved 7 August 2004 from http://www.mhc.govt.nz/pages/about.htm

Mental Health Commission. (2004b). Seclusion in New Zealand mental health services. Wellington: Author.

Ministry of Health. (1997). Moving forward: The national mental health plan for more and better services. Wellington: Author.

Ministry of Health. (2001). Building on strengths: A guide for action. Wellington: Author.

Ministry of Health. (2004). Improving mental health: The second national mental health and addiction plan 2005-2015 (consultation document). Wellington: Author.

Mohr, W.K., \& Horton-Deutsch, S. (2001). Malfeasance and regaining nursing's moral voice and integrity. Nursing Ethics: An International Journal for Health Care Professionals, 8 (1) 19-35. 
Morrison, P. (1990). A multidimensional scalogram analysis of the use of seclusion in acute psychiatric settings. Journal of Advanced Nursing, 15 (1) 59-66.

Morrison, P., \& le Roux, B. (1987). The practice of seclusion. Nursing Times, 83 (19) 62-66.

Morrison, P., \& Lehane, M. (1995). Staffing levels and seclusion use. Journal of Advanced Nursing, 22 (6) 1193-1202.

Morse, J.M. (Ed.). (1994). Critical issues in qualitative research methods. Thousand Oaks, CA: Sage Publications.

Morse, J.M., \& Field, P.A. (1996). Nursing research: The application of qualitative approaches ( $2^{\text {nd }}$ ed.). London: Chapman \& Hall.

Mosley, B.J. (2000). Seclusion: A literature review. Unpublished manuscript.

Mosley, B.J. (2002a). Literature review: The use of seclusion in acute mental health units. Unpublished manuscript.

Mosley, B.J. (2002b). Building on strengths: Redefining the strengths model for an in-patient unit. Incite: The Mental Health Journal of New Zealand, 2 (2) 3641.

Muir-Cochrane, E., Holmes, C., \& Walton, J. (2002). Law and policy in relation to the use of seclusion in psychiatric hospitals in Australia and New Zealand. Contemporary Nurse, 13 (2/3) 136-145.

Muir-Cochrane, E.C., \& Holmes, C.A. (2001). Legal and ethical aspects of seclusion: An Australian perspective. Journal of Psychiatric and Mental Health Nursing, 8, 501-506.

Myers, S. (1990). Seclusion: A last resort measure. Perspectives in Psychiatric Care, 26 (3) 24-28. 
National Advisory Committee on Health and Disability Support Services Ethics. (2003). Ethical review of observational research, audit and related activities: Discussion document. Wellington: Ministry of Health.

Needham, I., Abderhalden, C., Dassen, T., Haug, H.J., \& Fischer, J.E. (2002). Coercive procedures and facilities in Swiss psychiatry. Swiss Medical Weekly, 132 (19-20) 253-258.

New Zealand Nurses Organisation. (1993). Standards for nursing practice. Wellington: Author.

New Zealand Nurses Organisation. (1995). Code of ethics. Wellington: Author.

Nurses Act 1977

Nursing Council of New Zealand. (1999). Direction and supervision. Wellington: Author.

O’Hagan, M. (2003). Force in mental health services: International user/survivor perspectives. Incite: The Mental Health Journal of New Zealand, 2 (1) 3-14.

O’Malley, J., Wijnveld, A.M., Kerr, N., Kennedy, S., \& Frampton, C. (2003). Seclusion study in AIS. Conference proceedings: Specialised treatment in the inpatient setting. Christchurch, New Zealand (1-2 December).

Olofsson, B., \& Norberg, A. (2001). Experiences of coercion in psychiatric care as narrated by patients, nurses and physicians. Journal of Advanced Nursing, 33 (1) 89-97.

Owen, C., Tarantello, C., Jones, M., \& Tennant, C. (1998). Violence and aggression in psychiatric units. Psychiatric Services, 49 (11) 1452-1457.

Paterson, B., \& Leadbetter, D. (2004). Learning the right lessons. Mental Health Practice, 7 (7) 12-15. 
Patton, M.Q. (2002). Qualitative research and evaluation methods ( $3^{\text {rd }}$ ed.). Thousand Oaks, CA: Sage Publications.

Pickering, H. (2004). Operations windfall at hospital. (Daily newspaper article: name withheld to maintain confidentiality of area). (30 October).

Rapp, C.A. (1998). The Strengths Model: Case management with people suffering from severe and persistent mental illness. New York: Oxford University Press.

Read, J. (2003). Occasional paper no. 2: Emancipation songs: Individual participation by service users in mental health care. Wellington: Mental Health Commission.

Reed, J.L., \& Lyne, M. (2000). Inpatient care of mentally ill people in prison: Results of a year's programme of semistructured inspections. British Medical Journal, 320 (7241) 1031-1034.

Roberts, K., \& Taylor, B. (2002). Nursing research processes: An Australian perspective ( $\left.2^{\text {nd }} e d.\right)$. Melbourne: Nelson ITP.

Rolfe, G., \& Fulbrook, P. (Eds.). (1998). Advanced nursing practice. Oxford: Butterworth-Heinemann.

Russell, D., Hodgkinson, P., \& Hillis, T. (1986). Time out. Nursing Times, 82 (9) 4749.

Sandelowski, M. (2000). Focus on research methods: Whatever happened to qualitative description? Research in Nursing and Health, 23, 334-340.

Sandelowski, M. (2001). Focus on research methods: Real qualitative researchers do not count: The use of numbers in qualitative research. Research in Nursing and Health, 24, 230-240. 
Silverman, D. (2000). Doing qualitative research: A practical handbook. Thousand Oaks, CA: Sage Publications.

Smith, V. (1998). If it isn’t voluntary, it isn’t treatment. MadNation. Retrieved 19 May 2003, from www.madnation.cc/essays/voluntary.htm.

Standards New Zealand. (2001). New Zealand standard: Restraint minimization and safe practice. Wellington: Ministry of Health.

Stowers, C., Crane, C., \& Fahey, M. (2002). How patients and staff view the use of seclusion. Nursing Times, 98 (42) 38-39.

Swanson, J.M., \& Chapman, L. (1994). Inside the black box: Theoretical and methodological issues in conducting evaluation research using a qualitative approach. In J.M. Morse (Ed.), Critical issues in qualitative research methods, (pp. 66-93). Thousand Oaks, CA: Sage Publications.

Terpstra, T.L., Terpstra, T.L., Pettee, E.J., \& Hunter, M. (2001). Nursing staff's attitudes toward seclusion and restraint. Journal of Psychosocial Nursing and Mental Health Services, 39 (5) 20-28, 50-51.

Thompson, P. (1986). The use of seclusion in psychiatric hospitals in the Newcastle area. British Journal of Psychiatry, 149, 471-474.

Turnbull, J., Aitken, I., Black, L., \& Patterson, B. (1990). Turn it around: Short term management for aggression and anger. Journal of Psychosocial Nursing, 28, (6) 6-10.

Valimaki, M., Taipale, J., \& Kaltiala-Heino, R. (2001). Deprivation of liberty in psychiatric treatment: A Finnish perspective. Nursing Ethics: An International Journal for Health Care Professionals, 8 (6) 522-532.

Van Manen, M. (1990). Researching lived experience: Human science for an action sensitive pedagogy. London, Canada : State University of New York Press. 
Vittengl, J.R. (2002). Temporal regularities in physical control at a state psychiatric hospital. Archives of Psychiatric Nursing, 16 (2) 80-85.

Walkerdine,V., Lucey, H., \& Melody, J. (2002). Subjectivity and qualitative method. In T. May (Ed.), Qualitative research in action. London: Sage Publications.

Wynaden, D., Chapman, R., McGowan, S., Holmes, C., Ash, P., \& Boschman, A. (2002). Through the eye of the beholder: To seclude or not to seclude. International Journal of Mental Health Nursing, 11, 260-268.

Wynaden, D., Orb, A., McGowan, S., Castle, D., Zeeman, Z., Headford, C., Endersbee, W., \& Finn, M. (2001). The use of seclusion in the year 2000: What has changed? Collegian, 8 (3) 19-25.

Wynn, R. (2002). Medicate, restrain or seclude? Strategies for dealing with violent and threatening behaviour in a Norwegian university psychiatric hospital. Scandinavian Journal of Caring Sciences, 16 (3) 287-291.

Yee, B., \& Bateman, S. (2003). Seclusion: The views of service users. Incite: the Mental Health Journal of New Zealand, 2 (2) 3-10. 


\title{
APPENDICES
}

\author{
A Service Provision Framework documents* \\ B Quality project: Continuous reduction in the use of seclusion (stage one)* \\ C Quality project: Continuous reduction in the use of seclusion (stage two) \\ D Ethics Committee Letter of Approval* \\ E Information Sheet* \\ F Consent Form* \\ G Letter of Support: Maori Advisor* \\ H Letter of Support: Consumer Advisor* \\ I Audit Form \\ J Seclusion Recording Form* \\ K Seclusion Observation Forms \\ L Themes for Seclusion Use (Johnson, 1997) \\ M Request for Volunteers: Notice* \\ $\mathrm{N}$ Interview Format \\ O Demographic and Clinical Data Tables
}

* Identifying material has been removed to preserve confidentiality 


\begin{tabular}{|c|c|c|c|c|}
\hline & \multicolumn{4}{|c|}{ (Named) HOSPITAL AND COMMUNITY SERVICES } \\
\hline & \multicolumn{4}{|c|}{ CLINICAL SERVICES } \\
\hline \multirow{2}{*}{ POLICY STATEMENT: } & Prepared/review by: & Authorised by: & $\begin{array}{l}\text { Cultural safety } \\
\text { check: }\end{array}$ & $\begin{array}{l}\text { No. of pages: } 3 \\
\text { Date for Review: } \\
\text { May } 2006\end{array}$ \\
\hline & $\begin{array}{l}\text { Designation: } \\
\text { Director, Clinical } \\
\text { Services }\end{array}$ & $\begin{array}{l}\text { Designation: } \\
\text { Director, Clinical } \\
\text { Services }\end{array}$ & $\begin{array}{l}\text { Designation: } \\
\text { Maori Adviser }\end{array}$ & $\begin{array}{l}\text { Distribution: } \\
\text { All }\end{array}$ \\
\hline \multirow[t]{2}{*}{ SECLUSION POLICY } & $\begin{array}{l}\text { Date: } \\
\text { May } 2004\end{array}$ & $\begin{array}{l}\text { Date: } \\
\text { May } 2004\end{array}$ & $\begin{array}{l}\text { Date: } \\
\text { May } 2004\end{array}$ & Policy No: \\
\hline & \multicolumn{2}{|c|}{$\begin{array}{l}\text { Date Original Document: } \\
\text { May } 2003\end{array}$} & \multicolumn{2}{|l|}{$\begin{array}{l}\text { Review Dates: } \\
\text { May } 2004\end{array}$} \\
\hline
\end{tabular}

\section{Policy Statement:}

(Named) Hospital and Community Services will ensure that seclusion in all its forms is recognised and when practised complies with all legal and safety requirements. The use of seclusion is a clinical decision and not a treatment in itself.

The policy should be read in conjunction with the Restraint Policy, Incident Reporting Policy, Security Policy and Health and Safety Policies. Mental health staff should also refer to the (Named) Psychiatric Service Calming and Restraint Policy.

\section{Scope of Policy:}

This policy applies to (Named) Hospital and Community Services

\section{Key Aims:}

- To protect the safety and wellbeing of the consumer

- Ensure the requirements of legislation, consumer rights, current standards and relevant professional codes of practice are met

- To ensure that staff receive appropriate training so they recognise when seclusion is being used

- To practice competent safe care in relation to seclusion

- To involve the consumer and families in discussions

- To identify risk management issues and ethical considerations.

\section{Definitions:}

\section{$\underline{\text { Seclusion }}$}

Seclusion is defined as the placing of a person, at any time and for any duration, alone in an area where he/she cannot freely exit.

The key elements of the definition are:

(a) That the person is alone and/or deprived of the right of company;

(b) That seclusion applies at any time of the day or night;

(c) That duration is not an issue in determining what is or is not seclusion;

(d) That the person cannot exit of his or her own accord.

NB: In cases relating to infection control please refer to the isolation guidelines. 


\section{Categories of Seclusion:}

Involuntary Seclusion - occurs when a consumer is placed without their consent in a room from which they are prevented from leaving (ANZCMHN. Inc)

Voluntary Seclusion - occurs when a consumer is placed at their request in a room on their own (ANZCMHN. Inc)

\section{Indicators for when use of seclusion may be appropriate:}

Without delay - in an emergency situation it may be initiated by the senior registered nurse as per unit specific guidelines.

Imminent risk - if based on the clinical judgement, knowledge and assessment of the person and their behaviour, clinical staff believe that the person is soon likely to significantly harm themselves or put at significant risk the health or safety of another person, and seclusion is the least restrictive treatment response.

\section{Risk and Quality Management:}

Clinical risk assessment identifies the likelihood of an adverse outcome for the individual consumer and / or others potentially at risk. Each service will have guidelines for covering seclusion. This protocol should include the following -

- Assessment

- Approval process

- Recording and reporting

- Review timeframes

- Evaluation

- Monitoring guidelines

- Interventions

- Ending seclusion processes

- Debriefing

\section{Education:}

Training shall be appropriate to the client setting, be evidence based and consumer focused wherever possible. Care in relation to seclusion will consider the least restrictive interventions, and appreciating the physical and psychological impact seclusion has on the individual consumer, their family / whanau and others.

\section{Consumer Support and Communication:}

Throughout seclusion, service providers maintain effective, timely and appropriate ongoing dialogue with consumers including involvement in decisions relating to their care. Where appropriate, and with consent, this may include their advocate, family / whanau and / or significant others. 


\section{Cultural Recognition:}

Specific cultural needs of consumers during each stage of seclusion are recognised and relevant cultural advice and / or guidance is sought in order to maintain and practice cultural safety and holistic care. This may also include providing whanau / family information.

\section{General:}

Unit guidelines / procedures shall guide service providers in ensuring adequate and appropriate observations, care, dignity, respect, and on-going assessment occurs to minimise the risk of harm to consumers during seclusion. Unit procedures will clearly outline evaluation and review requirements of seclusion use.

\section{References:}

Standards New Zealand - NZS 8141 Restraint Minimisation and Safe Practice, 2001 ANZCMHN. Inc (Australian \& New Zealand College of Mental Health Nurses Inc.) 1998 


\begin{tabular}{|l|l|l|}
\hline & \multicolumn{2}{|l|}{$\begin{array}{l}\text { Review dates: Apr 95, April 2000, April2002, April } 2004 \\
\text { Date of original document: 1994 }\end{array}$} \\
\hline SECLUSION & $\begin{array}{l}\text { Valid to: April 2006 } \\
\text { No of pages: } 3\end{array}$ & Protocol No: \\
\hline
\end{tabular}

\section{SECLUSION}

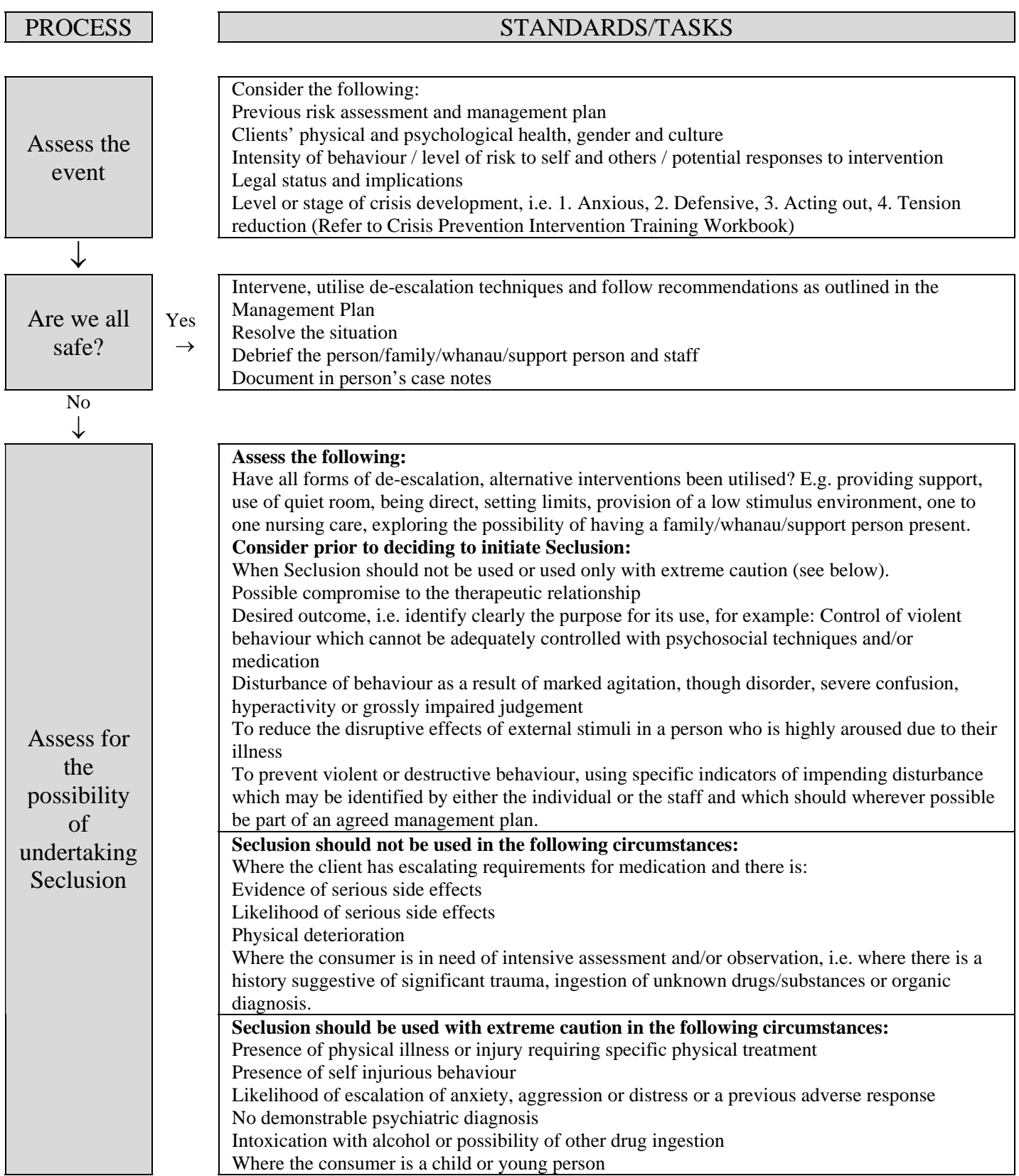

Key Worker

Legal status and implications

Level or stage of crisis development, i.e. 1. Anxious, 2. Defensive, 3. Acting out, 4. Tension

reduction (Refer to Crisis Prevention Intervention Training Workbook)

WHO

.

\begin{tabular}{|c|}
\hline Key \\
Worker/Staff \\
Member(s)
\end{tabular}

Key Worker/

Staff Members

$\downarrow$

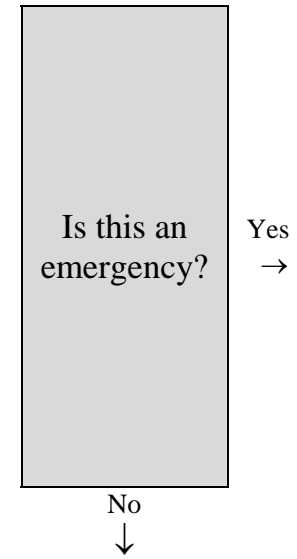

Identify any potential risks to carrying out the Seclusion process. Prepare room pertaining to the identified level of risk, clarify roles of individual team members.

Where appropriate, consult with the family/whanau/support person of what is going to happen.

Detain client under the Mental Health Act (S111, emergency holding power) if required.

Request the client to move to Seclusion voluntarily, if they refuse refer to the protocol on

restraint minimisation ensuring where possible at least one person is of the same gender as client.

Inform them of their rights, explain the conditions of Seclusion, inform the client what to expect and the reason for use of Seclusion.

Ensure the client's dignity is respected, privacy and adequate clothing pertaining to the level of risk.

Liaise with the Responsible Clinician as soon as possible or at least by the start of the next working day.

Contact House Surgeon who must assess the secluded client within the next two hours following the initiation of seclusion.

Complete S8 Application for Assessment, if required.
Key Worker/

Lead Nurse/

Clinical

Leader 


\section{SECLUSION CONTINUED (2)}

\section{PROCESS}

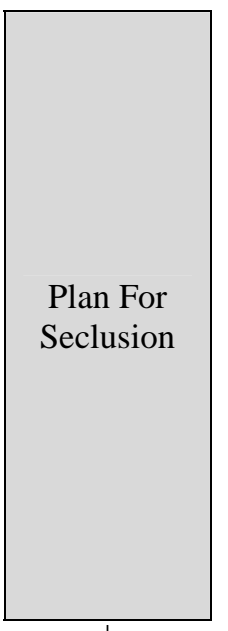

$\downarrow$

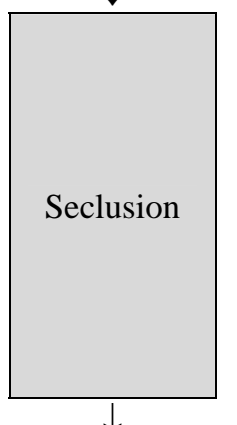

$\downarrow$

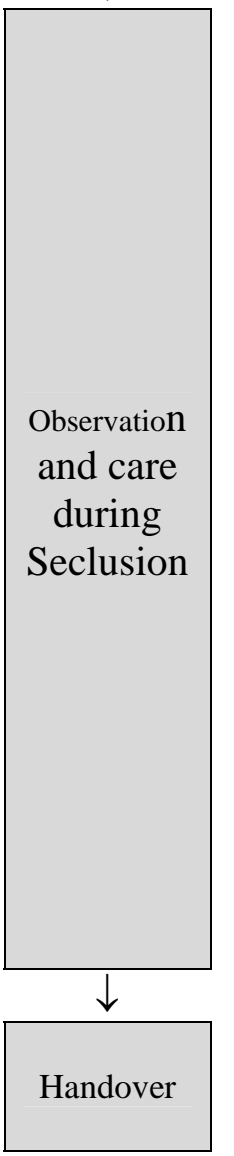

\section{STANDARDS/TASKS}

\section{Non-Emergency}

Identify any potential risks to carrying out the seclusion process

Identify proposed outcome of the intervention

Identify any specific cultural needs and obtain relevant advice, e.g. karakia as part of the seclusion process, whanau staying overnight, tapu i.e. food served in the same room as toileting/sleeping area

Where appropriate consult with the family/whanau/support person re: what is going to happen Liaise with the Responsible Clinician as soon as possible or at least by the start of the next working day

Consult with the Lead Nurse and/or Clinical Leader

Determine roles of individual team members

Criteria for ending the restraint

Commence the Mental Health Act if required

Organise environment, prepare room pertaining to the identified level of risk, i.e. room to be assessed for unsafe items

Ensure the client's dignity is respected, privacy and adequate clothing pertaining to the level of risk: consider removal of cords, belts, empty pockets, jewellery, use of protective clothing etc Consider the following needs: i.e. food/fluid intake, personal care/hygiene/toileting arrangements and medication requirements

Request the client to move to Seclusion voluntarily. If they refuse refer to the protocol on restraint minimisation ensuring where possible at least one person is of the same gender as client. In situations involving weapons or in emergencies or when there are insufficient staff on duty to manage the situation, contact the Police.

Inform them of their rights, explain the conditions of Seclusion, inform the client what to expect and the reason for use of Seclusion.

Contact House Surgeon who must assess the secluded client within two hours following seclusion.

Commence Seclusion Recording Form (Authorisation from Responsible Clinician to occur within 24 hours of commencement of Seclusion).

Complete relevant documentation, i.e. up -date case notes / historical risk sheet and on incident form and the Seclusion Register.

\section{Continuous - 10 minute observations}

Observation should be continuous or as frequent as possible. The longest interval between observations should be 10 minutes (the interval should vary within the 10 minutes)

The minimum observations within the 10 minute interval include but are not limited to general condition, colour, breathing, position, activity and behaviour. This will require physical observation and interaction with the client and cannot be achieved through electronic surveillance

\section{Two hourly observations}

An attempt should be made at least once every two hours to enter the room, unless there are documented reasons not to do so, e.g. the person is asleep or behaviour continues to put self and others at risk

\section{Entry to Seclusion Room}

Plan - assess potential requirements through observing the seclusion room environment and consulting with the client. Assess staff numbers required to attend to needs and clarify the role of team members prior to entry

Safety precautions should be taken when entering the room and should be appropriate to manage the potential risk involved

An assessment of the mental state should be made at this time. Further assessment of physical state should be carried out as clinically indicated

8 hourly observations and care

During the period of each shift an ongoing programme of care and assessment must be provided and recorded, e.g. use of WRAP, strengths, clinical assessment

Where possible care should be carried out predominantly by staff of the same gender and culture Responsibility for care delivery and observations during seclusion is that of the Registered Nurse Mandatory that a suitably qualified staff member psychiatrically assesses the client in seclusion at least once every 8 hours. A record of this assessment is documented

Following this assessment a decision is required to complete or extend seclusion. Confirmation should be provided by the initiating or supporting clinicians or another nurse or doctor if the original clinicians are not available

Clinical consultation with the responsible clinician should occur

Care requirements communicated verbally and via case notes to the next shift. To include the following information:

Food/fluid intake, personal care/hygiene/toileting arrangements, medication requirements, exercise/physiotherapy/visitors (chaplain, advocates, family).
WHO

Key Worker in conjunction

with team members

Key Worker

(Registered Nurse) 


\section{SECLUSION CONTINUED (3)}

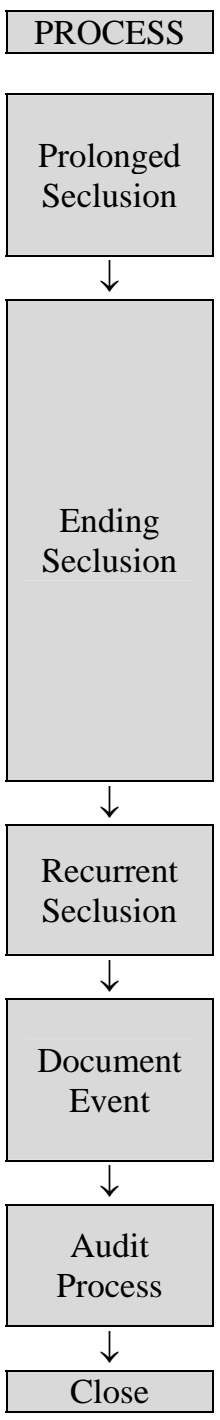

\section{STANDARDS/TASKS}

If the cumulative hours of seclusion exceed 24 hours in a four week period, reassessment in the form of a Case Management conference and a specialist opinion shall be sought from someone not directly involved in the case

A Management Plan that stipulates the rationale for continuation of seclusion and the expected path of treatment is developed

If the goals of seclusion have been achieved, a decision to end seclusion should be taken by two staff, either two registered nurses or a registered nurse and a doctor. The Responsible Clinician should be notified as soon as possible

An episode of seclusion has ended when a client has been out of seclusion for 2 or 4 hours

Purpose is to enable a short period of evaluation of the client within the normal ward environment

A planned and graduated process of reintegration into the ward may be required

Reintegration should start with the door open and move to integration during times of less stress and disruption

An assessment of reintegration attempts should be taken into account when making a decision whether or not to continue seclusion

Debrief the client/family/whanau/support person within 24 hours of restraint

Staff involved in event to carry out a debrief as per (named) debriefing protocol. This may

include the family/whanau/support person if appropriate

Event to be audited as per Seclusion Recording Form

It may be necessary to replace a client back in seclusion after a short period of evaluation or attempted reintegration. If the client has been out of seclusion for two or four hours (in the case of a client who has been secluded for 24 hours or more) a new seclusion event must be commenced

Complete Incident Recording Form as per Organisational Policy

Information may include some of the following: was individual plan followed, was de-escalation techniques attempted, was the least restrictive/intrusive intervention considered, were

policies/procedures followed, impact of seclusion on client/family/whanau/support person, was expected outcome achieved.

Meeting to be held on a quarterly basis with the Restraint/Seclusion Audit Review Committee Review of restraint/seclusion process via examination of Restraint Audit Tool/Incident Forms Seclusion Register to be reviewed on a quarterly basis
WHO

MDT Team

Appropriate

Staff

Members/

Key Worker

Key Worker

ead Nurse

Restraint

Audit

Committee

Please refer to the Organisational/(named) policies: Seclusion, Restraint Minimisation, Incident Reporting, and the Nonviolent Crisis Intervention Prevention Training Manual

Physical Restraint is only recommended when all verbal intervention strategies have been exhausted and the individual is presenting a physical danger to self or others

\begin{tabular}{|l|l|l|l|l|}
\hline Author: & $\begin{array}{l}\text { (Named) } \\
\text { Quality Facilitator }\end{array}$ & $\begin{array}{l}\text { Distribution: } \\
\text { MHS }\end{array}$ & Manager \\
\hline Approval: & Clinical Director & Maori Adviser & Consumer Adviser & \\
\hline Signature: & & & & \\
\hline
\end{tabular}




\section{Name of project}

Continuous reduction in the use of seclusion

\section{Project team}

Clinical Leader, (Unit)

All Staff, (Unit)

\section{Objectives}

Seclusion is used as a treatment option when a person is unable to remain on the open ward due to actual or potential harm to self or others. This option is only used when all other de-escalation options have been exhausted. In most instances seclusion is considered to be the least desirable outcome and it should never be considered as a first option.

Given that seclusion is the least desirable treatment option in the majority of cases then the use of seclusion would reflect on the level of skill, effort expended and consideration given to other methods. (Standard 16.8 NMHS: "The mental health service provides the least restrictive and least intrusive treatment and/or support possible to the consumer”).

The intention is to measure the overall use of seclusion on (unit) as a baseline for improvement. This will take the form of:

- $\quad$ Number of seclusion events

- $\quad$ Number of individuals secluded

- $\quad$ Amount of time in seclusion per event

- Amount of time in total

Using this information the team will be able to work on continuous reduction of seclusion as a treatment option.

When interpreting the data it will be important to look at not only the overall time people spend in seclusion but also and more importantly the number of individuals secluded. This will I believe more accurately measure the use of seclusion as a treatment option and reduce the danger of staff ending seclusion too early or indeed failing to seclude when this is the only safe option remaining. 


\section{Tasks}

\begin{tabular}{|l|l|l|l|}
\hline STEPS NEEDED TO ACHIEVE OUTCOMES & $\begin{array}{l}\text { WHO } \\
\text { RESPONSIBLE }\end{array}$ & $\begin{array}{l}\text { BY } \\
\text { WHEN }\end{array}$ & $\begin{array}{l}\text { SIGNED } \\
\text { OFF }\end{array}$ \\
\hline Present staff with summary of seclusion data & (noted) & July 2003 & Done \\
\hline $\begin{array}{l}\text { Provide staff with articles detailing seclusion } \\
\text { reduction attempts in similar settings }\end{array}$ & (noted) & Aug 2003 & \\
\hline $\begin{array}{l}\text { Ensure all staff have Minimisation and Restraint } \\
\text { Training }\end{array}$ & (noted) & Aug 2003 & Done \\
\hline $\begin{array}{l}\text { Modify (unit) environment to make it more } \\
\text { welcoming and less institutional }\end{array}$ & (noted) & Aug 2003 & Done \\
\hline $\begin{array}{l}\text { Locate NHI numbers for clients who have been } \\
\text { secluded since } 1997 \text { so as to track usage over time }\end{array}$ & (noted) & & \\
\hline
\end{tabular}

\section{Outcomes}

Seclusion data to date:

\begin{tabular}{|l|l|l|}
\hline YEAR & MINUTES & INDIVIDUALS \\
\hline 1997 & 26615 & 11 \\
\hline 1998 & 23250 & 14 \\
\hline 1999 & 22595 & 16 \\
\hline 2000 & 23060 & 9 \\
\hline 2001 & 34240 & 17 \\
\hline 2002 & 49371 & 21 \\
\hline
\end{tabular}

The above data reveals a major jump in seclusion minutes and in individuals requiring seclusion. There are several reasons possible for this rather dramatic increase one being the inclusion of (town) as part of the ward's catchment area in 2001 with this in turn increasing the potential admission numbers (15\% of admissions ex (town) area in 2001). Another explanation is that the higher than usual numbers are simply part of statistical regression in that 1998 and 1999 also had similar numbers of individuals requiring seclusion. Yet another explanation could be that one of those individuals admitted in 2001 was secluded for 30\% of the total time recorded and without their admission the total would be in line with the figures for 2000 (this same individual accounts for $50 \%$ of 2002 time to date).

It is very clear to me that measuring the outcomes of this quality project is fraught with difficult. One may not be able to accurately infer or predict a trend from these figures. Given that there is no other way to more precisely measure a reduction through interventions, we will continue to collect the data and hope that over a greater period of time we will see a trend emerging that informs our efforts to reduce the use of seclusion as a therapeutic intervention.

Most recent efforts to expand de-escalation options involve converting one of the seclusion rooms into a quiet room and requesting the re-installation of a sound system so that relaxing music can be piped in. 
A visit by the accreditation team in June indicated that seclusion figures were still very high and staff have been given the challenge of coming up with ideas on how we might reduce those numbers. I have emphasised that safety of people on the unit is paramount and that any alternative interventions must fully consider this. 


\section{Name of project}

Continuous reduction in the use of seclusion (stage two)

\section{Project team}

Barbara Mosley, RCpN

Clinical Leader, In-Patient Unit

All Staff, In-Patient Unit

\section{Background}

The provision of treatment and support for mental illness is delivered with a recovery focus in present day settings and the emphasis is on management of a person's illness within the least restrictive environment. Standard 16.1 of the National Mental Health Sector Standard states: “The mental health service provides the least restrictive and least intrusive treatment and/or support possible to each person who receives the service” (Standards New Zealand, 2001).

Seclusion is used as a treatment option when a person is unable to remain on the open ward due to actual or potential harm to self or others. This option should only be used when all other de-escalation options have been exhausted. In most instances seclusion is considered to be the least desirable outcome and it should never be considered as a first option.

Comment from the accreditation team that visited in June 2003 was that seclusion use was very high. We were, therefore, faced with the task of coming up with ideas of how we might reduce seclusion use whilst ensuring that the safety of people in the unit (both patients and staff) was maintained.

\section{Stage One Outcomes}

The quality original project (referred to here as Stage One) was developed in 2002 to measure the annual use of seclusion in the in-patient unit as a baseline for improvement. Information gathered included:

- $\quad$ Number of seclusion events

- Amount of time in seclusion per event

- $\quad$ Number of individuals secluded

- $\quad$ Number of times each individual secluded

- Amount of time in total each year 
Information was gathered for the years 1997-2002 inclusive. Data from 2003 has now been collected and has been added to the previous information. This data shows that the increase in seclusion use continued during this year. An updated summary of the information is appended to this document. From this summary it is apparent that, in the last three years, there has been a large increase in the annual amount of seclusion use and the number of patients involved when compared with the years 1997-2000. For the past two years there has also been a dramatic increase in the number of seclusion events.

Some other tasks were proposed in stage one, the outcomes of which are as follows:

1 Provide staff with summary of seclusion data: Staff were informed of the amount of seclusion use over the years 1997-2002 (completed July 2003).

2 Modify the environment to make it more welcoming and less institutional: This was achieved within the overall refurbishment and redecoration of the unit. It included modifying the foyer from an admission and reception type centre to a lounge environment.

3 Locate NHI numbers for clients who have been secluded since 1997 so as to track usage over time: This was completed alongside the measurement of seclusion use.

$4 \quad$ Ensure all staff have minimisation and restraint training: This was delayed due to the unavailability of the tutor to present the CPI course in the latter part of 2003. However, CPI training was again held in February 2004 for staff who had not previously attended such a course, and there is an ongoing programme for conducting updates for staff who have completed the full course.

5 Provide staff with articles detailing seclusion reduction attempts in similar settings: Not completed.

A further task that was carried out was converting one of the two seclusion rooms into a quiet room. The room was equipped with a mat, chairs and other comfort items. It was used on only a few occasions and there were several drawbacks to its use. It was situated in the acute wing which could often be noisy and disturbing, the seclusion room was next door and could house people who were very distressed, and the quiet room was sometimes needed as a second seclusion room at short notice either for a second seclusion event or because the person in the first seclusion room needed to be moved. At the time of writing the proposed quiet room had been set up as a seclusion room again for several months.

\section{Stage Two Objectives}

The objectives of the second stage of this project are:

1 To continue the work of the first stage. It was noted during this previous stage that some seclusion events were not recorded and that there was some inaccurate recording within the seclusion register. 
2 To look at patterns of seclusion use related to demographic details of individuals, unit functioning and characteristics, data related to the seclusion event itself and the relationship of seclusion to the availability of risk assessments and treatment plans.

3 To further progress information gathering to establish the reasons for seclusion use. It is only by understanding the antecedents for seclusion that properly planned and effective interventions for reducing its use can be initiated. Seven broad themes, factors, behaviours or aspects of functioning have been identified as associated in the decision to initiate or continue seclusion (Johnson, 1997):

- $\quad$ Violence and the threat of violence

- $\quad$ Agitation, frustration and coping skills

- $\quad$ Cognitive processes and functioning

- $\quad$ Mood and affective functioning

- $\quad$ Comprehension, understanding and feelings

- Compliance and conformity

- External variables (e.g. age, ethnicity, gender, ward atmosphere, staffing levels)

\section{Stage Two Tasks}

To conduct a file audit of all persons secluded during the period under investigation (1997-2003) to:

- $\quad$ Establish accuracy of recorded data in the seclusion register

- $\quad$ Obtain demographic details including age, gender and ethnicity

- Obtain information related to admission, whether seclusion initiated at time of admission, time of day, day and date of seclusion event, medications utilised, and diagnosis

- $\quad$ Establish the reasons, as recorded in the documentation, for the seclusion event

- Investigate whether the person had a treatment/crisis plan or advance directive in place, and whether information regarding triggers had been identified and considered before the seclusion event

- $\quad$ Establish what involvement the family/whanau had in the care of the person prior to the seclusion event

To carry out interviews with staff members who have previously been involved in seclusion events to:

- $\quad$ Establish what congruency or discrepancy exists between documentation and staff thoughts and perceptions of what occurs when seclusion is initiated

- Discuss their thoughts and ideas about possible ways of reducing seclusion use

- Increase both the interest and involvement of staff in the process of considering seclusion reduction 
- $\quad$ Encourage staff to consider the seclusion process and how it fits with a recovery approach to their work

- $\quad$ Consider broader service issues that may be impacting on seclusion use

To inform staff, on a regular basis, of the progress of this project:

- $\quad$ By developing a questionnaire for staff to complete to establish current knowledge of the seclusion process and to provide feedback of results

- $\quad$ By updating staff regarding progress of this project on a monthly basis

- $\quad$ To keep staff informed of the current trend in seclusion use by presenting monthly statistics

- $\quad$ To provide them with relevant and current literature on seclusion use and reduction

Responsibility for this project: Barbara Mosley

Completion date: November 2004

\section{Timeline}

\begin{tabular}{|l|l|l|l|}
\hline \multicolumn{1}{|c|}{ Task } & \multicolumn{1}{|c|}{ Who Responsible } & \multicolumn{1}{c|}{ By When } & Signed Off \\
\hline File Audit (123 files) & B Mosley & July 2004 & \\
\hline Staff Questionnaire & All staff & April 2004 & \\
\hline Staff Interviews & B Mosley and Staff & May 2004 & \\
\hline Relevant Literature & B Mosley and Staff & June 2004 & \\
\hline Progress Report to Staff & B Mosley & $\begin{array}{l}\text { Monthly: } \\
\text { April-Nov 2004 }\end{array}$ & \\
\hline Written Report & B Mosley & November 2004 & \\
\hline
\end{tabular}

\section{Outcomes}

Once all possible de-escalation techniques have been attempted, the safety of patients, staff and others at risk is paramount when determining whether seclusion should be implemented. A possible immediate outcome of bringing issues of seclusion to staff attention is that they will act to reduce seclusion use inappropriately. Throughout this project, it will be emphasised that staff utilising seclusion as a treatment option should ensure they do not terminate seclusion too early or fail to seclude a person when this is the only safe option remaining.

Incident rates have been compared with unit size, bed occupancy, admission rates and length of stay in the literature. All of these measures have limitations and produce inaccurate data. They also fail to take account of unique features of a unit at any given time, e.g. patient mix, acuity, staffing. There may also be unique features of each unit such as layout, activities, treatment and intervention models which impact on the use of seclusion. 
For the above reasons, and because it is virtually impossible to measure all these impacts on seclusion use over time, outcomes of this project will be a basic measure of seclusion as an intervention. The data collected will be compiled into a report and presented with recommendations for implementing an education and training package aimed at continuous reduction of seclusion use.

\section{References}

Johnson DJ (1997). Factors in the continuance and discontinuance of seclusion in a special hospital. (Masters Dissertation, University of Liverpool).

Standards New Zealand (2001). National mental health sector standard. Wellington: Ministry of Health.

\section{Attachments}

Summary of seclusion use 1997-2003

Staff questionnaire

\section{Barbara Mosley RCpN}

Staff Nurse

14 April 2004 


\section{COPY}

(Named)

Ethics Committee

(Address)

12 July 2004

Barbara Mosley

(Address)

Dear Barbara

An investigation into the use and minimisation of seclusion in an acute psychiatric in-patient unit: to identify trends in seclusion use over the past seven years, to establish the clinical basis for its use and the practice issues involved in both using and minimising its use, and to explore how seclusion use fits with the present-day recovery philosophy

Investigator: Barbara Mosley Supervisor: Chris Walsh

Ethics ref: CTR/04/06/093

Thank you for your response to the Committee's suggestions. The above study has now been given ethical approval.

Approved Documents

Information sheet and consent form dated 2 July 2004

Advertisement

Audit Form

Interview Format

\section{Certification}

The Committee is satisfied that this study is not being conducted principally for the benefit of the manufacturer or distributor of the medicine or item in respect of which the trial is being carried out.

\section{Accreditation}

The Committee is accredited by the Health Research Council and is constituted and operates in accordance with the Operational Standard for Ethics Committees, March 2002.

\section{Progress Reports}

The study is approved until 15 July 2005. A final report is required at the conclusion of the study.

\section{Amendments}

All amendments to the study must be advised to the Committee prior to their implementation, except in the case where immediate implementation is required for 
reasons of safety. In such cases the Committee must be notified as soon as possible of the change.

It is also a condition of approval that the Committee is advised of any adverse events, if the study does not commence, or the study is altered in any way, including all documentation eg advertisements, letters to prospective participants.

\section{General}

It should be noted that Ethics Committee approval does not imply any resource commitment or administrative facilitation by any healthcare provider within whose facility the research is to be carried out. Where applicable, authority for this must be obtained separately from the appropriate manager within the organisation.

We wish you well with your study.

Yours sincerely,

(Signed)

(Name)

Ethics Committee Administrator 


\section{Victoria \\ Te Whare Wānanga \\ o te Üpoko o te Ika a Māui

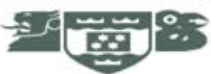

GRADUATE SCHOOL

OF NURSING \& MIDWIFERY

\section{Research Study}

\section{Participant Information Form}

\section{Seclusion Management in an Acute In-Patient Unit}

Researcher: Barbara Mosley

\section{Introduction:}

You are invited to take part in a research study that I am carrying out during 2004 as part of a Master of Nursing. My topic of interest is the use of seclusion in the inpatient unit.

Over the past few years there has been considerable debate about the ethical issues related to the use of seclusion. This has meant that mental health professionals have had to make decisions about its use while considering the balance between patients' rights to least restrictive treatment and the need to protect the safety of patients and others in the immediate environment.

There is a big drive both here in New Zealand and overseas to reduce seclusion use. However, in our own unit, seclusion has been used more and more frequently over the past 2-3 years. I hope, through this study, to find some of the reasons for this increase.

\section{Aim of this study:}

My aim in this study is to investigate the reasons for the increase in the use of seclusion. I believe that it is only by gaining an understanding of why this increase is happening, that we can then work effectively to reduce its use. We cannot make an informed decision about the type of interventions needed to decrease its use until we know why an increase has occurred.

\section{How will potential participants be identified and accessed?}

It is my intention to talk with 4-6 registered nursing staff who volunteer to take part and who have been involved in the seclusion process. 


\section{Who will be the participants?}

Participants will be registered nursing staff who volunteer to take part during the data collection period of the study (June - August 2004).

\section{What will my participation involve?}

Should you agree to join this study, you will be asked to attend a face-to-face interview with me to discuss seclusion events. The discussion will be quite informal and will include looking at things such as your role in a particular seclusion event of your choice, what you think were the main reasons it was necessary to use seclusion, whether you believe there were relevant clinical indicators, what your feelings were about using seclusion and if you think the situation could have been dealt with in any other way. I anticipate these interviews will last approximately one hour and may be held at an office at the (unit) ${ }^{1}$ or another agreed place.

\section{How will confidentiality and/or anonymity be protected?}

Any approach you make about participating in an interview will be kept confidential by me. However, because of the work environment your participation may become known to other staff working in the area. Anything you say during the interview will remain confidential, and this information will not be used in any way that could identify you or in any way that could be used against you.

\section{What data or information will be collected and how will it be used?}

With your agreement, the interview will be audiotaped. The tapes will remain in my possession, will be transcribed by me and no-one else will have access to those tapes. Written notes may also be taken during the interview. These will also remain in my possession and no-one else will have access to those notes. The information gathered will be used to develop an understanding about the reasons why seclusion is used and will be published in a report.

Results of this study may be published but any data included will in no way be linked to any specific participant. You may request a copy of the results and these will be available from me at the conclusion of the study. I will also provide you with a copy of your interview transcript to check the accuracy of the information and to make any necessary amendments before using the data in any reports.

\section{Data storage:}

The data collected will be securely stored in such a way that only I, as the researcher, will have access to it. At the end of the study any personal information will be

\footnotetext{
${ }^{1}$ Name removed to ensure confidentiality 
destroyed. Raw data and audiotapes on which the results are based will be retained in secure storage for a period of five years, after which they will be destroyed.

Can participants change their minds and withdraw from the study?

You can decline to participate without any disadvantage to yourself of any kind. If you choose to participate, you may withdraw from the study at any time, without giving reasons for your withdrawal. You can refuse to answer any particular questions, and can ask for the audiotape to be turned off at any stage.

What if participants have any questions?

If you have any questions about this study, either now or in the future, please feel free to contact me at:

Phone: $\quad$ (removed to maintain confidentiality)

E-Mail: $\quad$ barbaram@xtra.co.nz

My supervisor for this study is:

Chris Walsh

Senior Lecturer (Mental Health)

and may be contacted at:

Graduate School of Nursing and Midwifery

Victoria University of Wellington

Phone: $\quad$ (04) 4636652

E-Mail: $\quad$ Christine.Walsh@vuw.ac.nz

If you have any queries or concerns regarding your rights as a participant in this study, you may wish to contact your professional organisation.

\section{Statement of Approval}

This study has received ethical approval from the Regional Ethics Committee.

The General Manager of Mental Health Services has given permission for this study to be carried out.

\section{Barbara Mosley \\ July 2004}




\section{Victoria \\ Te Whare Wānanga \\ o te Üpoko o te Ika a Māui

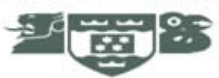 \\ GRADUATE SCHOOL}

OF NURSING \& MIDWIFERY

Research Study

Participant Consent Form

Seclusion Management in an Acute Psychiatric In-Patient Unit

- I have read and understand the information sheet dated July 2004 for volunteers taking part in the study designed to investigate the use of seclusion in an acute psychiatric in-patient unit. I have had the opportunity to discuss this study. I am satisfied with the answers I have been given.

- I understand that my participation in the study is entirely voluntary (my choice) and that I may withdraw from the study at any time and that this will in no way affect my continuing employment.

- I understand that my participation in this study is confidential and that no material which could identify me will be used in any reports on this study.

- I know who to contact if I have any questions about the study.

- I consent to the interview being audio-taped. YES /NO

- I understand I will have access to the results of the study when it is completed and will be provided with a copy of my interview transcript.

I

this study

(full name) agree to take part in

Signature:

Date:

Researcher: Barbara Mosley

Contact: $\quad$ (Removed to maintain confidentiality)

Study explained by:

Study role:

Signature:

Date:

This project has been reviewed and approved

by the Regional Ethics Committee

Consent Form (2/7/04) 


\section{COPY}

\section{Maori Mental Health Unit}

\section{April 2004}

\section{Kia ora Barbara,}

Thank you for our discussion about your proposed study with regards to "Seclusion Management in an Acute Psychiatric In-Patient Unit”. The Maori Mental Health Team fully support you in your study.

Whenever possible we would also like to be involved whenever there is/are Maori clients (Takata Whaiora) in the ward and is/are being taken into seclusion. Thank you also for the invitation to attend your in-service presentations, and likewise all information will remain confidential.

(Signed)

Kaumatua/Cultural Adviser 


\section{COPY}

(Named) Hospital and

Community Services

(Contact Details)

6 May 2004

(Named) ETHICS COMMITTEE

TO WHOM IT MAY CONCERN

I am writing this letter in support of the Research Project which Barbara Mosley is conducting around the use of seclusion.

I am sure the outcomes of this project will ultimately benefit the consumers of the (Named) Psychiatric Service and also the staff.

Yours sincerely

(Signed)

CONSUMER ADVISER

Information released to a third party requires that person(s) to ensure any information used is still accurate, up-to-date and not misleading (Health Information Privacy Code, Rule 8). Attached documentation must not be duplicated/disclosed without the express consent of the individual, their trustee(s) and by prior arrangement with the Privacy Officer or Quality Facilitator of (Named) Hospital and Community Services, Psychiatric Service. 


\section{Audit Form}

\section{Seclusion Management in an Acute In-Patient Unit}

Seclusion Event:

Year:

Personal Details

DOB:

Diagnosis: ${ }^{1}$

Date of admission:

\section{National No:}

Gender: $\quad$ M / F
Seclusion Data

Seclusion date:

Time in:

Length of seclusion:
Age:

Ethnicity: ${ }^{2}$

\section{Event No (this person): ${ }^{3}$}

Day of week:

At admission: ${ }^{4}$ Yes / No

Date and time out:

Hours Mins

\section{Seclusion Details}

Mental Health Act Status: ${ }^{5}$

Medications Administered: ${ }^{6}$

Reasons for Seclusion: ${ }^{7}$

Clinician on duty:

Staff members involved: 
Other notes:

\section{Notes:}

$1 \quad$ As recorded by clinician for this admission

$2 \quad$ As recorded on admission documentation

3 The number of times this person has been secluded to date for this year

4 Does not include a seclusion event occurring on the same day but was not part of admission process

5 Was the person subject to the MHA at time of seclusion or did the MHA need to be commenced or Section 111 procedures need to be commenced

6 What medications, if any, were administered as part of the seclusion procedure

7 Information obtained from the seclusion register (SR), from the Seclusion Recording Form (SRF) and progress notes (PN).

8 Information so obtained will be coded according to the seven themes identified by Johnson (1997):

- $\quad$ Violence and the threat of violence

- $\quad$ Agitation, frustration and coping skills

- $\quad$ Cognitive processes and functioning

- $\quad$ Mood and affective functioning

- $\quad$ Comprehension, understanding and feelings

- $\quad$ Compliance and conformity

- $\quad$ External variables (including age and ethnicity of person, unit atmosphere, staffing levels etc.) 
SECLUSION NURSING OBSERVATION RECORD

Start a new sheet for each duty and retain this record in the patient's Unit file

Patient's Name:

Unit:

Room No:

Date:

Shift:

SECLUSION ROOM ENVIRONMENT: (Please $\checkmark$ appropriate box at start of seclusion and start of each duty)

\begin{tabular}{llll} 
BEDDING: & Large Squab & $\square$ & Stitched blankets \\
Small Squab & $\square$ & Bedclothes & $\square$ \\
Pillow & $\square$ & Pillowcase & \\
Other & & & \\
\hline
\end{tabular}

a
ATTIRE:
Pyjamas
Nightie

Stitched

$\square$
$\square$
$\square$

Other

(specify)
COMFORT: Fluid Jug
Fluid Cup Pan/Paper

Other (specify)

ROOM CLEANED: $\square$ Time:

\section{SAFETY INSPECTION CARRIED OUT:}

口 Time/s:

By:

\begin{tabular}{|r|l|l|l|}
\hline $\begin{array}{c}\text { Observation } \\
\text { Time }\end{array}$ & $\begin{array}{c}\text { PATIENT PRESENTATION } \\
\text { i.e. appearance, affect, activity, position, safety }\end{array}$ & $\begin{array}{c}\text { NURSING INTERVENTION } \\
\text { Key points only, full report to go on progress notes }\end{array}$ & $\begin{array}{c}\text { STAFF MEMBER/S INVOLVED } \\
\text { Print initial, surname/s \& designation }\end{array}$ \\
\hline$: 00$ & & & \\
\hline$: 10$ & & & \\
\hline$: 30$ & & & \\
\hline$: 50$ & & & \\
\hline$: 10$ & & & \\
\hline$: 20$ & & & \\
\hline$: 30$ & & & \\
\hline$: 50$ & & & \\
\hline
\end{tabular}

N.B. TWO HOURLY FORMAL OBSERVATION MUST TAKE PLACE, TO ASCERTAIN / ASSESS MENTAL STATE

I.E. PHYSICALLY ATTEMPT TO ENTER ROOM UNLESS DOCUMENTED REASONS NOT TO DO SO 


\begin{tabular}{|c|c|c|c|}
\hline $\begin{array}{c}\text { Observation } \\
\text { Time } \\
\end{array}$ & $\begin{array}{c}\text { PATIENT PRESENTATION } \\
\text { i.e. appearance, affect, activity, position, safety } \\
\end{array}$ & $\begin{array}{c}\text { NURSING INTERVENTION } \\
\text { Key points only, full report to go on progress notes }\end{array}$ & $\begin{array}{l}\text { STAFF MEMBER/S INVOLVED } \\
\text { Print initial, surname/s \& designation }\end{array}$ \\
\hline \multicolumn{4}{|l|}{$: 00$} \\
\hline \multicolumn{4}{|l|}{ :10 } \\
\hline \multicolumn{4}{|l|}{$: 20$} \\
\hline \multicolumn{4}{|l|}{ :30 } \\
\hline \multicolumn{4}{|l|}{$: 40$} \\
\hline \multicolumn{4}{|l|}{ :50 } \\
\hline \multicolumn{4}{|l|}{$: 00$} \\
\hline \multicolumn{4}{|l|}{ :10 } \\
\hline \multicolumn{4}{|l|}{ :20 } \\
\hline \multicolumn{4}{|l|}{ :30 } \\
\hline \multicolumn{4}{|l|}{$: 40$} \\
\hline \multicolumn{4}{|l|}{$: 50$} \\
\hline \multicolumn{4}{|l|}{$: 00$} \\
\hline \multicolumn{4}{|c|}{ :10 } \\
\hline \multicolumn{4}{|l|}{$: 20$} \\
\hline \multicolumn{4}{|l|}{ :30 } \\
\hline \multicolumn{4}{|l|}{$: 40$} \\
\hline 50 & & & \\
\hline
\end{tabular}

Total hours:

N.B. TWO HOURLY FORMAL OBSERVATION MUST TAKE PLACE, TO ASCERTAIN / ASSESS MENTAL STATE

I.E. PHYSICALLY ATTEMPT TO ENTER ROOM UNLESS DOCUMENTED REASONS NOT TO DO SO 


\section{THEMES ASSOCIATED WITH THE DECISION TO USE SECLUSION (Johnson, 1997, pp 29-36, 44-45)}

\section{Violence and the Threat of Violence (Aggression)}

The primary reason for the use of seclusion has been identified as a response to violence. The threat of violence is seen as a valid and important criteria for its use. The use of seclusion has been identified as relating directly to the perception of personal threat, and nursing staff use seclusion because they perceive themselves or others to be under threat, usually in the case of actual or threatened violence.

- $\quad$ Physical violence

- $\quad$ Threats to display physical violence

- $\quad$ Threats to destroy property

- $\quad$ Verbal abuse and hostility

- $\quad$ Provocative behaviour

- $\quad$ Aggressive posturing

- $\quad$ Generalised hostility (not directed at any specific person)

- $\quad$ Focused hostility (directed at specific person or group of persons)

- Threats of retaliatory action

- $\quad$ History of retaliatory action and acting on threats

- $\quad$ History of behaviour escalating from verbal aggression to physical violence

\section{$2 \quad$ Agitation, Frustration and Coping Skills (Anxiety)}

Agitation can cover many aspects of mental state and physical behaviour. Some aspects include motor agitation, irritability, loud and pressured speech, demanding behaviour, anxiety, euphoria, anger, lability of affect, memory impairment and disorientation. Agitation has also been recognised as a potential precursor to violence. seclusion may be used to enable the restoration of self-control. Key indicators of selfcontrol are the ability to tolerate frustration, the ability to control impulses and a willingness to agree to contractual behaviours.

- $\quad$ Agitation

- $\quad$ Restlessness

- Tension

- $\quad$ Irritability

- $\quad$ Tolerance to the approaches of staff

- $\quad$ Tolerance to the approaches of peers

- $\quad$ Ability to wait for gratification of needs

\section{Cognitive Processes and Functioning (Cognition)}

Active symptoms of severe mental illness can increase the risk of violence. Those experiencing symptoms such as delusions and hallucinations have been involved in violence. The presence of psychosis should make one take threats of violence very seriously and makes the assessment of violence potential essential. 
- $\quad$ Organisation of thoughts

- $\quad$ Relevance of speech content

- $\quad$ Presence of delusions

- $\quad$ Acting on delusions

- $\quad$ Presence of hallucinations

- $\quad$ Acting on hallucinations

- $\quad$ Suspiciousness

- $\quad$ Orientation to time, place, person

\section{$4 \quad$ Mood and Affective Functioning (Mood)}

Manic and hypomanic patients can become hostile and violent when faced with sensory overload. Introducing a low stimulus environment or the removal from frustrating social interactions can help a patient regain the ability to tolerate incoming stimuli. Euphoria, irritability and lability in affect may indicate that a patient is having difficulty maintaining control.

- $\quad$ Current mood and level of arousal

- Incongruity of affect (out of character)

- $\quad$ Range of affect (out of character)

- $\quad$ Lability of affect (out of character)

\section{$5 \quad$ Comprehension, Understanding and Feelings (Perceptions)}

Psychotic disorganisation and disorientation can give rise to agitation, reducing a patient's understanding and awareness. Current perceptions and comprehension are relevant or potentially important in determining future short-term behaviour.

- $\quad$ The patient's understanding of the behaviours expected

- $\quad$ Perception of current management (i.e. restrictive, punitive, etc)

- $\quad$ Remorse for actions

- Appreciation of seriousness of actions

- $\quad$ Perception of behaviour of others in inducing particular actions

- Whether the patient takes responsibility or blames others for their actions

\section{Compliance and Conformity (Compliance)}

This is a controversial reason for the use of seclusion. It implies its use as a means of discipline and social control rather than for the containment of disruptive behaviour or the treatment of clinical symptomatology. Compliance and conformity can be important aspects of the regime in some institutions.

- $\quad$ Compliance with staff requests

- $\quad$ Acceptance of prescribed medication 


\section{$7 \quad$ External Variables (External Variables)}

A number of other factors can influence seclusion use. These have been widely debated in the literature and have given rise to some contradictory and conflicting opinion and argument. These include demographic variables of the patient, diagnostic categories, staffing issues, and environmental factors.

- $\quad$ Age of patient

- $\quad$ Ethnic origin of patient

- $\quad$ Physical prowess of patient

- $\quad$ Gender of patient

- Ward atmosphere

- $\quad$ Staffing levels and other staffing considerations

- $\quad$ Concerns over criticisms from colleagues

- $\quad$ Concerns over criticisms from managers, advocates, solicitors etc 


\section{Seclusion}

As part of ongoing Quality Project work and for my Master of Nursing thesis, I am carrying out a study into the use of seclusion

I would like to talk to nursing staff individually about their experiences when using seclusion

If you wish to discuss this further or if you think you may like to take part in this study, please see me for more information and to have any questions answered

Victoria

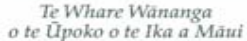

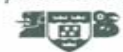

Barbara Mosley Rср

Staff Nurse, (Unit) 


\section{Interview Format}

\section{Date:}

Time:

Place:

Interview with:

Code:

Beginning the Interview

Introduce the study

Discuss detail from the information form

Discuss audiotaping the interview and obtain permission

Ask if the participant has any questions

Discuss the consent form and obtain written consent

\section{Questions to Guide the Interview}

Think about a particular seclusion event you have been involved in recently or that has had an impact on you. How would you describe this event?

How did the process leading up to seclusion unfold?

What do you believe the main reasons were for seclusion being used?

What were the major decision making points during this process?

What other means (if any), do you think, could have been used to deal with the situation?

What were the obstacles to using these, or other de-escalation methods? 
What do you believe were the clinical indicators for the use of seclusion and what are your reasons for this belief?

What were the outcomes?

How do you think the staff present managed this seclusion event?

What issues do you have, if any, about the use of seclusion when considering it alongside the use of the recovery / strengths approach we use here

\section{Ending the Interview}

Reiterate confidentiality

Discuss how results of the study will be disseminated

Thank participant 
Demographic Data Tables

Table A.1

Gender of Person

\begin{tabular}{|l|c|c|c|c|c|c|c|c|}
\hline Gender & $\mathbf{1 9 9 7}$ & $\mathbf{1 9 9 8}$ & $\mathbf{1 9 9 9}$ & $\mathbf{2 0 0 0}$ & $\mathbf{2 0 0 1}$ & $\mathbf{2 0 0 2}$ & $\mathbf{2 0 0 3}$ & Total \\
\hline Male & 4 & 7 & 9 & 7 & 9 & 15 & 11 & $\mathbf{6 2}$ \\
\hline Female & 6 & 7 & 9 & 3 & 10 & 14 & 13 & $\mathbf{6 2}$ \\
\hline Total & $\mathbf{1 0}$ & $\mathbf{1 4}$ & $\mathbf{1 8}$ & $\mathbf{1 0}$ & $\mathbf{1 9}$ & $\mathbf{2 9}$ & $\mathbf{2 4}$ & $\mathbf{1 2 4}$ \\
\hline
\end{tabular}

Table A.2

Age of Person at Time of Seclusion Event

\begin{tabular}{|l|c|c|c|c|c|c|c|c|}
\hline Age & $\mathbf{1 9 9 7}$ & $\mathbf{1 9 9 8}$ & $\mathbf{1 9 9 9}$ & $\mathbf{2 0 0 0}$ & $\mathbf{2 0 0 1}$ & $\mathbf{2 0 0 2}$ & $\mathbf{2 0 0 3}$ & Total \\
\hline $10-19$ & 0 & 1 & 4 & 1 & 2 & 2 & 0 & $\mathbf{1 0}$ \\
\hline $20-29$ & 6 & 6 & 3 & 3 & 7 & 8 & 5 & $\mathbf{3 8}$ \\
\hline $30-39$ & 2 & 4 & 5 & 3 & 2 & 6 & 7 & $\mathbf{2 9}$ \\
\hline $40-49$ & 0 & 0 & 4 & 2 & 2 & 6 & 8 & $\mathbf{2 2}$ \\
\hline $50-59$ & 1 & 2 & 1 & 1 & 6 & 5 & 1 & $\mathbf{1 7}$ \\
\hline $60-69$ & 1 & 1 & 0 & 0 & 0 & 1 & 3 & $\mathbf{6}$ \\
\hline $70-79$ & 0 & 0 & 0 & 0 & 0 & 0 & 0 & $\mathbf{0}$ \\
\hline $80+$ & 0 & 0 & 1 & 0 & 0 & 1 & 0 & $\mathbf{2}$ \\
\hline Total & $\mathbf{1 0}$ & $\mathbf{1 4}$ & $\mathbf{1 8}$ & $\mathbf{1 0}$ & $\mathbf{1 9}$ & $\mathbf{2 9}$ & $\mathbf{2 4}$ & $\mathbf{1 2 4}$ \\
\hline
\end{tabular}

Table A.3

Ethnicity of Person

\begin{tabular}{|l|c|c|c|c|c|c|c|c|}
\hline Ethnicity & $\mathbf{1 9 9 7}$ & $\mathbf{1 9 9 8}$ & $\mathbf{1 9 9 9}$ & $\mathbf{2 0 0 0}$ & $\mathbf{2 0 0 1}$ & $\mathbf{2 0 0 2}$ & $\mathbf{2 0 0 3}$ & Total \\
\hline NZ European & 10 & 13 & 16 & 10 & 17 & 24 & 20 & $\mathbf{1 1 0}$ \\
\hline Maori & 0 & 1 & 2 & 0 & 0 & 5 & 3 & $\mathbf{1 1}$ \\
\hline Other & 0 & 0 & 0 & 0 & 2 & 0 & 1 & 3 \\
\hline Total & $\mathbf{1 0}$ & $\mathbf{1 4}$ & $\mathbf{1 8}$ & $\mathbf{1 0}$ & $\mathbf{1 9}$ & $\mathbf{2 9}$ & $\mathbf{2 4}$ & $\mathbf{1 2 4}$ \\
\hline
\end{tabular}




\section{CLINICAL INFORMATION}

Table A.4

Diagnosis at Discharge of Person

\begin{tabular}{|l|c|c|c|c|c|c|c|c|}
\hline Diagnosis & $\mathbf{1 9 9 7}$ & $\mathbf{1 9 9 8}$ & $\mathbf{1 9 9 9}$ & $\mathbf{2 0 0 0}$ & $\mathbf{2 0 0 1}$ & $\mathbf{2 0 0 2}$ & $\mathbf{2 0 0 3}$ & Total \\
\hline Schizophrenia & 4 & 3 & 4 & 2 & 5 & 6 & 4 & $\mathbf{2 8}$ \\
\hline Bipolar - Manic & 4 & 5 & 5 & 0 & 5 & 10 & 6 & $\mathbf{3 5}$ \\
\hline Bipolar - Depression & & & & & & & & $\mathbf{0}$ \\
\hline Depression & 1 & 2 & 4 & 4 & 1 & 6 & 2 & $\mathbf{2 0}$ \\
\hline Psychosis & 1 & & 5 & 2 & 3 & 6 & 5 & $\mathbf{2 2}$ \\
\hline Anxiety & & & & & & 1 & 2 & $\mathbf{3}$ \\
\hline OCD & & & & & & & 1 & $\mathbf{1}$ \\
\hline Schizoaffective & & 1 & 1 & 1 & & 1 & 2 & $\mathbf{6}$ \\
\hline Borderline & 1 & 2 & 2 & 1 & 4 & 2 & 5 & $\mathbf{1 7}$ \\
\hline Alcohol/Drug & 1 & 6 & 5 & 4 & 5 & 4 & 4 & $\mathbf{2 9}$ \\
\hline Eating Disorders & & 1 & & & 1 & & & $\mathbf{2}$ \\
\hline Total & $\mathbf{1 2}$ & $\mathbf{2 0}$ & $\mathbf{2 6}$ & $\mathbf{1 4}$ & $\mathbf{2 4}$ & $\mathbf{3 6}$ & $\mathbf{3 1}$ & $\mathbf{1 6 3}$ \\
\hline Co-morbid x2 & $\mathbf{2}$ & $\mathbf{4}$ & $\mathbf{8}$ & $\mathbf{4}$ & $\mathbf{3}$ & $\mathbf{7}$ & $\mathbf{7}$ & $\mathbf{3 5}$ \\
\hline Co-morbid x 3 & & $\mathbf{1}$ & & & $\mathbf{1}$ & & & $\mathbf{2}$ \\
\hline
\end{tabular}

Table A.5

Medications Utilised at Seclusion

\begin{tabular}{|c|c|c|c|c|c|c|c|c|}
\hline Medication & 1997 & 1998 & 1999 & 2000 & 2001 & 2002 & 2003 & Total \\
\hline Acuphase & 8 & 10 & 16 & 4 & 13 & 17 & 10 & 78 \\
\hline Chlorpromazine & 9 & 3 & & 2 & 1 & 2 & & 17 \\
\hline Clonazepam & & 2 & 2 & & 3 & & 5 & 12 \\
\hline Diazepam & & & & & & & 1 & 1 \\
\hline Droperidol & & 1 & 4 & & & & & 5 \\
\hline Haloperidol & 1 & 3 & 2 & & 3 & & 2 & 11 \\
\hline Midazolam & & & & & & & 3 & 3 \\
\hline Olanzapine & & & & & & 1 & 2 & 3 \\
\hline Thioridizine & & 1 & & & & & & 1 \\
\hline Total per Year & 18 & 20 & 24 & 6 & 20 & 20 & 23 & 131 \\
\hline $\begin{array}{l}\text { Times Medications used } \\
\text { in Combination }\end{array}$ & 1 & 4 & 4 & $\mathbf{0}$ & 3 & $\mathbf{0}$ & 3 & \\
\hline
\end{tabular}


Table A.6

Mental Health Act Status

\begin{tabular}{|l|c|c|c|c|c|c|c|c|}
\hline MHA & $\mathbf{1 9 9 7}$ & $\mathbf{1 9 9 8}$ & $\mathbf{1 9 9 9}$ & $\mathbf{2 0 0 0}$ & $\mathbf{2 0 0 1}$ & $\mathbf{2 0 0 2}$ & $\mathbf{2 0 0 3}$ & Total \\
\hline 9 & 0 & 0 & 0 & 0 & 1 & 7 & 4 & $\mathbf{1 2}$ \\
\hline 11 & 10 & 18 & 19 & 7 & 12 & 14 & 22 & $\mathbf{1 0 2}$ \\
\hline 13 & 9 & 4 & 14 & 0 & 0 & 11 & 12 & $\mathbf{5 0}$ \\
\hline 29 & 0 & 0 & 0 & 0 & 0 & 2 & 9 & $\mathbf{1 1}$ \\
\hline 30 & 20 & 1 & 7 & 9 & 3 & 18 & 8 & $\mathbf{6 6}$ \\
\hline 111 & 4 & 2 & 4 & 3 & 10 & 11 & 5 & 39 \\
\hline Informal & 0 & 0 & 0 & 0 & 1 & 3 & 0 & $\mathbf{4}$ \\
\hline Total & $\mathbf{4 3}$ & $\mathbf{2 5}$ & $\mathbf{4 4}$ & $\mathbf{1 9}$ & $\mathbf{2 7}$ & $\mathbf{6 6}$ & $\mathbf{6 0}$ & $\mathbf{2 8 4}$ \\
\hline
\end{tabular}


SECLUSION EVENT

Table A.7

Day of Week of Seclusion Event

\begin{tabular}{|l|c|c|c|c|c|c|c|c|}
\hline Day & $\mathbf{1 9 9 7}$ & $\mathbf{1 9 9 8}$ & $\mathbf{1 9 9 9}$ & $\mathbf{2 0 0 0}$ & $\mathbf{2 0 0 1}$ & $\mathbf{2 0 0 2}$ & $\mathbf{2 0 0 3}$ & Total \\
\hline Monday & 4 & 4 & 6 & 2 & 4 & 5 & 5 & $\mathbf{3 0}$ \\
\hline Tuesday & 6 & 3 & 12 & 1 & 7 & 5 & 10 & $\mathbf{4 4}$ \\
\hline Wednesday & 11 & 2 & 4 & 4 & 5 & 8 & 8 & $\mathbf{4 2}$ \\
\hline Thursday & 5 & 3 & 4 & 1 & 1 & 12 & 11 & $\mathbf{3 7}$ \\
\hline Friday & 4 & 5 & 6 & 3 & 6 & 8 & 9 & $\mathbf{4 1}$ \\
\hline Saturday & 8 & 3 & 3 & 5 & 1 & 13 & 4 & $\mathbf{3 7}$ \\
\hline Sunday & 5 & 5 & 9 & 3 & 3 & 15 & 13 & $\mathbf{5 3}$ \\
\hline Total & $\mathbf{4 3}$ & $\mathbf{2 5}$ & $\mathbf{4 4}$ & $\mathbf{1 9}$ & $\mathbf{2 7}$ & $\mathbf{6 6}$ & $\mathbf{6 0}$ & $\mathbf{2 8 4}$ \\
\hline
\end{tabular}

Table A.8

Time of Day of Seclusion Event

\begin{tabular}{|c|c|c|c|c|c|c|c|c|}
\hline Time of Day & 1997 & 1998 & 1999 & 2000 & 2001 & 2002 & 2003 & Total \\
\hline 0000-0059 & 1 & 1 & 5 & 1 & 1 & 3 & 2 & 14 \\
\hline 0100-0159 & 1 & 1 & 2 & 1 & 1 & 5 & 1 & 12 \\
\hline 0200-0259 & 0 & 2 & 3 & 3 & 0 & 2 & 0 & 10 \\
\hline 0300-0359 & 0 & 0 & 2 & 1 & 3 & 1 & 1 & 8 \\
\hline 0400-0459 & 0 & 1 & 3 & 0 & 0 & 1 & 2 & 7 \\
\hline 0500-0559 & 1 & 0 & 0 & 1 & 1 & 1 & 5 & 9 \\
\hline 0600-0659 & 1 & 0 & 1 & 0 & 2 & 0 & 0 & 4 \\
\hline 0700-0759 & 0 & 0 & 1 & 0 & 1 & 0 & 0 & 2 \\
\hline 0800-0859 & 1 & 1 & 2 & 1 & 1 & 3 & 3 & 12 \\
\hline 0900-0959 & 1 & 2 & 0 & 1 & 2 & 3 & 0 & 9 \\
\hline $1000-1059$ & 2 & 0 & 0 & 0 & 0 & 6 & 2 & 10 \\
\hline $1100-1159$ & 2 & 0 & 0 & 1 & 1 & 4 & 4 & 12 \\
\hline $1200-1259$ & 2 & 1 & 2 & 1 & 0 & 2 & 3 & 11 \\
\hline $1300-1359$ & 2 & 3 & 2 & 1 & 0 & 3 & 6 & 17 \\
\hline $1400-1459$ & 3 & 1 & 0 & 1 & 2 & 2 & 6 & 15 \\
\hline $1500-1559$ & 7 & 1 & 2 & 2 & 1 & 4 & 6 & 23 \\
\hline $1600-1659$ & 5 & 0 & 3 & 1 & 1 & 2 & 4 & 16 \\
\hline $1700-1759$ & 6 & 3 & 4 & 0 & 4 & 6 & 1 & 24 \\
\hline $1800-1859$ & 1 & 1 & 2 & 0 & 3 & 2 & 3 & 12 \\
\hline $1900-1959$ & 2 & 0 & 2 & 1 & 0 & 3 & 1 & 9 \\
\hline $2000-2059$ & 3 & 1 & 2 & 1 & 0 & 2 & 2 & 11 \\
\hline $2100-2159$ & 1 & 1 & 1 & 0 & 0 & 3 & 2 & 8 \\
\hline $2200-2259$ & 1 & 2 & 4 & 1 & 1 & 3 & 3 & 15 \\
\hline 2300-2359 & 0 & 3 & 1 & 0 & 2 & 5 & 3 & 14 \\
\hline Total & 43 & 25 & 44 & 19 & 27 & 66 & 60 & 284 \\
\hline
\end{tabular}

